\title{
Preliminary Survey and Evaluation of Nonaquifer Thermal Energy Storage Concepts for Seasonal Storage
}

November 1980

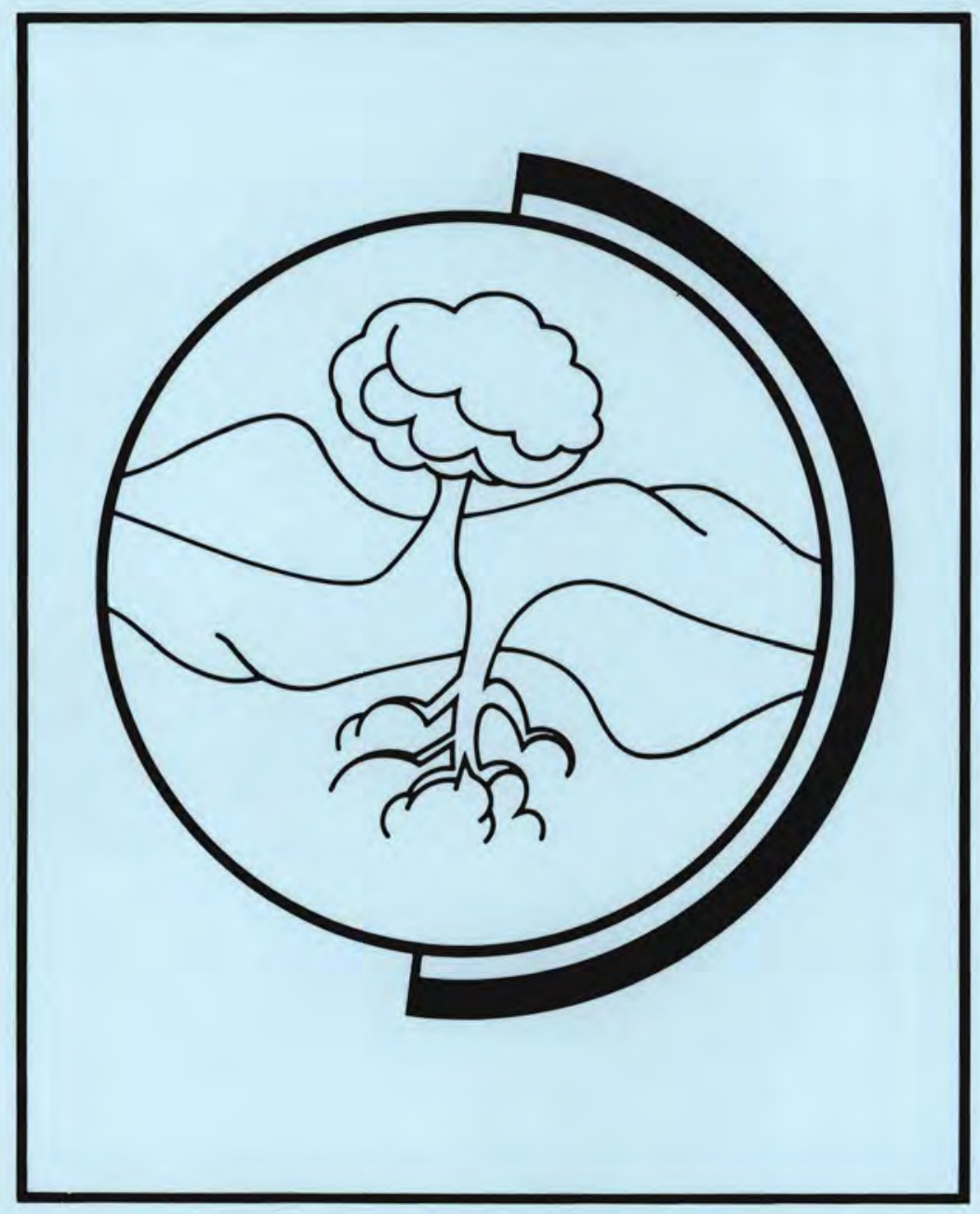

Prepared for the U.S. Department of Energy under Contract DE-AC06-76RLO 1830

Pacific Northwest Laboratory Operated for the U.S. Department of Energy by Battelle Memorial Institute 
NOTICE

This report was prepared as an account of work sponsored by the United States Government. Neither the United States nor the Department of Energy, nor anv of their employees, nor any of their contractors, subcontractors. or their employees, makes any warranty, express or implied, or assumes any legal liability or responsibility for the accuracy completeness or usefulness of any information, apparatus, product or process disclosed, or represents that its use would not infringe privatelv owned rights.

The views, opinions and conclusions contained in this report are those of the contractor and do not necessarily represent those of the United States Government or the United States Department or Energy.

\author{
PACIFIC NORTHWEST LABORATORY \\ operated by \\ BATTELLE \\ for the \\ UNITED STATES DEPARTMENT OF ENERGY \\ Under Contract DE-AC06-76RLO 1830
}

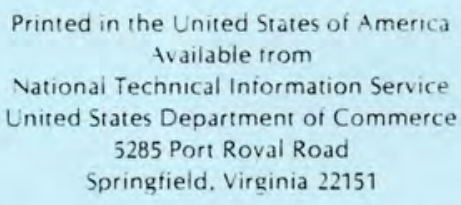

Price: Printed Copv 5 $\because$ Microfiche $\$ 3.00$

\begin{tabular}{cr} 
•Pages & \multicolumn{1}{c}{$\begin{array}{c}\text { NTIS } \\
\text { Selling Pric }\end{array}$} \\
$001-025$ & $\$ 4.00$ \\
$026-050$ & $\$ 4.50$ \\
$051-075$ & $\$ 5.25$ \\
$076-100$ & $\$ 6.00$ \\
$101-125$ & $\$ 6.50$ \\
$126-150$ & $\$ 7.25$ \\
$151-175$ & $\$ 8.00$ \\
$176-200$ & $\$ 9.00$ \\
$201-225$ & $\$ 9.25$ \\
$226-250$ & $\$ 9.50$ \\
$251-275$ & $\$ 10.75$ \\
$276-300$ & $\$ 11.00$
\end{tabular}




\section{3}

PRELIMINARY SURVEY AND EVALUATION OF NONAQUIFER THERMAL ENERGY STORAGE

CONCEPTS FOR SEASONAL STORAGE

D. E. Blahnik

November 1980

Prepared for the U.S. Department of Energy under Contract DE-AC06-76RLO 1830

Pacific Northwest Laboratory Richland, Washington 99352 


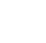

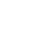




\section{ACKNOWLEDGEMENT}

Lon Inaba obtained the literature needed for this report and the nonaquifer thermal energy storage library. Steve Matsumoto edited and prepared this report for publication. Their assistance was appreciated. 
SUMMARY

Literature was scanned up to September 1979 to review nonaquifer thermal eneray storage (TES) methods that might be used on a seasonal basis. Since the oil embargo in 1973, many studies, much laboratory work, and engineering tests have researched TES. Most of the research supported energy conservation and solar energy programs and applied to hourly and daily (short-term) storage, rather than seasonal storage.

The most developed TES methods are also for short-term storage. The only large-scale applied development for seasonal thermal energy storage (STES) has been in the use of aquifers. Nonaquifer STES applied development has been mostly limited to small-scale solar ponds and earth storage.

For a coarse evaluation, this study divided the TES methods into categories of sensible, latent, and thermochemical thermal energy storage. Each category was further subdivided and analyzed with reference to the primary components of a TES system: storage medium, containment, insulation, and heat exchanger.

\section{SENSIBLE TES}

Sensible thermal energy is the energy associated with changes in the temperature of a material without a phase change, for example, the heat in hot water. Sensible TES is the most advanced technology because of its simplicity and relatively low cost. The most developed sensible TES methods are used mainly for short-term storage. In Europe, daily storage with off-peak electrically powered alumina, magnesia, and cast iron TES furnaces is a welldeveloped method. Hot water heater tank TES is an old and well-developed method that applies only to daily or weekly storage. Short-term storage with high-temperature, pressurized water $\left(>100^{\circ} \mathrm{C}\right)$ is also well developed, but the high cost of pressure vessels makes longer storage unlikely. This concept is used mainly to supply peaking steam and to heat boiler feedwater.

Daily and weekly storage systems using water and/or rocks are used extensively in solar home heating applications. Masonry walls are used for passive 
solar heating. Earth and wet earth (mud) storage have been used in agriculture and home heating; wet earth TES, which has promise for these and other sma11scale STES systems, should be studied further.

Large insulated-pond TES with water appears to be one of the most promising methods for STES. Large volumes of low-temperature heat can be stored at a relatively low cost. This would be attractive for district water heating and agricultural uses. Coupled with heat pumps in buildings, this method can be used for both heating and cooling when two ponds are used. This method provides an alternative to aquifer TES where aquifer storage is not practical. Ponds can also be covered with solar heat collectors to provide a heat source for the ponds.

Other storage concepts that may be used for sensible STES include natural lakes and ponds, solar ponds, mine open pits, caverns, and rock. Abandoned underground mines or natural caverns that can be easily sealed and are not too deep would be good candidates as containment for sensible heat storage materials. However, these concepts are very site specific; the lack of a nearby energy source or delayed use for the heat can be a problem.

The use of large insulated tanks should also be explored because tanks are the least site specific. The apparently higher cost of tanks may be offset by better storage efficiencies.

\section{LATENT TES}

Latent thermal energy is the energy associated with a phase change in a material, for example, with melting or freezing of ice. Overall, latent TES is not a well-developed method and is usually more complex and costly than sensible heat concepts. Researchers are experimenting with Glauber's salt, calcium chloride hexahydrate, and paraffin for daily, low-temperature TES. Salts and eutectics are being developed for daily, high-temperature TES applications such as power generation, boiler feedwater preheating, and industrial process heating. 
Near-term use of latent heat in seasonal applications will probably be limited to ice cooling of buildings and of refrigeration facilities. Compacted winter snow and ice can be harvested and placed in an insulated reservoir for summer air conditioning or refrigeration of crops. Sites for use of this concept are limited, however, and ice harvesting methods and economics must be studied further.

Practically all other latent heat TES concepts will be limited to shortterm storage, perhaps up to a week. This is due to the high cost of materials, heat exchangers, and containment. A hybrid concept of sensible heat water storage and encapsulated phase change material may provide a daily fixedtemperature buffer storage for a STES system.

\section{THERMOCHEMICAL TES}

Thermochemical energy is the thermal energy associated with a chemical reaction and the change in chemical composition of materials, for example, burning wood. For application to energy storage, however, the chemical reactions must be controlled and reversible. Thermochemical TES is even less developed and more complex than latent TES. The development work in this area has been primarily limited to paper studies and laboratory-scale tests. The only concept advanced enough to be considered for seasonal use is the sulphuric acid/water heat pump.

Reports disagree about the potential of thermochemical TES for STES applications. Engineering and full-scale tests must be performed to determine the actual potential of thermochemical STES.

RECOMMENDATIONS

Based on this quick literature review and preliminary evaluations, the currently most promising nonaquifer STES concepts for more detailed evaluation are:

- Large engineered insulated-pond TES with $\angle 95^{\circ} \mathrm{C}$ water (sensible STES heating)

- Wet earth TES with $<95^{\circ} \mathrm{C}$ water (sensible STES heating) 
- Natural lakes and ponds, solar ponds, rocks, and water in mines, caverns, and large tanks (sensible STES heating)

- Ice and compacted snow TES (latent STES cooling)

- Sulphuric acid/water heat pumps at 66 to $200^{\circ} \mathrm{C}$ (thermochemical STES heating and cooling).

These recommended concepts should be considered for use in conjunction with heat pump systems, for use with each other, and perhaps, except for thermochemical STES, for coupling with aquifers. With heat pumps, the sensible STES heating methods could also be used for cooling. Sensible heat and cold storage concepts currently have the most promise because they are the most developed concepts. In general the promising STES concepts use low temperatures $\left(<95^{\circ} \mathrm{C}\right)$, low-cost storage media (water and rock), construction with earth, good insulation and leak tightness, and economies of large scale.

A more in-depth review might reveal that some concepts were over looked or underevaluated in this broad but shallow overview of thermal energy storage concepts possibly applicable to seasonal storage. Research and development may improve other concepts enough that they should be considered for STES. Because of the need to store large thermal inventories over relatively long periods, the principal criteria for successful STES will be low costs of construction, storage media, and operation. 


\section{CONTENTS}

ACKNOWLEDGEMENT

SUMMARY

1.0 INTRODUCTION

2.0 THERMAL ENERGY STORAGE TECHNOLOGIES $\quad$ - $\quad$ •

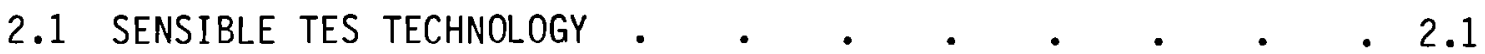

2.1.1 Sensible TES Media (Materials) . . . . . 2.3

2.1.2 Sensible TES Containers . . . . . . 2.3

2.1.3 Sensible TES Insulation . . . . . 2.5

2.1.4 Sensible TES Heat Exchangers . . . . . 2.6

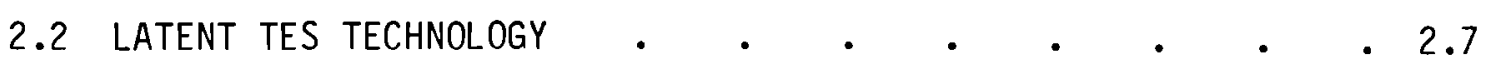

2.2.1 Latent TES Media (Materials) . • • . . 2.8

2.2.2 Latent TES Containers . . . . . . . . 2.11

2.2.3 Latent TES Insulation . • • • • . 2.12

2.2.4 Latent TES Heat Exchangers . . . . . . 2.12

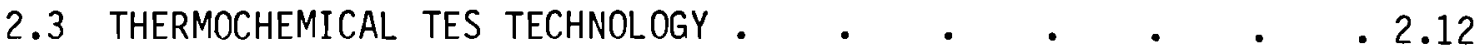

2.3.1 High-Temperature TES $\left(>250^{\circ} \mathrm{C}\right)$. . . . . 2.13

2.3.2 Low-Temperature TES $\left(<250^{\circ} \mathrm{C}\right)$. . . . . 2.14

2.3.3 Thermochemical TES Media (Materials) • . . . 2.15

2.3.4 Thermochemical TES Containers . . . . . 2.15

2.3.5 Thermochemical TES Insulation . . . . . 2.16

2.3.6 Thermochemical TES Heat Exchangers . . . . 2.16

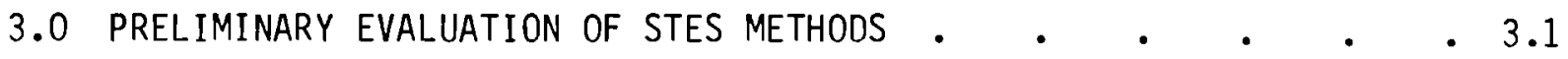

3.1 OPERATING CHARACTERISTICS EVALUATION $\quad$ • $\quad$ • $\quad$ • $\quad 3.2$ 


\section{CONTENTS (contd)}

3.2 EVALUATION OF POSSIBLE STES APPLICATIONS $\quad . \quad$ • $\quad$ • $\quad 3.4$

3.3 POTENTIAL STES THERMAL EFFECTIVENESS $\quad$ • $\quad$ • $\quad$ • $\quad$ • 3.5

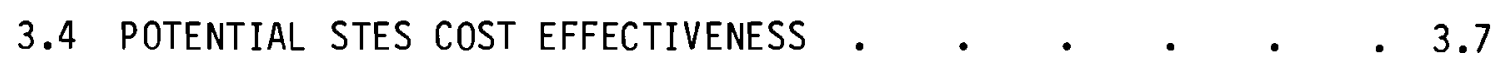

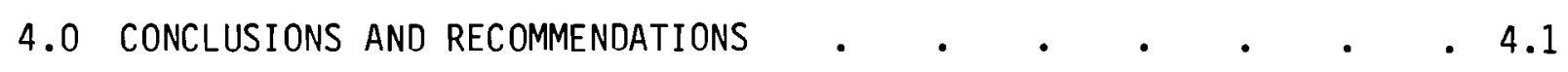

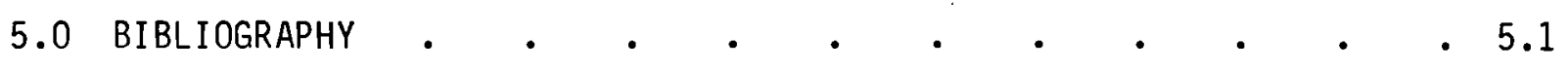

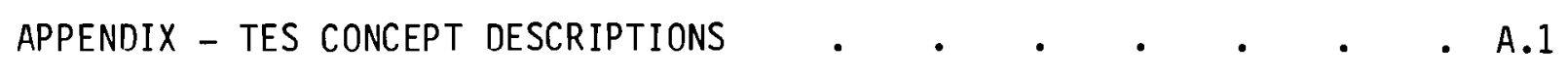




\section{FIGURES}

1 Thermal Energy Storage Sources and Uses . . . . . . 1.2

2 Boundaries for The Thermal Storage Heat Loss Model • • • 2.6

3 Initial Storage System Capital Cost . . . . . . . 3.10

4 References for Alternate TES Methods . . . . . . . 5.2

\section{TABLES}

1 Generalized Relative Comparison of TES Technologies . • • . 2.2

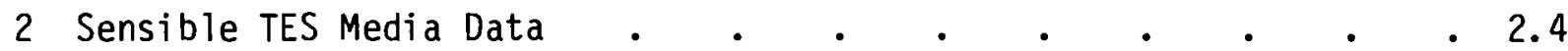

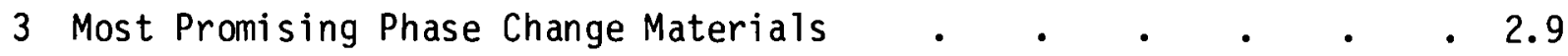

4 Preliminary Evaluation of Operating Characteristics of STES Methods • • • • • • • • • • . 3.3

5 Thermal Recovery Efficiency Estimates . . . . . . 3.6

6 Storage System Cost Summary . . . . . . . . . . . 3.9

7 Energy Cost Comparisons . . . . . . . . . . . . 3.9

8 Rough Cost Estimates for TES Containers . . . . . . . 3.11 


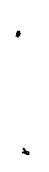




\subsection{INTRODUCTION}

Thermal energy storage enables the capture and retention of heat energy (or cold) during one time period for use during another. Seasonal thermal energy storage (STES) involves a period of months between the input and recovery of energy. The purpose of this study was to make a preliminary investigation and evaluation of potential nonaquifer STES systems. Current literature was surveyed to determine the state of the art of thermal energy storage (TES) systems such as hot water pond storage, hot rock storage, c0ol ice storage, and other more sophisticated concepts which might have potential for future STES programs.

The study was made as part of the nonaquifer STES task for the Seasonal Thermal Energy Storage Program managed by the Pacific Northwest Laboratory. The work is sponsored by the U.S. Department of Energy, Office of Advanced Conservation Technologies, Thermal Energy Storage Program.

Figure 1 indicates the main energy sources for TES and the uses for which the stored energy could be employed. These main sources provide energy that would be wasted or poorly utilized if the energy could not be used on a delayed basis. The main uses of the stored thermal energy are heating, cooling, and steam generation. Approximately one-third of the energy consumed in the U.S. is employed at less than $95^{\circ} \mathrm{C}$. Space heating alone requires about 20 percent of the energy.

Thermal energy can be stored in three ways: 1) as sensible heat by raising or lowering the temperature of the storage medium, 2) as latent heat by freezing or melting the medium, and 3 ) as thermochemical heat by causing a chemical change in the composition of the storage medium.

Sensible heat is the energy associated with changes in the temperature of a material without a phase change. Sensible heat is stored in water, rocks, earth, metals, ceramics, and other materials.

Latent heat is the energy associated with a change in the phase of a material, such as melting or freezing of ice. Latent heat is released or absorbed at the melting point of materials such as ice, paraffin wax, salts, 
and metals. A phase change material (PCM) is a material used to store thermal energy as latent heat.

Thermochemical heat is the thermal energy associated with a change in the chemical composition of a mixture of materials. The heat released during combustion of a fuel is one example of thermochemical heat. For application to energy storage, however, the chemical reactions must be controlled and reversible. Heat reactions are endothermic one way and exothermic in the reverse. Often a catalyst is required to speed up the reverse reaction.

\begin{tabular}{|l} 
ENERGY SOURCE \\
- WINTER CHILIED AIR \\
- OCEAN, LAKES, AQUIFERS \\
- SOLAR THERMAL ENERGY \\
- WIND ELECTRICAL ENERGY \\
- INDUSTRIAL WASTE HEAT \\
- OFF-PEAK ELECTRICAL POWER \\
- COGENERATION HEAT \\
- HEAT PUMP SUPPLY (HEAT OR COLD)
\end{tabular}

THERMAL ENERGY STORAGE

\section{DELAYED USE}

- DISTRICT HEATING AND COOLING OF BUILDINGS - HOURLY, DAILY, WEEKLY, AND SEASONAL TES

- INDUSTRIAL PROCESS HEAT (HOT WATER, HOT AIR, AND STEAM) - HOURLY, DAILY, WEEKLY, AND SEASONAL TES

- AGRICULTURAL INDUSTRY HEATING AND COOLING - WEEKLY AND SEASONAL TES

- BOILER FEEDWATER HEATING - HOURLY AND DAILY TES

- POWER GENERATION - HOURLY AND DAILY TES

- theRMAL ENGINE - HOURLY AND DAILY TES

- HEAT PUMP (HEATING OR COOLING) - HOURLY, DAILY, WEEKLY, AND SEASONAL TES

FIGURE 1. Thermal Energy Storage Sources and Uses 
Section 2 of this report reviews the development of sensible, latent, and thermochemical TES technologies. Section 3 is a preliminary evaluation of the TES methods most applicable to seasonal storage uses. Section 4 outlines preliminary conclusions drawn from the review of current TES literature and recommends further research based on these conclusions. Section 5 is a bibliography of the nonaquifer STES literature review. An appendix gives examples of 53 different TES concepts drawn from the literature. 



\subsection{THERMAL ENERGY STORAGE TECHNOLOGIES}

Of the three basic TES technologies, sensible heat storage is the simplest and most developed technology. Latent heat storage is more complex and is in an intermediate stage of development. Thermochemical heat storage is the most complex and least developed technology. Design concepts and schematics of the three technologies are illustrated in the appendix.

A very general comparison of the three technologies is given in Table 1. This comparison is likely to change as development improves the latent and thermochemical TES concepts. Also, more will be learned about seasonal applications for TES during demonstration projects.

The thermal energy storage system is usually composed of an energy source, a delayed use for the energy, and the following primary components:

- heat or cold storage medium (water, salt, chemical, etc.)

- a container for the storage medium (pond, tank, etc.)

- insulation to minimize heat or cold storage losses (cover, foam, batting, etc.)

- heat exchanger for transfering energy from the energy source to the storage medium to the delayed use (tubes, resistance heater, etc.). Sensible, latent, and thermochemical TES are reviewed here with reference to each of the primary components of a TES system. For a final design, an entire TES system must work as a single unit.

\subsection{SENSIBLE TES TECHNOLOGY}

Sensible heat has been stored in water and brick on an hourly and daily basis for many years. In recent years Europe has heated buildings using resistance-heated thermal energy storage furnaces powered by off-peak electricity. The furnaces use alumina, magnesia, cast iron, and water as storage media. The use of heating and cooling with off-peak power is spreading throughout the world.

Solar thermal energy is being stored in water tanks and rock beds on hourly, daily, and multiple-day bases. 
TABLE 1. Generalized Relative Comparison of TES Technologies

Subject of Comparison

- State of Technology Development

Simplicity

- Reliability

- Near-Term Implementation ( $<5$ yrs)

- Safety and Environmental Considerations

- Potential TES Time Applications

Hourly Storage

Weekly Storage

Seasonal or Annual Storage

Multi-Year Storage

- Advantages

Sensible TES
(a)
1
1
1
1
1
1
1
1
2
$x$

1. Most well developed and used TES technology

2. Simplest and most reliable

3. Low cost material and container

4. No phase change to contend with

5. Materials are readily available

6. Simple heat exchangers used

- Oisadvantages
1. Energy returned at an ever-decreasing temperature;

May require booster he

2. Must be well insulated.
Latent TES ${ }^{(a)}$

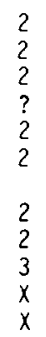

1. Energy stored and recovered at a nearly
constant temperature

2. Continued development may verify lower cost and higher performance of PCM for energy storage

3. Smaller volume required if

temperature swing is smal

4. Usually less site specific than

5. Some sensible heat is also stored

1. Technology not well developed

2. Volume increases $5-40 \%$ during melting

3. Corrosion uncertainties.

4. Must be well insulated.

cycling and leaks.

6. Temperature governs material selection.
Thermochemical TES $(\mathrm{a})$

3
3
3
3
3
3
3
3
3
3
3

1. Permits indefinite storage at ambient temperature with essentially no time-dependent heat losses; has poteritial for multi-year storage if inventory cost is justifie

2. Energy storage density
is high ( $7-15$ times sensible is high $(7-15$

3. Energy can be released to meet variable demands . Has potentially large internal heat fluxes

5. Stores high temperature heat period.

1. Technology not developed many technical problems;

2. Safety problems due to Material handling problems.

4. Uncertain reliability and lifetimes.

5. High cost until breakthroughs are made.

6. For the high temperature reactions more sophisticated materials, catalysts, and safety designs are

$$
\text { required. }
$$

7. High temperature reaction material will also react with water and carbon dioxide. Therefore system must be well sealed.

(a) Ratings: 1 = Predictable, good, or developed

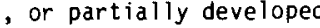
$3=$ Unpredictable, poor, or undeveloped $x=$ Not feasible

Note: Development advancements can change the ratings. There are two specific exceptions; ice in latent TES
and sulfuric acid/water reactions in thermochemical TES. 
High-temperature pressurized water has been stored and used for steam generation and boiler feedwater heating for many years on an hourly basis.

Until recently no sensible TES method has been used on a seasonal basis. Some experiments are now under way using aquifers to store heated and cooled water. Solar ponds and moist earth are also being tested for seasonal storage on a small scale.

\subsubsection{Sensible TES Media (Materials)}

The most common sensible heat materials being considered for TES are listed in Table 2. Some of the data that apply to the materials are also listed in the table.

The best materials for STES appear to be water, rock, and mud (wet earth). They function at low temperatures where STES systems can be designed at low cost with a minimum of surprises. As temperatures increase, more insulation, more expensive seals, more corrosion, and more unknowns are encountered. The higher-temperature materials are more suitable for short-period TES up to a week.

\subsubsection{Sensible TES Containers}

The sensible heat storage materials are the easiest to contain and control because they operate without any phase or chemical changes. The TES material can be contained in earth, caverns, mine excavations, tanks, or some combination. The earth and mine pits can be used to contain ponds, lakes, mud, rock beds, and earth itself. Caverns which are adequately sealed and insulated can be used to hold water, oil, rock, or some combination of the materials. Tanks can be used to contain liquids and solids.

Use of earth and caverns as TES containers is highly site specific. It is necessary to seal, insulate, and cover the container, especially for STES applications. Liners are needed to prevent fluid leaks that lose energy. Insulation is required to reduce thermal losses through the top, sides, and bottom. A cover is needed to prevent ingress of rain and snow because such ingress will reduce the storage efficiency. The cover also provides an insulating air barrier and reduces thermal losses from convection and evaporation. Soil surrounding the container must be kept dry. 
TABLE 2. Sensible TES Media Data

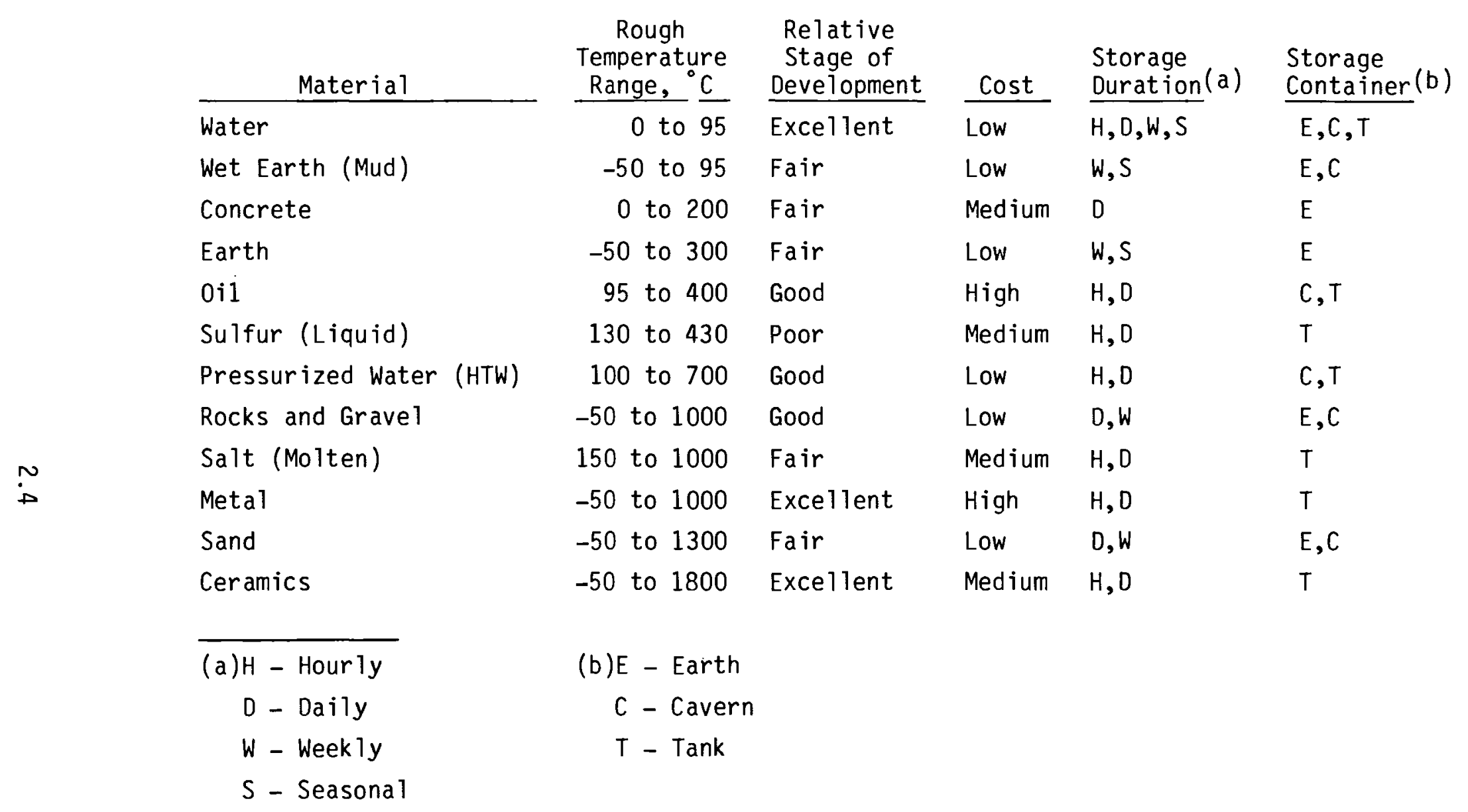


Tanks are usually fabricated out of reinforced concrete, fiberglass, or steel, depending on temperature and corrosion requirements. Some tanks are lined or coated with plastic, rubber, or another appropriate material. Tanks can be made in section modules to reduce costs, but their lifetimes are hard to predict. The main limitation of using tanks for STES is the high cost.

The use of tanks or insulated ponds are the least site-specific STES methods. They, along with wet earth storage, will probably be the best alternatives to aquifer STES. Sites that have natural valleys for constructing ponds, natural caverns, and abandoned mines might be attractive because of reduced excavation costs.

\subsubsection{Sensible TES Insulation}

A STES system is basically charged and discharged only once per year. The storage unit is sized to match the energy source and user demands in an optimal fashion. In a system where source energy is available for one month and demand is primarily spread over the remaining eleven months, the storage would be of maximum size. In a system where the source is a steady 365 days per year, such as an aluminum plant, the storage size would be about 5 to 25 percent as 1 arge. A typical annual-storage solar space-heating system has a storage capacity equal to 35 to 60 percent of the annual heat load for the buildings. By the same token, the solar collector system can be smaller than that required on daily basis and yet meet 100 percent of the heating requirements.

In any case, the energy must be stored in inventory for long periods of time in large quantities; therefore the prevention of heat loss is crucial to the system.

A model of heat flow from a thermal storage unit is shown in Figure 2. The greatest rate of heat loss is at the top and in the shortest path to the water table. Insulation must be heaviest in those regions to protect the natural thermocline stratification. Wet soil should not be allowed to come in contact with the container because the thermal conductivity of wet soil can be ten or more times that of dry soil.

Tanks above ground will require a substantial amount of insulation, and commercial insulation is available to do the job. Commercial insulation is 


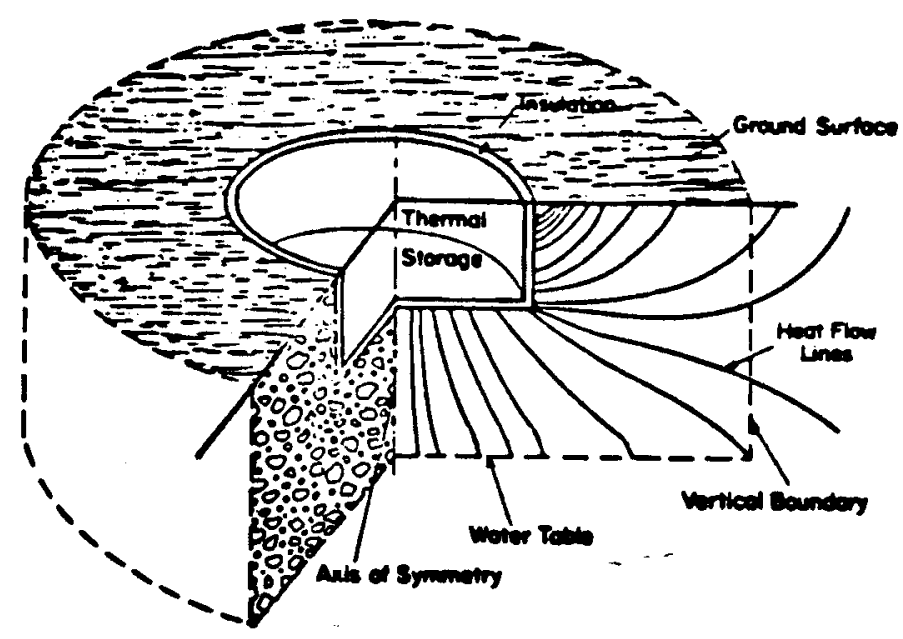

FIGURE 2. Boundaries for The Thermal Storage Heat Loss Model (56a; Hooper 1979, p. 13)

probably available for the other methods of storage also, but some testing will be required. Foam insulation, such as isocyanurate foam used for swimming pools, may find application in ponds. Urethane foam can be used for floating covers and to help stratify temperatures. Foam concrete can be used in the structures.

Additional research should be done to determine or develop insulation for the various applications. Insulation will be the most important factor to justify STES projects at many sites.

\subsubsection{Sensible TES Heat Exchangers}

Heat exchangers for STES are incorporated in the design of the system. For solid sensible heat media, such as rocks and gravel, the fluid (air, water, etc.) should be passed in direct contact through the media to add or retrieve heat. For fluid media, such as water, tube-type heat exchangers can be used or the water can interact directly with the source and use without heat exchangers internal to the storage system.

The heat exchangers $c$ an be located in the medium or remote from the medium. Except for heat exchanger fouling and corrosion, not many problems are anticipated at the low temperatures $\left(<95^{\circ} \mathrm{C}\right)$.

Some of the heat exchanger concepts are shown in the appendix. 


\subsection{LATENT TES TECHNOLOGY}

The latent heat of fusion is the thermal energy associated with a change in the physical condition (phase change) of a material by melting or freezing. The harvest of natural ice during the winter for use in summer refrigeration is a historical example of latent thermal energy storage. It probably still has the best near-term potential for latent TES. Use of Glauber's salt, calcium chloride hexahydrate, and paraffin has been under development for several years for low-temperature heat $\left(<90^{\circ} \mathrm{C}\right)$.

Use of the latent heat of vaporization or sublimation does not appear to be practical, except perhaps for extremely short-term energy storage (up to an hour), because of the large storage volumes required for vapor (e.g., steam occupies $26 \mathrm{ft}^{3} / 1 \mathrm{~b}$ at $100^{\circ} \mathrm{C}$ and atmospheric pressure). The latent heat of transformation may have potential for daily storage, but very little literature was available, and the concept is not discussed in this report.

Storage as latent heat has the advantage that energy is stored and recovered at nearly constant temperature. This temperature is a unique property of the storage material and will govern the selection of a storage material for a specific application. Solid-liquid processes are the most practical for near-term applications and include both melting of salt mixtures and crystallization of salt solutions.

Latent heat storage technologies are significantly less advanced than those for sensible heat. Continued development is expected to verify the lower cost and higher performance potential of phase change materials (PCMs) for energy storage. The use of phase change for seasonal applications is probably unlikely because of the higher material cost. The main use will be for the short-term energy storage perhaps up to several days. Use of the PCMs on a daily basis coupled with seasonal storage or incorporated with a sensible system to stablize temperature (e.g., paraffin stored in containers in water) has some potential. Some commercial TES equipment is available to couple latent and sensible heat on a daily basis. 


\subsubsection{Latent TES Media (Materials)}

Numerous materials are available for latent heating and cooling from the melt/freeze phase changes. The general categories of materials (listed in approximate order of increasing melting temperatures) are as follows:

- clathrates

- water

- clathrate hydrates

- hydrate eutectics

- paraffin wax

- organics

- inorganic salts

- metals

The most promising PCMs according to the literature are listed in Table 3 along with some of their properties. Numerous studies have reviewed and evaluated thousands of materials according to several selection criteria. The evaluations have reduced the quantity of PCMs to just a few which provide optimum performance in various temperature ranges.

Typical PCM selection criteria include the following:

1. The material should have a melting point within the temperature range of the heating or cooling requirements. Although this seems to be quite obvious, many materials tend to supercool when cooling, such that their effective solidification temperature falls below the temperature range of cycling. This makes them useless as TES materials.

2. The material should have a large heat of fusion. A larger heat of fusion allows storage of larger amounts of energy. All of the materials considered for low-temperature heating and cooling applications have lower heats of fusion than water. 


\section{Table 3. Most Promising Phase Change Materials}

\begin{tabular}{|c|c|c|c|c|}
\hline Material & $\begin{array}{l}\text { - Melting } \\
\text { Point, }{ }^{\circ} \mathrm{C} \\
\end{array}$ & $\begin{array}{c}\text { Heat of } \\
\text { Fusion (Btu/lb) }\end{array}$ & $\begin{array}{l}\text { Density, } \\
\text { 1b/ft3 }\end{array}$ & $\begin{array}{l}\sim \cos t, \\
8 / 1 \mathrm{~b}\end{array}$ \\
\hline Water & 0 & 144 & 62.4 & $0.00-0.02$ \\
\hline Clathrate Hydrate, $\mathrm{C}_{4} \mathrm{H}_{8} \mathrm{O} \cdot 17 \cdot 2 \mathrm{H}_{2} \mathrm{O}$ & 4 & 109 & - & -- \\
\hline 1 - Decanol & & 88 & -- & 0.38 \\
\hline \multicolumn{5}{|l|}{ Paraffins } \\
\hline$C_{14}-C_{16}$ Paraffin & 5 & 65 & -- & 0.16 \\
\hline C16 Paraffin & 16 & 86 & $\overline{0}$ & 0.40 \\
\hline P116 & & & & \\
\hline \multicolumn{5}{|l|}{ Salt Hydrates (Inorganic) } \\
\hline $\mathrm{K}_{2} \mathrm{HPO}_{4} \cdot 6 \mathrm{H}_{2} \mathrm{O}$ & 13 & -- & -- & -- \\
\hline $\mathrm{ZnCl} 2 \cdot 3 \mathrm{H}_{2} \mathrm{O}$ & 10 & $\overline{-z}$ & -- & -- \\
\hline $\begin{array}{l}\mathrm{Na}(\mathrm{OH}) \cdot 3-1 / 2 \mathrm{H}_{2} \mathrm{O} \\
\mathrm{CaCl}_{2} \cdot 5 \mathrm{H}_{2} \mathrm{O}\end{array}$ & $\begin{array}{c}15 \\
29-39\end{array}$ & $\begin{array}{l}96 \\
75\end{array}$ & $\overline{102}$ & $0 . \overline{02}$ \\
\hline $\mathrm{Na}_{2} \mathrm{CO}_{3} \cdot 1 \mathrm{OH}_{2} \mathrm{O}$ & $32-36$ & 106 & 90 & -- \\
\hline $\mathrm{Na}_{2} \mathrm{HPO}_{4} \cdot 12 \mathrm{H}_{2} \mathrm{O}$ & 36 & 114 & 95 & -- \\
\hline $\mathrm{Na}_{2} \mathrm{SO}_{4} \cdot 10 \mathrm{H}_{2} \mathrm{O}$ & 32 & 108 & 91 & -- \\
\hline $\mathrm{Na}_{2} \mathrm{~S}_{2} \mathrm{O}_{3} \cdot 5 \mathrm{H}_{2} \mathrm{O}$ & 48 & 90 & 104 & 0.14 \\
\hline $\mathrm{MgCl} 2 \cdot 6 \mathrm{H}_{2} \mathrm{O}$ & 117 & 72 & -- & 0.07 \\
\hline $\mathrm{Mg}\left(\mathrm{NO}_{3}^{2}\right)_{2} \cdot 6 \mathrm{H}_{2} \mathrm{O}$ & 90 & 73 & -- & -- \\
\hline $\mathrm{Mg}\left(\mathrm{NO}_{3}\right)_{2} \cdot 2 \mathrm{H}_{2} \mathrm{O}$ & 130 & -- & -- & -- \\
\hline \multicolumn{5}{|l|}{ Organics } \\
\hline Phthal ic Anhydride & 131 & 65 & -- & 0.27 \\
\hline Polyethelene (High Density) & $125-135$ & 81 & 60 & 0.32 \\
\hline Polypropylene (Isotactic) & $155-165$ & 79 & 57 & 0.32 \\
\hline \multicolumn{5}{|l|}{ Saits } \\
\hline $\mathrm{KNO}_{3} \cdot \mathrm{CaNO}_{3}(66 / 34)$ & 146 & $-\overline{3}$ & -- & -0 \\
\hline $\mathrm{NaNO}_{3} \cdot \mathrm{KNO}_{3}(50 / 50)$ & 222 & 43 & -- & 0.09 \\
\hline $\mathrm{NaNO}_{3} \cdot \mathrm{CaNO}_{3}(71 / 29)$ & 232 & -- & -- & - \\
\hline \multirow{2}{*}{$\begin{aligned} \mathrm{Na}(\mathrm{OH}) \cdot & \mathrm{NaNO}_{3} \cdot \mathrm{MnO}_{2} \\
& (91.8 / 8 / 0.2)\end{aligned}$} & 283 & -- & -- & -- \\
\hline & $234-293$ & -- & -- & -- \\
\hline $\mathrm{NaNO}_{3}$ & 310 & 75 & 141 & 0.08 \\
\hline $\mathrm{K}(\mathrm{OH})$ & 360 & 58 & 127 & -- \\
\hline $\mathrm{KCl} \cdot \mathrm{NaCl} \cdot \mathrm{MgCl}_{2}(15 / 22 / 63)$ & 385 & 126 & 140 & -- \\
\hline $\mathrm{LiCO}_{3} \cdot \mathrm{K}_{2} \mathrm{CO}_{3}(35 / 65)$ & 505 & 148 & $\cdots$ & -- \\
\hline $\mathrm{KNO}_{3} \cdot \mathrm{NaNO}_{3} \cdot \mathrm{NaNO}_{2}$ & 538 & -- & -- & -- \\
\hline $\mathrm{NaF} \cdot \mathrm{ZnF}_{2}(63 / 37)$ & 640 & 231 & $14 \overline{6}$ & $\overline{0.31}$ \\
\hline $\mathrm{CaF}_{2} \cdot \mathrm{KF}^{2} \cdot \mathrm{NaF}(7 / 54 / 39)$ & 682 & 240 & 124 & 0.21 \\
\hline \multicolumn{5}{|l|}{ Metals } \\
\hline$M g-\operatorname{Zn}(71 / 29)$ & 343 & 77 & -- & -- \\
\hline$A 1-M g(67.5 / 37.5)$ & 451 & 131 & -- & -- \\
\hline$A 1-S i(88 / 12)$ & 579 & 217 & -- & -- \\
\hline A? & 660 & 169 & -- & 0.65 \\
\hline Si-Mg $(53 / 47)$ & 946 & 344 & -- & -- \\
\hline
\end{tabular}


3. The material should have a congruent melting/freezing points. The material should melt completely at a fixed temperature or within a very narrow range of temperature (at most $5^{\circ} \mathrm{C}$ or $9^{\circ} \mathrm{F}$ ). Otherwise, the difference in densities between solid and liquid will cause segregation, resulting in changes in the chemical composition of the material. This introduces complications in the cooling behavior. Also a low change of volume upon fusion is desirable.

4. The material should not supercool. When the TES material is cooled while in the liquid phase, the melt should solidify at the thermodynamic melting point. This requires a large rate of nucleation and growth. Otherwise, the liquid will supercool and the stored energy will not be released. Some materials require addition of nucleating agents to prevent super-cooling and to promote a uniform crystallization of the medium. Larger storage systems are less likely to experience supercooling. Thermal conductivity and specific heat should also be adequate.

5. The material should be stable. All applications to be considered in this report are long-term uses of thermal energy storage materials. The envisaged lifetime of such a system is about twenty years or more. Hence, the materials to be used should be very stable and not tend to decompose into other materials. This is particularly critical for TES materials at high temperatures in the liquid state, since the diffusion of atoms is enhanced, and the rates of chemical reactions generally increase in these conditions. The possible reactions should be investigated from the thermodynamic and the kinetic points of view to determine whether they should be considered or whether they can be safely ignored. Material breakdown will occur more slowly in a seasonal system because of less frequent thermocycling across the melting point. The material vaporization pressure characteristics must also be reviewed closely.

6. The material should not interact with the container or heat exchanger. This is an extension of point 4 above, but it relates to material-container interaction rather than internal reactions of the 
material. The material should not corrode or react with the container and heat exchanger.

7. The material should not be dangerous. Since the possibility of accidental leakage is always present, it is preferable to choose a material that is nonexplosive, nonflammable, and nontoxic and that does not have a bad sme11. A low vapor pressure must be avoided.

8. The material should be cheap and available. This point is not very well defined. The cost of a material that is presently available may be much higher than the cost of the same material if a large demand were generated for that material or if a more economic way of producing it were found. The ultimate cost is related to the avai1ability of the material or of its primary elements. We should attempt to confine our choices to common materials which are available in large quantities at low cost.

It will be difficult to find a material that simultaneously satisfies all these requirements. It is possible to find some materials that are acceptable, if the disadvantages are factored into the system design.

\subsubsection{Latent TES Containers}

Tanks will be the primary method of storing PCMs. However, if desirable, PCMs can be encapsulated in small capsules or containers and placed within a larger container; for instance, PCM capsules could be placed in tanks, ponds, caverns, etc., to form a hybrid system.

Tanks or capsules for storing PCM heat require development for the higher temperatures $\left(>95^{\circ} \mathrm{C}\right.$ ) because of corrosion, PCM expansion during melting (5 to 40 percent), and incorporation of heat exchangers. Even low-temperature experience $\left(<95^{\circ} \mathrm{C}\right)$ with Glauber's salt indicates that it is difficult to incorporate effective heat exchange due to supercooling and selective crystallization of salts which will deteriorate the storage and heat exchange efficiency. 


\subsubsection{Latent TES Insulation}

Insulation is very important for latent TES, as it is for sensible TES. Adequate insulation must surround the storage tank to minimize heat losses. Standard commercial insulation should be available for most latent TES systems because PCMs are contained in tanks or in capsules within vessels.

\subsubsection{Latent TES Heat Exchangers}

TES materials which are placed in containers can be designed to exchange heat directly with the cooling and heating media. Conventional designs such as the tube/shell concept can be used, but special materials and designs are likely to be required. Materials, especially for the higher temperatures, will have to be carefully selected.

Some of the heat exchanger concepts which have been reviewed for salt media TES include: 1) direct contact open system, 2) she11 and tube, 3) reflux boilers, 4) jet impingement, 5) tumbling abrasive, 6) external and internal scrapers, and 7) passive tube intensive.

Some heat exchanger concepts are illustrated in the figures of the appendix. Much development work remains in this area.

\subsection{THERMOCHEMICAL TES TECHNOLOGY}

Thermochemical energy storage uses reversible chemical reactions to store thermal energy as chemical-bond energy by changing the chemical composition of the storage medium. The concept of advanced thermochemical energy storage is to employ controllable chemical reactions in a closed cycle with a net exchange of thermal energy and no net gain or loss of material.

The concept is a long way from being developed for commercial applications. Most of the research has been done for solar electric power generation and building heating and cooling. A few high-temperature systems and one lowtemperature system are described in the next two sections. 


\subsubsection{High-Temperature TES $\left(>250^{\circ} \mathrm{C}\right)$}

Development of thermochemical methods for daily storage of thermal energy in solar-thermal power plants involves identifying a chemically reacting system which is rapid and controllable and which accepts and returns thermal energy in the temperature range of $400^{\circ}$ to $800^{\circ} \mathrm{C}\left(750^{\circ}\right.$ to $\left.1475^{\circ} \mathrm{F}\right)$. The three systems shown below are promising candidates:

$$
\begin{aligned}
& \text { Thermal Energy }+\mathrm{NH}_{4} \mathrm{HSO}_{4} \stackrel{525^{\circ} \mathrm{C}}{=} \mathrm{NH}_{3}+\mathrm{H}_{2} \mathrm{O}+\mathrm{SO}_{3} \text { (Ammonium Bisulfate) } \\
& \text { Thermal Energy }+20_{3}^{\circ} \mathrm{C} \mathrm{SO}_{3} \stackrel{750^{\circ} \mathrm{C}}{450^{\circ} \mathrm{C}} 2 \mathrm{SO}_{2}+\mathrm{O}_{2} \quad \text { (Sulfur Trioxide) } \\
& \text { Thermal Energy }+\mathrm{Ca}(\mathrm{OH})_{2} \frac{525^{\circ} \mathrm{C}}{350^{\circ} \mathrm{C}} \mathrm{CaO}+\mathrm{H}_{2} \mathrm{O} \quad \text { (Hydrated Lime) }
\end{aligned}
$$

Thermal energy from the receiver causes decomposition of the starting material to form a series of high-energy products, such as $\mathrm{CaO}$ (1ime) and $\mathrm{H}_{2} \mathrm{O}$ (water) in system (3). Separation and containment of the high-energy products at ambient temperatures result in energy storage with no time-dependent loss. The products are recombined on demand to recover the stored energy and to retrieve the starting material. While the equipment for reacting, treating, and storing the chemical products is complex, thermochemical storage is suited to seasonal storage because of the increased storage density ( 2 to 15 times that of sensible or latent technologies) and the absence of a time-dependent energy loss.

More than five hundred chemical reactions were evaluated for use in TES applications. Most of those investigated involve solid or entirely gaseous constituents which are difficult to manipulate and difficult to store. 
Although a purely liquid system is highly desirable, no purely liquid system with high-temperature capabilities has been identified. The best compromise in terms of energy storage density and high-temperature capability is the sulfur dioxide/oxygen system, even though one of the reactants has to be stored as a gas.

While there is considerable experience in carrying out these chemical reactions in industry, no experience has been obtained using the reactions for actual energy storage. Most of the research done thus far has been in the form of paper studies. The most extensive systems analysis was done on the sulfur trioxide reaction listed as system (2).

During the course of the sulfur trioxide analyses, the following areas had uncertainties that must be addressed in subsequent research:

- materials selection

- system lifetime

- oxygen versus air (effluents)

- catalysts

- complexity

- reliability

- cost analysis

- safety - leaks cause sulfuric acid; flammable; hot $\mathrm{O}_{2}$ could burn metal pipes, etc.; mechanical strength up to $800^{\circ} \mathrm{C}$

\subsubsection{Low-Temperature TES $\left(<250^{\circ} \mathrm{C}\right)$}

A lower-temperature reaction concept, which would apply primarily to lowtemperature steam and the heating and cooling of buildings, is being developed with engineering-scale tests using an all-liquid reversible chemical reaction between sulfuric acid and water. This reaction operates from 66 to $200^{\circ} \mathrm{C}$. It looks promising based upon studies and tests done to date. It is also sometimes referred to as a chemical heat pump. Other chemical heat pump concepts under study, but not as far progressed, include metal hydrides, ammoniated salts, magnesium chloride/water, and methanol-based salts. 
The chemical heat pump/thermal energy storage device using the reversible reaction $\mathrm{H}_{2} \mathrm{SO}_{4} \cdot \mathrm{H}_{2} \mathrm{O}=\mathrm{H}_{2} \mathrm{SO}_{4}+\mathrm{H}_{2} \mathrm{O}$ operates by storing energy at a low temperature when the chemicals are separated and returning the energy at the user-designated temperature during the recombination reaction. The device can be used for heat pumping, space cooling, and extended-duration thermal energy storage capabilities. In addition, the unique properties of the $\mathrm{H}_{2} \mathrm{SO}_{4} / \mathrm{H}_{2} \mathrm{O}$ system include:

- high energy density $\left(60,000 \mathrm{Btu} / \mathrm{ft}^{3}\right.$ and greater)

- long duration storage potential (energy not stored in high-temperature gradients)

- relatively available and inexpensive thermal energy storage capacity (media cost less than $\$ 0.02 / 1 b$ )

Recent analyses indicate that the $\mathrm{H}_{2} \mathrm{SO}_{4} / \mathrm{H}_{2} \mathrm{O}$ system also operates favorably with solar energy, off-peak electric heating and cooling, waste heat coupled absorption chillers, and heat pumping of industrial fluid streams to higher useful temperatures.

Except for the work on the $\mathrm{H}_{2} \mathrm{SO}_{4} / \mathrm{H}_{2} \mathrm{O}$ system, thermochemical TES systems are in the infancy stage. It is an emerging technology, currently at the bench-scale level of development, and is seen as a long-term prospect .

\subsubsection{Thermochemical TES Media (Materials)}

Hundreds of common materials have been investigated for use in this concept. The materials mentioned earlier in this section appear to be the closest to implementation. The $\mathrm{H}_{2} \mathrm{SO}_{4} / \mathrm{H}_{2} \mathrm{O}$ reaction is probably the only reaction that should now be studied further for STES.

\subsubsection{Thermochemical TES Containers}

More containers are employed in thermochemical TES systems than in the sensible and latent TES systems. Illustrations of the $\mathrm{H}_{2} \mathrm{SO}_{4} / \mathrm{H}_{2} \mathrm{O}$ system and the $\mathrm{SO}_{3}$ system (Figures $\mathrm{A} .49$ and $\mathrm{A} .50$ in the appendix) show the additional complexity. Considerable additional development is needed before the systems can be scaled up for demonstration projects. 


\subsubsection{Thermochemical TES Insulation}

Insulation is not as important for this method of storage as it is for sensible and latent heat storage; however, insulation is still important for short-term storage applications. For monthly and seasonal storage the need is not as critical because the material will be stored in ambient conditions anyway. Reaction vessels and pipelines can be insulated with commercially available insulations.

\subsubsection{Thermochemical TES Heat Exchangers}

Commercially available reactors, tanks, and piping can be used for the lower-temperature reactions by careful selection of materials. More research is needed for selection of the best materials for the higher-temperature reactions. Development of low-cost heat transfer systems is needed. 


\subsection{PREL IMINARY EVALUATION OF STES METHODS}

Based on the review of literature it appears that the best STES methods will utilize sensible heat using low-cost storage media (water, rock), construction with earth, good insulation and leak tightness. and economies of large scale. The best application is in the $<95^{\circ} \mathrm{C}$ temperature range for district or large building heating and cooling and agriculture industry heating and drying. Cooling can also be done effectively where ice and snow can be harvested efficiently.

Where suitable aquifers are available, it is unlikely that nonaquifer methods can compete economically. Where suitable aquifers are not available, the use of engineered, insulated ponds is probably the most attractive alternative. Two ponds, one for heating and the other for cooling, can be coupled with district home heat pumps to provide low cost heating and cooling. A favorable climate is also necessary, however.

If open pit mine excavations or natural valleys can be adequately sealed and insulated, they might provide a lower-cost pond alternative. Also natural caverns, salt domes, or underground mine caverns might be considered. Engineered caverns might be justified if high-temperature water $\left(250-350^{\circ} \mathrm{C}\right)$ is used.

Natural ponds and lakes with very favorable site characteristics might be considered. Site-specific problems such as spring water inflow, seepage, wet soil thermal conduction, air convection and evaporation losses, ingress of snow-rain/runoff, wind and storm protection, etc. must be countered to reduce heat loss from the storage media. Costs to reduce these losses may end up being higher than the cost of a man-made pond.

Wet earth surrounded by vapor barriers and dry earth can provide seasonal storage on a smaller scale for agricultural uses (e.g., animal shelters, crop drying, greenhouses). Development of low-cost installation techniques may make wet earth or dry earth STES possible for individual homes also.

Huge insulated water tanks may be considered if costs can be reduced sufficiently. 
The most promising latent heat STES application is for cooling with the use of natural harvested ice and highly compacted snow. This restricts use to the northern or mountainous regions where ice and cold is available. Use of ice manufactured with off-peak power is a consideration where favorable power rates are available.

Other latent heat materials do not appear attractive on an annual or seasonal basis because of higher material cost and greater complexity in storage and heat exchanger systems. Seasonal storage using latent heat does not appear to be practical except in special applications where requirements for a higher density and steady output temperature justify the added cost (e.g., space exploration, factory ships, marine laboratories). Latent heat concepts will compete primarily in the hourly, daily, and perhaps weekly storage ranges. In some instances latent heat might be coupled with water STES systems to provide more stable output temperatures or daily buffering.

Thermochemical STES may be practical in the long term for storage of hightemperature $\left(>250^{\circ} \mathrm{C}\right)$ heat. The only near-term exception might be all-liquid reactions like the $\mathrm{H}_{2} \mathrm{SO}_{4} / \mathrm{H}_{2} \mathrm{O}$ reaction $\left(<250^{\circ} \mathrm{C}\right)$. The $\mathrm{H}_{2} \mathrm{SO}_{4} / \mathrm{H}_{2} \mathrm{O}$ reaction could be used for both heating and cooling applications. Some safety concerns will have to be resolved first, however.

The next four subsections evaluate the 1) operating characteristics, 2) possible applications, 3) potential thermal effectiveness, and 4) potential cost effectiveness of the most promising STES concepts.

\subsection{OPERATING CHARACTERISTICS EVALUATION}

A preliminary evaluation of the operating characteristics of the most promising STES concepts is provided in Table 4. Because of simplicity, demonstrated reliability, and good safety, the sensible TES concepts have the best potential for STES in the near term. Latent heat STES requires more development and some large breakthroughs before it can be considered (an exception is ice storage). Thermochemical TES has potential for seasonal storage and even multiyear storage. It also has potential for transporting the energy between sites by pipeline or rail. However, much more development and experience is required before thermochemical STES can be seriously considered (except for the $\mathrm{H}_{2} \mathrm{SO}_{4} / \mathrm{H}_{2} \mathrm{O}$ reaction). 


\section{TABLE 4. Preliminary Evaluation of Operating Characteristics of STES Methods}

\begin{tabular}{l}
$\frac{\text { Method }}{\text { Sensible STES (Heat or Cold) }}$ \\
\hline Insulated Pond w/water \\
and cover. (Pond can he \\
engineered or in mine pit \\
or in natural valley) \\
Wet Earth (Mud)
\end{tabular}

Netural Pond or Lake

Cavern w/water

Insulated Water Tanks

Rock Bed

Latent STES

lce Storage (cooling)

Paraffin and Salt

Hydrates, Various temp.
Temperature

Range, ${ }^{\circ} \mathrm{C}$

$<95$

-40 to 12

0 to 100

ton

Artificial pond's well developed. Liners and insulation may neen additional

development. Some experience with small solar ponds. Water is 1.ell uncerstcod.

Small greenhouse successful. Plain earth usea to heat animal shelters. Develapent of lowcoct installation techniques will help.

No experience except paper studies. Stucies indicate this type of storage is feasible. Water is rell understond, but currents and thermal stratification require more study.

No experience. Some rork done on compressed air storage. Hater ic well understood.

Well developed.

Experience with sclar heating and cooling. Also crop drying. No STES experience. Air flow is not completely uncerstood.

Many years experience. Harvesting and handling costs must he reduced hy impraved equipment. Well understond. Heat exchanger may need slight development. Ice making w: off-peak power might be ecoromical in some locations.

Experience with small quartities in heating and cooling of buildings. Could be used

to stabilize water temperatures.

Engineering-scale test in progress. Safety problems need research. Appears economically feasible. Heat exchangers and materials need research. Thermal efficiency also needs mor
study.

\author{
Advantages and Disadvantages \\ Adv. - less site specific. Low cost \\ for large pond's. Can be coupled with \\ solar energy. Simple, safe. \\ Disaov. - Land is required. \\ Adv. - Water improves heat conductivity \\ and capacity in soil. Simple and safe. \\ Land can be used for some other purposes. \\ Can be used in smaller applications. \\ Disadv. - Land may not.be as stable for \\ supporting structures. iveed deep soil. \\ Adv. - Construction costs may be \\ reduced. Simple. \\ Disadv. - Hard to stop thermal losses. \\ Very site specific. Weather can cause \\ damage. \\ Adv. - Natural salt domes or mine \\ caverns would be low' cost. Excavated \\ caverns might be okay for pressurized \\ water. Attractive where land is \\ uravailable (cities). \\ Disadv. - Sealirig is crucial to prevent \\ leaks. Very site specific. Pumping costs. \\ Adv. - Not site specific. High storage \\ efficiency. Simple. Safe. \\ Disadv. - High cost. \\ Adv. - Leak problems not as severe. \\ Higher temperature than water. \\ costs more and requires \\ materials handling. Site specific. Heat \\ exchangers may be difficult. \\ extratem to control.
}

Adv. - Requires $1 / 3$ or less the volume of water storage. Nature can provide the

cold. Cools at steady temperature.

Simple and safe. Disposal of city sriow. Disadv. - Considerable material handling required. Insulation.

Adv. - Releases heat (or cool) at steady temperature. May be encapsulated to work with water storage.

Disadv. - Slow heat transfer. Expensive.

Paraffin is combust ible.

Adv. - Can be used to heat or cool. Has large heat storage capacity. Acid readily available at low cost.

handling - Safety prohilems with acio handling and leaks. Complex system. 


\subsection{EVALUATION OF POSSIBLE STES APPLICATIONS}

The best possible applications for the STES methods listed in Table 4 are primarily for low-temperature heating and cooling. Building heating and cooling will probably be the best application. The useful temperatures are:

$\begin{aligned} 5-15^{\circ} \mathrm{C} & \text { Air Conditioning } \\ 45-55^{\circ} \mathrm{C} & \text { Heating } \\ 65-80^{\circ} \mathrm{C} & \text { Hydronic Heating } \\ 100-140^{\circ} \mathrm{C} & \text { Absorption Air Conditioning } \\ >100^{\circ} \mathrm{C} & \text { Steam } \\ 200-220^{\circ} \mathrm{C} & \text { Thermosorb }\end{aligned}$

Ponds, lakes, caverns, and tanks can be used for district heating of buildings. When coupled with heat pumps they can provide cooling as well. Covered ponds in some areas of the country can be utilized with solar collectors, providing the energy source as well as thermal energy storage. A hybrid solar pond layer over a conventional pond may be the most economical.

Wet earth TES can be used for both heating and cooling in the agricultural industry. Low-temperature heat is needed for greenhouses, aquaculture, animal shelters, and others. Cooling can be used in summer for similar applications.

Rock beds can also be used for heating and cooling of buildings. Because of their higher temperature capability, it may be possible for hot rocks to generate steam for industrial or peaking power generation.

Latent energy from ice can provide cooling for buildings and agricultural refrigeration applications.

Thermochemical STES with the sulfuric acid and water system can also be used for heating and cooling of buildings. The system operates favorably for off-peak electric heating and cooling, waste heat coupled absorption chillers, industrial steam generation, and heat pumping of industrial fluid streams to higher useful temperatures.

All of the methods listed in Table 4 can be coupled with heat pumps for heating and cooling. Heat pumps are being developed which can increase temperatures to above $160^{\circ} \mathrm{C}$. Heat in the 60 to $200^{\circ} \mathrm{C}$ range is used extensively in the chemical, paper, food, and forest product industries. 


\subsection{POTENTIAL STES THERMAL EFFECTIVENESS}

No good comparisons of the different systems were found in the literature. The ones which were found are probably optimistic and biased and probably use different bases and definitions. It would be helpful if standard terminology, definitions, and measurements would be established so systems can be compared on a common basis.

It is important to design the storage system so it takes advantage of proper thermal stratification. Stratification leads to better overall system performance for 2 reasons:

(1) It improves storage discharge efficiency by taking heat out at the higher temperature.

(2) It improves storage charge efficiency and hence source collector efficiency.

Current experiments on all concepts have shown that it is important to have adequate insulation. The performance of test ponds has been poor because they have been insufficiently insulated and too small.

Seasonal storage would therefore require very good insulation and larger medium masses when sensible heat or ice storage is used. For thermochemical STES there are disputes about how much insulation is needed. Some reports claim little heat is lost when storing at ambient temperatures and others claim a large amount of energy is lost in tanks, pipes, catalysts, and reaction tanks.

Some heat recovery efficiency data based upon smal1-scale tests and computer studies are given in Table 5. Thermal studies need to be made on the STES methods like ponds, lakes, tanks, rockbeds, caverns, icebeds, and sulfuric acid/water reactions.

It has been found that moisture in the earth greatly accelerates heat losses. In most soils the thermal conductivity varies by an order of magnitude or more over the full range from dry to saturated soil. In underground tanks 10 to 60 of the heat delivered $c$ an be lost through the surrounding soil medium. 
TABLE 5. Therma 1 Recovery Efficiency Estimates

\begin{tabular}{|c|c|c|c|}
\hline Method & $\begin{array}{c}\text { Operating } \\
\text { Temperature, }\end{array}$ & $\begin{array}{l}\text { Storage } \\
\text { Round Trip } \\
\text { Efficiency }\end{array}$ & $\begin{array}{c}\text { Storage } \\
\text { Cycle } \\
\text { Time } \\
\end{array}$ \\
\hline \multicolumn{4}{|l|}{ Sensible TES } \\
\hline $\begin{array}{l}\text { Hot Water Storage in Insulated Tank } \\
\text { Moist Soil Insulated by Dry Soil and } \\
\text { Vapor Barriers } \\
\text { Granite Pebble Bed } \\
\text { MgO Storage in Insulated Tank }\end{array}$ & $\begin{array}{c}30 \text { to } 70 \\
30 \text { to } 80 \\
49 \text { to } 65 \\
533 \text { to } 752\end{array}$ & $\begin{array}{l}40 \text { to } 90 \\
50 \text { to } 80 \\
57 \\
77\end{array}$ & $\begin{array}{l}\text { Seasonal } \\
\text { Seasonal } \\
\text { Daily } \\
\text { Daily }\end{array}$ \\
\hline $\begin{array}{l}\text { Latent TES } \\
\qquad \begin{array}{l}\mathrm{Na}_{2} \mathrm{~S}_{2} \mathrm{O}_{3} \cdot 5 \mathrm{H}_{2} \mathrm{O} / \text { Varsol } \\
\mathrm{Na}_{2} \mathrm{HPO}_{4}: 12 \mathrm{H}_{2} \mathrm{O} / \mathrm{Varsol} \\
7 \mathrm{CaF} \mathrm{Car}_{2}-54 \mathrm{KF}-39 \mathrm{NaF}\end{array}\end{array}$ & $\begin{array}{c}47 \\
34 \\
550 \text { to } 800\end{array}$ & $\begin{array}{r}95 \\
77 \\
64.8\end{array}$ & $\begin{array}{l}\text { Daily } \\
\text { Daily } \\
\text { Daily }\end{array}$ \\
\hline \multicolumn{4}{|l|}{ Thermochemical TES } \\
\hline $\begin{array}{l}\mathrm{H}_{2} \mathrm{SO}_{4} / \mathrm{H}_{2} \mathrm{O} \text { Heat Pump } \\
\mathrm{SO}_{2} / \mathrm{O}_{2}\end{array}$ & $\begin{array}{r}66 \text { to } 200 \\
430 \text { to } 875\end{array}$ & $\begin{array}{l}74 \text { to } 80 \\
68.5\end{array}$ & $\begin{array}{l}\text { Daily } \\
\text { Daily }\end{array}$ \\
\hline
\end{tabular}


Soil moisture mechanisms such as water percolation during rainfall, spring runoff, and evaporation and condensation of the soil moisture involve a mass transfer of either liquid or vapor, and hence transfer of the internal energy of the migrating water. Soil properties and the heat flow regime are also influenced by the freezing and thawing cycle.

To minimize heat losses it is essential to be concerned about the type of backfill, soil layering, surface grading, moisture barriers, type of drainage system, and type of insulation. It is probably necessary to add good foam insulation around tanks, pond bottoms, etc. to reduce heat losses, especially on a seasonal basis. The container surface area with the storage medium should be minimized (e.g., a large shallow pond has higher heat loss than a small deep one).

As the size of the storage reservoir increases, it becomes more cost effective because of the lower cost-per-unit capacity and the lower unit heat losses resulting from decreasing the surface-to-volume ratio.

Storage demonstrations with large volumes must be made to better assess the effectiveness of the STES concepts. Things that have been learned in small-scale tests to date should be incorporated in the large-scale designs. More heat transfer and thermal analysis is needed for all of the nonaquifer STES concepts.

\subsection{POTENTIAL STES COST EFFECTIVENESS}

The potential cost effectiveness of nonaquifer seasonal storage is dependent upon many site-specific variables and the energy source/use requirements. A specific concept will vary in cost between sites. Not enough data is available to accurately compare the costs of STES systems.

The STES system for an energy source that provides a steady uniform supply of thermal energy (e.g., aluminum plant) can be substantially smaller and less costly than a system that uses an energy source that supplies the bulk of heat in summer (solar) and does not use the energy until winter when insolation is low. 
Lower-temperature storage means that insulation requirements are not as great as for high-temperature storage. A lower-temperature gradient means less insulation and lower cost. Lower temperatures also mean that a larger variety of materials and lower-cost materials can be considered in the construction of the containers and heat exchangers.

If complex special heat exchangers are required to minimize corrosion and fouling, to maintain cleanliness, etc., the cost will be much higher than for simple units where storage media are directly interfaced with heating and cooling fluids.

Probably the most important cost element to consider in seasonal or annual storage systems is the cost of the storage medium. A rough comparison of costs for a $56^{\circ} \mathrm{C}$ storage temperature swing is:

$\begin{array}{lr}\text { Material } & \text { Btu/\$ } \\ \text { Water } & 625,000 \\ \text { Rock } & 10,000 \\ 0 i 1 & 400\end{array}$

The STES systems become more economic as the capacity increases because of economies of scale. Large systems have lower costs and smaller heat loss percentages.

The only common basis for costs of the three basic systems (sensible, latent, and thermochemical) was found in a study for power plants. The three systems were compared using the Solar-Brayton power cycle operating at 400$800^{\circ} \mathrm{C}$. The cost analys is is summarized in Tables 6 and 7 . The analysis is like comparing apples and oranges because only the sensible heat concept is now close to being technically and economically viable.

A cost analysis comparing various sensible STES concepts for storing waste heat from an aluminum plant is shown in Figure 3 . The initial storage cost is estimated as a function of storage capacity. Table 8 gives some order-ofmagnitude costs based upon review of the literature and some of my own estimates. More cost work needs to be done on nonaquifer STES systems, especially on a life-cycle basis. 
TABLE 6. Storage System Cost Summary

(Millions of Dollars)

\begin{tabular}{|c|c|c|c|}
\hline Account & Thermochemical & Phase Change & Sensible Heat \\
\hline Storage medium & 0.5 & 2.0 & 3.0 \\
\hline Storage container(s) & 1.8 & 0.3 & 13.0 \\
\hline Reactor & 4.9 & -- & -- \\
\hline \multicolumn{4}{|l|}{ Heat exchanger } \\
\hline Tubes & -- & 3.1 & -- \\
\hline Construction & -- & 0.3 & 0.5 \\
\hline Misc plant equipment & 3.4 & -- & - \\
\hline He circulating system & 1.1 & 1.4 & 1.3 \\
\hline Total system & 11.7 & 7.1 & 17.8 \\
\hline
\end{tabular}

- 50 MWe module

- 6 hours storage

TABLE 7. Energy Cost Comparisons

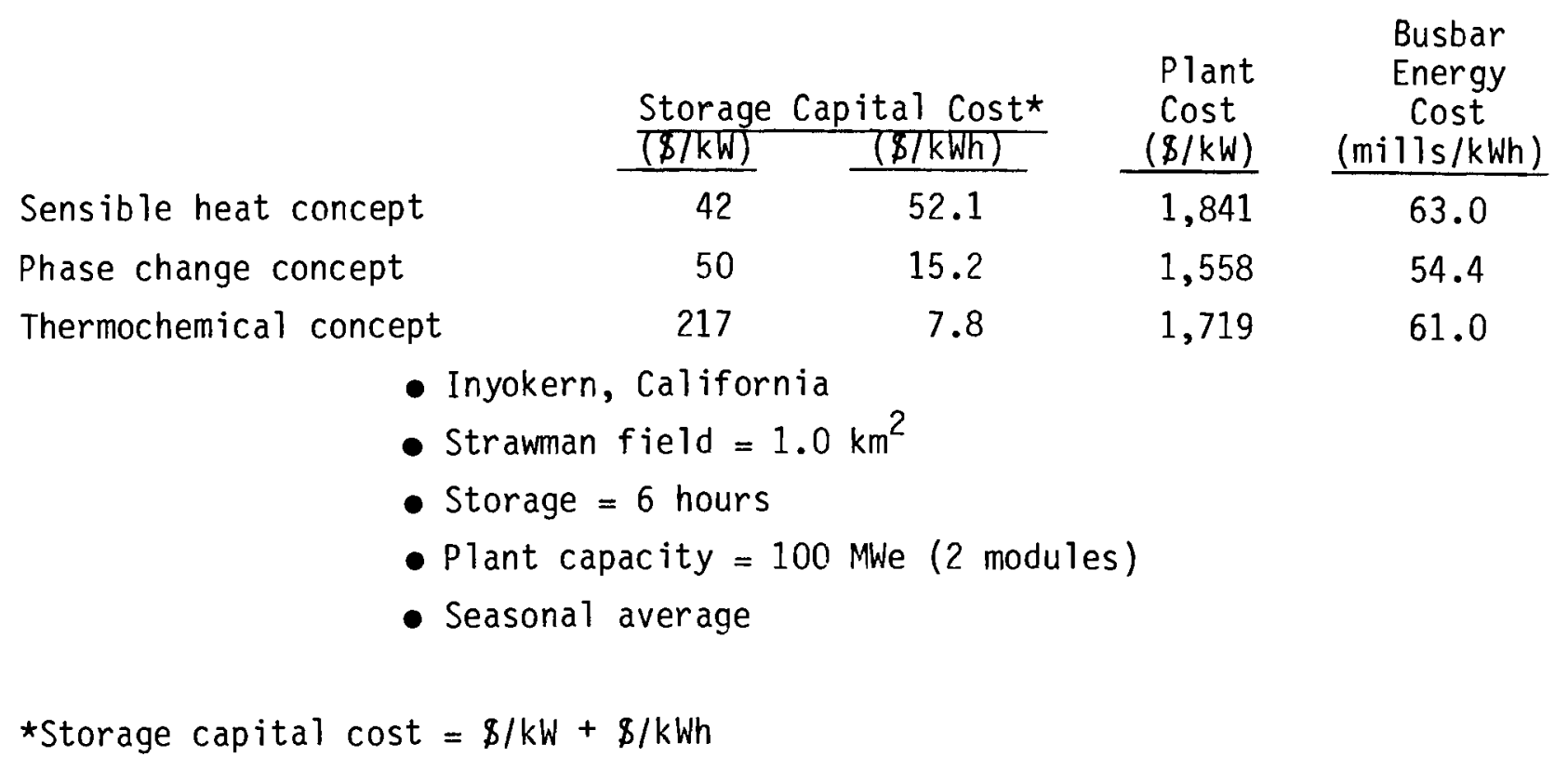




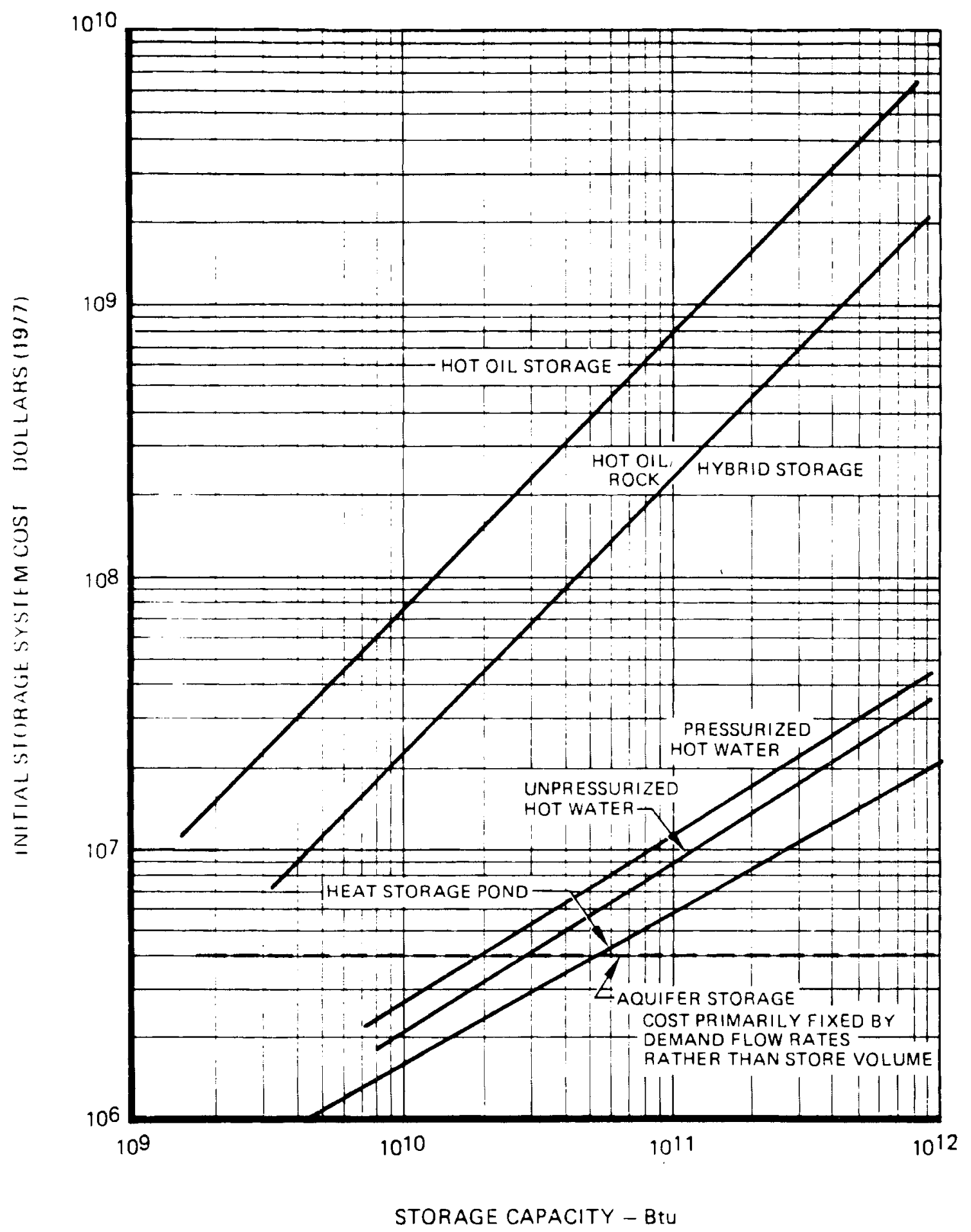

FIGURE 3. Initial Storage System Capital Cost (2; Katter and Hoskins 1978, p. 102) 
TABLE 8. Rough Cost Estimates for TES Containers

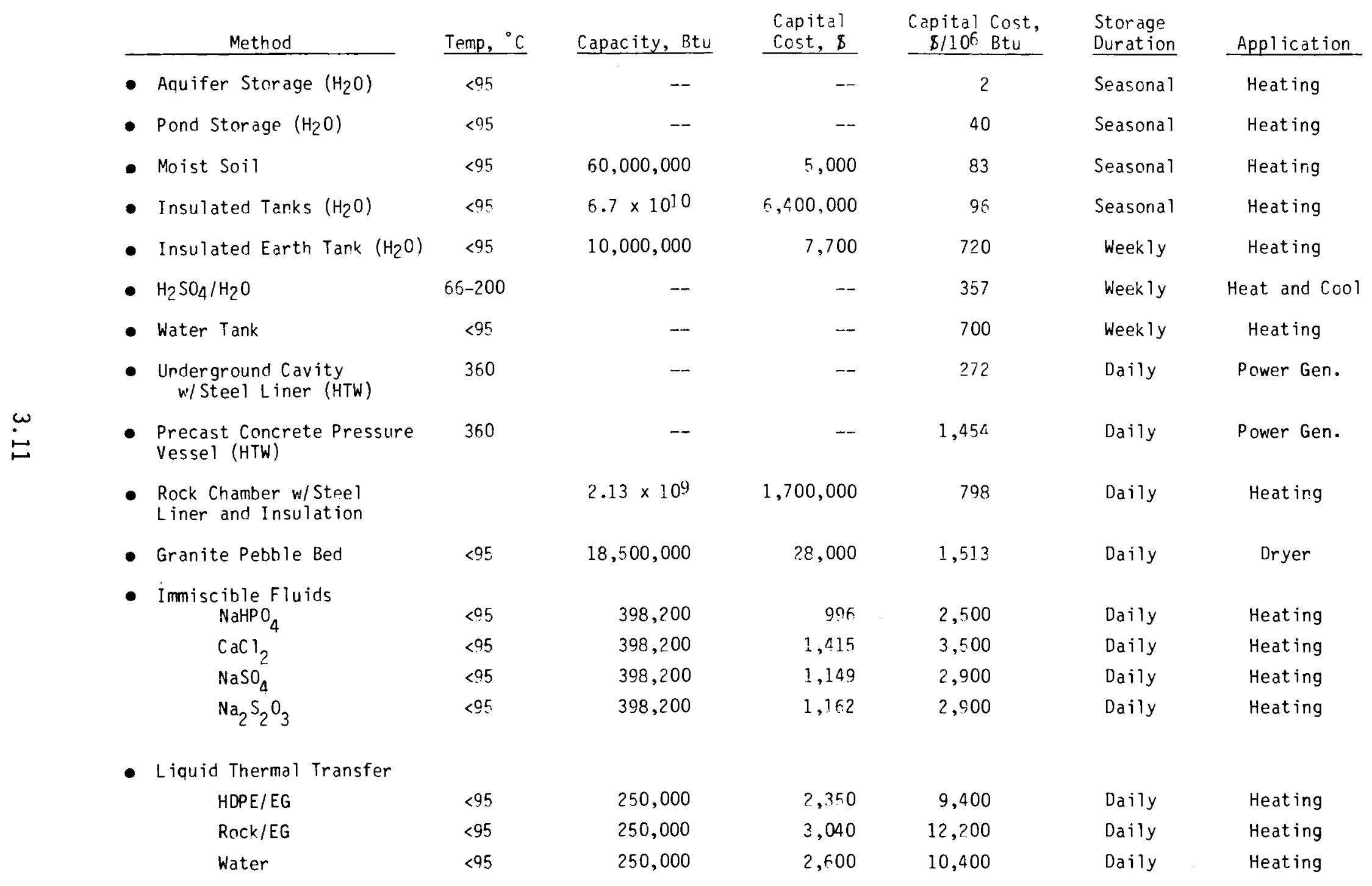


It appears that the most cost effective seasonal storage will be to use the best technology at temperatures suitable for district heating and cooling and agricultural uses. This is in the $\angle 200^{\circ} \mathrm{C}$ range. Use of water and/or rock as a storage medium with earth for the container appears the least costly at the current time: the simpler and less unknown, the better.

Most of the present cost estimates are based upon paper studies, and they should be refined after experience is gained with actual testing.

Many estimates are based on the capacity for one home and a daily or multiday duration. These estimates are hard to compare and use for seasonal storage. Supporting information for costs is often lacking, and estimates may be biased. As stated earlier, there is a need for improved cost estimates, especially for the nonaquifer STES concepts that have near-term applications.

Although the cost of the TES system is one consideration, the overall cost, including the source and use systems, is the most important consideration at a particular site. Sometimes a more expensive TES system is needed to accommodate the energy source or use requirements. 


\subsection{CONCLUSIONS AND RECOMMENDATIONS}

Based on the literature reviewed so far, the use of seasonal nonaquifer thermal energy storage should be limited to the sensible heat methods in the low-temperature $\left(\angle 95^{\circ} \mathrm{C}\right)$ ranges during the next few years. Use of the hightemperature range with sensible heat methods seems practical for only the daily mode of TES due to the higher costs for material and insulation.

Use of latent heat for TES also appears to be only practical for daily storage applications because of high costs and further development requirements. It is unlikely that use of latent heat for seasonal storage will ever be practical. It may be used for daily buffer storage of an STES system, however. The only exception for latent STES would be in cooling applications with ice.

Thermochemical STES above $250^{\circ} \mathrm{C}$ requires much more development and may never be feasible, technically and economically. Liquid thermochemical STES below $250^{\circ} \mathrm{C}$ appears to be marginally feasible if safety concerns with the sulfuric acid/water method can be resolved.

The currently most promising nonaquifer concepts for more detailed evaluation of potential energy savings, thermal effectiveness, and cost effectiveness are:

$\underline{\text { Sensible STES Heating }}^{(\mathrm{a})}$

- Large engineered, insulated ponds with $<95^{\circ} \mathrm{C}$ water

- Wet earth storage with $<95^{\circ} \mathrm{C}$ water

- Others that have less potential but still might be considered: deep natural lakes and ponds, solar ponds, mine open pits, caverns, rock storage and water tanks. Rocks can also be used for cooling.

Latent STES Cooling

- Ice and compacted snow storage

(a) May be used for cooling also with heat pumps. Heat pumps should be considered for use in all the concepts. 


\section{Thermochemical STES Heating and Cooling}

- Sulfuric acid/water storage

The best applications for these seasonal concepts is district heating and cooling and agricultural uses (greenhouses, crop drying, animal shelters, aquaculture, etc.). These concepts, coupled with heat pumps, show good near-term promise. Once the more advanced high-temperature heat pumps are developed, the application of these concepts can be increased to include industrial steam for food, textiles, paper, and chemicals. High-temperature heat pumps can work with temperatures to $160^{\circ} \mathrm{C}$ and can increase temperatures by up to $100^{\circ} \mathrm{C}$.

As a minimum, preliminary studies should be made of the concepts listed above to evaluate the thermal insulation requirements and life-cycle costs before spending large sums of money on the concepts. Costs estimates should be made for systems capable of heating and/or cooling 100, 1000, and 10,000 homes.

Probably one of the most promising corcepts would be to cover an engineered pond with solar heat collectors. This would combine the source of the heat as well as storage, make better use of the land, and increase the sites available for STES applications. 


\subsection{BIBLIOGRAPHY}

The references accumulated to date are in the STES Library operated by Midwest Research Institute for the Pacific Northwest Laboratory in Richland, Washington. The STES Library listings (which include nonaquifer references) are lengthy and will be published in a separate report. Presented here is a "library" of references specific to nonaquifer STES. Also listed are references selected from the bound, unbound $(u)$, and microfiche $(m)$ portions of the general STES Library.

Figure 4 lists the alternative TES methods and their respective references as they are numbered in the STES library and in this bibliography. Since these references are selected references, their numeration is not consecutive. Use of Figure 4 will allow the reader to refer to the references associated with each of the alternative TES methods. 


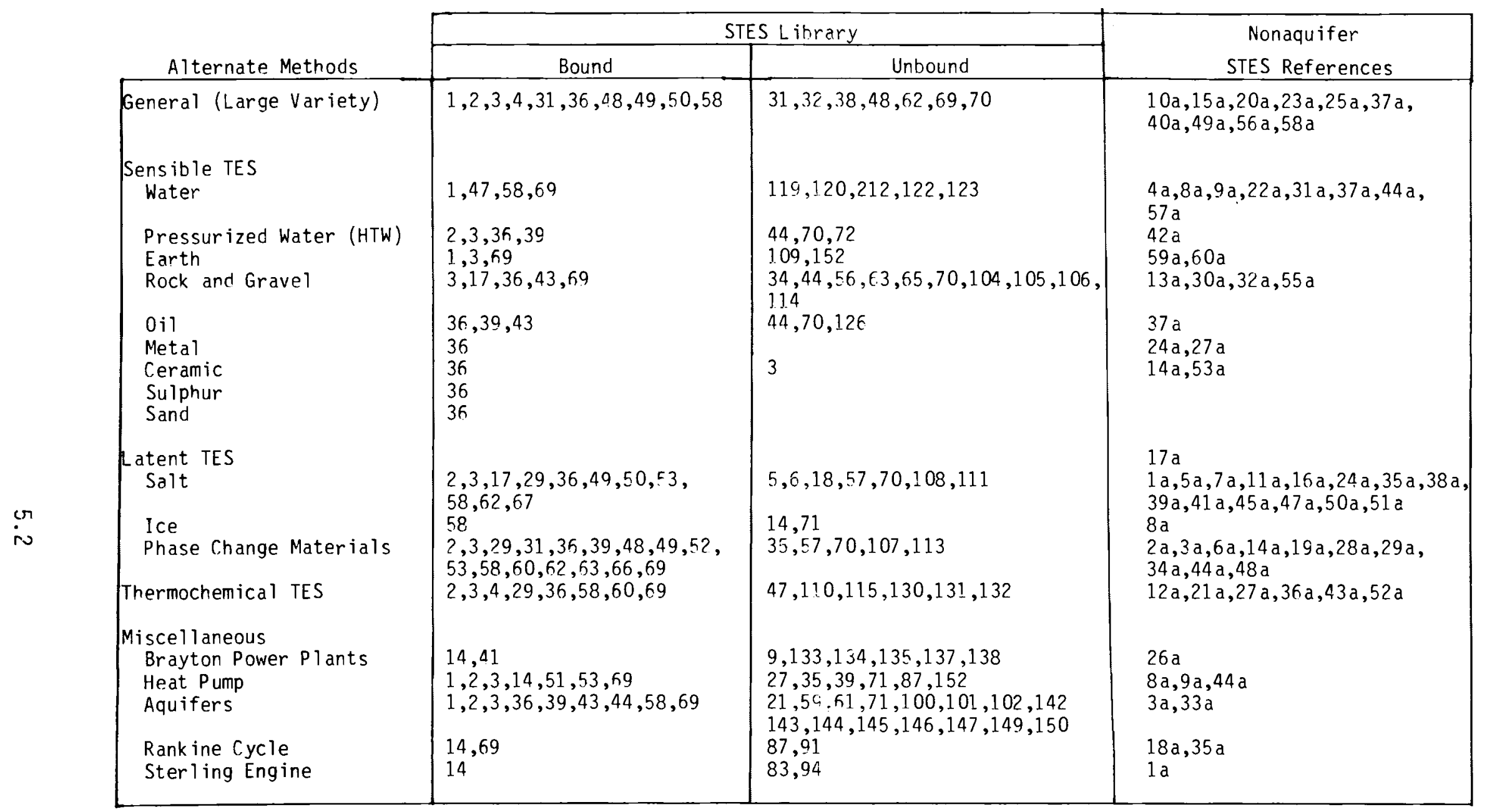

\section{FIGURE 4. References for Alternate TES Methods}


NONAQUIFER STES LIBRARY REFERENCES

1a. Asselman, G. A. A. 1976. "Thermal Energy Storage Unit Based on Lithium Fluoride." Energy Conversion, 16:35-47.

2a. Batutis, E. F. 1963. "Storing Thermal Energy." pp. 102-103.

3a. Bathelt, A. G., R. Viskanta and W. Leidenfrost. 1978. "Heat Transfer From Cylinders During Melting of a Thermal Energy Storage Material." Heat Transfer 1978. 4:179-184.

4a. Behnia, M., and R. Viskanta. 1979. "Free Convection in Thermally Stratified Water Cooled From Above." Int. J. Heat Mass Transfer. 22:611-623.

5a. Boser, 0. "Safety Considerations for High Temperature Thermal Energy Storage in Fluoride Salts." In Proceedings of the 12th Intersociety Energy Conversion Engineering Conference. 2:575-582.

6a. Botham, R. A., G. H. Jenkins, G. L. Ball III and I. 0. Sayer. 1978. "Crosslinked HDPE Makes the Grade in Thermal Energy Storage." Modern Plastics. pp. 54-56.

7a. Caldwe11, R. T., J. W. McDonald and A. Pietsch. 1965. "Solar-Energy Receiver with Lithium-Hydride Heat Storage." Solar Energy, 9(1):48-60.

8a. Calm, J. M., and P. T. Bauer. 1979. "District Heating and Cooling with Heat Pump Systems." Paper No. 799357, American Chemical Society, pp. 1681-1686.

9a. Clark, G., and C.P. Allen. 1979. "Sensible and Latent Cooling Requirements of Conventional and Passively Cooled Residences in American Climates." Paper No. 799057, American Chemical Society, pp. 269-273.

10a. Davis, D. C., J. S. Romberger, C. A. Pettibone and G. A. Kranzler. "Waste Heat from Food Processing Plants in the Pacific Northwest." Scientific paper No. 5298, Washington State University, College of Agriculture Research Center, Pullman, Washington.

11a. Ferrara, A., R. Haslett and J. Joyce. "Molten Salt Thermal Energy Storage for Utility Peaking Loads." In Proceedings of the 12th Intersociety Energy Conversion Engineering Conference. 2:547-554.

12a. Fujii, I., and K. Tsuchiya. "Experimental Study of Thermal Energy Storage by Use of Reversible Chemical Reactions." In Alternative Energy Sources, McGraw-Hill International Book Company, 9:4021-4035. 
13a. Gnirk, P. F., and A. F. Fossum. 1979. "On the Formulation of Stability and Design Criteria for Compressed Air Energy Storage in Hard Rock Caverns." American Chemical Society, pp. 429-440.

14a. Godfrey, R. D., and S. A. Mumma. 1976. "Thermal Performance of Paraffin Phase Change Materials Dispersed in a Concrete Mortar Filler Matrix." Paper No. 76-WA/HT-33, The American Society of Mechanical Engineers.

15a. Gordon, L. H. "Thermal Storage Technologies for Solar Industrial Process Heat Applications." National Aeronautics and Space Administration, Lewis Research Center.

16a. Grange, B. W., R. Viskanta and W. H. Stevenson. 1976. "Diffusion of Heat and Solute During Freezing of Salt Solutions." Int. J. Heat Mass Transfer. 19:373-384.

17a. Hal1, R. C. 1964. "The Use of Latent Energy of Vaporization in Energy Reservoirs." Solar Energy. 8(3):99-102.

18a. Hatami, R. 1979. "Solar Heated Absorption Refrigeration System." Paper No. 799059, American Chemical Society. p. 278.

19a. Heine, D, F. Heess and M. Groll. 1979. "Investigation of the Corrosion and Melting/Freezing Behavior of High Temperature Latent Heat Storage Materials." Paper No. 799096, American Chemical Society, pp. 459-466.

20a. Heitner, K. L. 1979. "Energy Storage Systems for Improved Load Management." Power Engineering. pp. 56-59.

21a. Hiller, C. C., and E. C. Clark. 1979. "Development and Testing of the Sulfuric Acid-Water Chemical Heat Pump/Chemical Energy Storage System." Paper No. 799104, American Chemical Society, pp. 510-515.

22a. Jayadev, T. S., M. Edesess, and J. Henderson. 1979. "Solar Pond Concepts: 0ld and New." Paper No. 799008, American Chemical Society, pp. 45-52.

23a. Joy, P., and B. Shelpuk. 1976. "Solar Heating Thermal Storage Feasibility." Paper No. WA/HT-36, The American Society of Mechanical Engineers.

24a. Kauffman, K. W., and H. G. Lorsch. 1977. "Design and Costs of High Temperature Thermal Storage Devices Using Salts or Alloys." Paper No. 76-WA/HT-34, The American Society of Mechanical Engineers.

25a. Koefoed, J. 1976. "Thermal Energy and Its Storage." In Proceedings of a NATO Science Committee Conference on Thermal Energy Storage (TES), March 1-5, 1976, Turnberry, Scotland. ATso in Energy. 2:53-101, 1976. 
26a. Lampinen, B. E., R. R. Gutowski, A. Topouzian and M. A. Pulick. 1979. "The Indirect Brayton Energy Recovery System." Paper No. 799337, American Chemical Society, pp. 1625-1629.

27a. Libowitz, G. G. 1974. "Metal Hydrides for Thermal Energy Storage." In Proceedings of the 9th Intersociety Energy Conversion Engineering Conference. pp. 322-325.

28a. Lorsch, H. G. 1974. "Thermal Energy Storage Devices Suitable for Solar Heating." In Proceedings of the 9th Intersociety Energy Conversion Engineering Conference. pp. 572-577.

29a. Lorsch, H. G., K. W. Kauffman and J. C. Denton. 1975. "Thermal Energy Storage for Solar Heating and Off-Peak Air Conditioning." Energy Conversion. 15:1-8.

30a. Margen, P. H. "Thermal Energy Storage in Rock Chambers." In A/CONF.49/P/798, pp. 177-194.

31a. Margen, P. H. 1978. "A Hot-Water Reservoir for Long-Term Storage." Akt iebolaget Atomenergi. AE-E-209, 1978-01-02.

32a. Meredith, D. B., and P. J. Wilbur. 1979. "The Desiccant/Rock Bed Method of Solar Cooling with Air Collectors." Paper No. 799058, American Chemical Society, pp. 274-277.

33a. "Need for Large-Scale Thermal Energy Storage." In Proceedings of the Fifth Energy Technology Conference, February 27 - March 1, 1978, Washington, DC, pp. 177-188.

34a. Nichols, M. C., and R. M. Green. "Direct Contact Heat Exchange for Latent Heat-of-Fusion Energy Storage Systems." In Alternative Energy Sources. McGraw-Hill International Book Company, $\underline{9}: 3939-3958$.

35a. Petri, R. J., T. D. Claar and L. G. Marianowski. 1979. "Evaluation of Molten Carbonates as Latent Heat Thermal Energy Storage Materials." Paper No. 799100, American Chemical Society, pp. 487-493.

36a. Radebold, R. D. "New Generation MHD-Systems Based on Alkali Metals for the Storage of Solar Energy on Hydrazine and Hydrogen-Peroxide." Arbeitsgemeinschaft Exergietransformer. pp. 23-38.

37a. Raetz, J. E., C. r. Easton, and R. J. Holl. 1975. "The Selection and Use of Energy Storage for Solar Thermal Electric Application." IECEC '75 Record. pp. 576-582.

38a. Schroder, J. 1974. "Thermal Energy Storage and Control." Paper No. 74-WA/OCT-1, The American Society of Mechanical Engineers. 
39a. Schroder, J. 1975. "Thermal Energy Storage and Control." Journal of Engineering for Industry. pp. 893-896.

40a. "Sharing the Sun Solar Technology in the Seventies." In Storage, Water Heater, Data Communication Education. Joint Conference American

Section, International Solar Energy Society and Solar Energy Society of Canada, Inc., August 15-20, 1976.

41a. Stunic, Z., V. Djurickovic and Z. Stunic. 1978. "Thermal Storage: Nucleation of Melts of Inorganic Salt Hydrates." J. Appl. Chem. Biotechnol. 28:761-764.

42a. Talaat, M. E. 1976. "A Pressurized Liquid Concept for Solar-Thermal Energy Storage for the 24-Hour Cont inuous Operation of an Energy Conversion System." Paper No. 76-WA/HT-38, The American Society of Mechanical Engineers.

43a. Tanaka, T., K. Sakuta, M. Kamimoto, T. Tani, S. Sawata and T. Horigome. 1978. "Solar Thermal Energy Storage Using Heat of Dilution: Analysis of Heat Generation in Multistage Mixing Column." Energy Conversion, $18: 57-65$.

44a. Telkes, M. 1964. "Solar-Heat Storage." Paper No. 64-WA/SOL-9, The American Society of Mechanical Engineers.

45a. Telkes, M. 1975. "Thermal Energy Storage." In Proceedings of the Tenth Intersociety Energy Conversion Engineering Conference. pp. 111-115. (Submitted to IECEC 175 Record.)

46a. Turner, R. D. 1979. "Superconducting Magnetic Energy Storage for Electric Power System Stabilization." Paper No. 799101, American Chemical Society, pp. 494-499.

47a. Tye, R. P., A. 0. Desjarlais and J. G. Bourne. "Thermophysical Property Measurements on Thermal Energy Storage Materials." In Proceedings of the Seventh Symposium on Thermophysical Properties. pp. 189-197.

48a. Van Vechten, J. A. 1974. "Latent-Heat Energy Storage is Feasible." Electrical World. p. 41.

49a. Vaccari, J. A. 1979. "Key to New Energy Storage Systems." Product Engineering. pp. 46-49.

50a. Verma, A. 1978. "Medium-Temperature Heat Storage in Sodium Sulphate." CIM Bulletin. pp. 84-90.

51a. Verma, A., K. E. Johnson and E. 0. Sherman. 1976. "Thermal Energy Storage in Inorganic Salts." The Canadian Journal of Chemical

Engineering. 54:285-289. 
52a. Wentworth, W. E., and E. Chen. 1976. "Simple Thermal Decomposition Reactions for Storage of Solar Thermal Energy." Solar Energy. $18: 205-214$.

53a. Wessling, F. C., Jr. 1974. "Thermal Energy Storage in Adobe and in Stone Structures." Paper No. 74-WA/HT-15, The American Society of Mechanical Engineers.

54a. Whike, A. S. 1979. "Energy Conservation and Pollution Control - Two Advantages of Coil Coating." Paper No. 799343, American Chemical Society, pp. 1653-1655.

55a. Wiles, L. E. 1979. "Analys is of Mass Cycling in Porous Rock Reservoirs for Compressed Air Energy Storage." Paper No. 799092, American Chemical Society, pp. 441-445.

56a. CONF-790328-P1aP2 Proceedings of Solar Energy Storage Options, March 19-20, 1979, San Antonio, Texas.

57a. Kays, W. B. 1977. Construction of Linings for Reservoirs, Tanks, and Pollution Control Facilities. John Wiley and Sons.

58a. Baylin, F. 1979. Low Temperature Thermal Energy Storage: A State-ofthe-Art Survey. SERI/RR-54-164, Solar Energy Research Institute.

59a. "Energy System Uses Earth's Own Heat." 1979. In Geothermal World News Report, Geothermal Energy, p. 8.

60a. "Joseph Orr's Fabulous Mud Heat Storage Solar Greenhouse." May/June 1978. The Mother Earth News. 
SELECTED STES LIBRARY REFERENCES (BOUND MATERIALS)

1. Thermal Energy Storage Application Areas. March 1979. Prepared for the Department of Energy by TRW.

2. 3rd Annual Proceedings of Thermal Energy Storage Contractors Information Exchange Meeting. December 5-6, 1978. CONF-781231. Springfield, Virginia.

3. Proceedings of the Second Annual Thermal Energy Contractors' Information Exchange Meeting. September 29-30, 1977. CONF-770955, Gatlinburg, Tennessee.

4. Energy Storage, User Needs and Technology Applications. February 8-13, 1976, CONF-760212, An Engineering Foundation Conference, Asilomar,

Pacific Grove, California.

6. Dean, T. S. 1978. Thermal Storage, Franklin Institute Press, Philadelphia, Pennsylvania.

7. Turner, R. H. 1978. High Temperature Energy Thermal Storage, Frank1in Institute Press. Philadelphia, Pennsylvania.

14. Industrial Applications Study, Volume III, Techonology Data Base Evaluation of Waste Recovery Systems. January 1977. C00-2862-3, Drexe1 University, United Technologies Research Center, Mathematica, Inc.

17. Jaeger, F. A., D. G. Beshore, F. M. Miller and E. M. Gartner. October 1978. Application of Thermal Energy Storage in the Cement Industry.

Final Report, September 1977 - March 1978, CONS 5084-1. Mart in Marietta Aerospace, Denver Colorado and Portland Cement Association, Skokie, Illinois.

29. Industrial Applications of Solar Total Energy. April 1977. Final Report, Volume 2, Technical, DOE SAN/1132-2/1, McDonne 11 Douglas Astronautics Co.

31. Advanced Therma1 Energy Storage (TES) Systems. Ju1y 1, 1976 December 31, 1976. Volume 1, Final Technical Report, ERDA EY-76-C-03-1300, Boeing Engineering and Construction.

36. Hause, A Berkowitz and Hare. October 1978. Conceptual Design of Thermal Energy Storage Systems for Near-Term Electric Utility Applications. DOE/NASA/0012-78/1, EPRI RP1082/1, GE Tempos Vol. 2.

39. Hausz, A. Berkowitz and Hare. October 1978. Conceptual Design of Thermal Energy Storage Systems for Near-Term Electric Utility Applications, Screening of Concepts. DOE/NASA/0012-78/1, G.E. Tempo, Vol. 1. 
41. Advanced Thermal Energy Storage Concept Definition Study for Solar Brayton Power Plants. November 1977. Volume 1, Final Technical Report, JuTy 1 - December 32, 1976, DOE SAN/1300-1, Boeing Engineer ing and Construction.

43. Katter, B. Lincoln, Haskins and L. Rande1. October 1978. Applications of Thermal Energy to Process Heat and Waste Heat Recovery in the Primary Aluminum Industry. Final Report for the Period September 1977 September 1978, DOE CONS/5080-1, Rocket Research Co.

47. Survey of the Applications of Solar Thermal Energy Systems to Industrial Process Heat. January 1977. Volume 3, Solar Thermal Energy System Analysis and Preliminary Assessment of Related Nontechnical Issues, DOE TID-27348/3, Battelle, Columbus Laboratories and Honeywe 11, Inc.

48. Hale, D. V. September 1971. Phase Change Materials Handbook, N72-19956. Lockheed Missiles and Space Company.

49. Lane, George A. May 1975. Storage Energy Subsystems Employing Isothermal Heat Storage Materials. ERDA-117, Dow Chemical Company.

50. Borucka, A. June 1975. Survey and Selection of Inorganic Salts for Application to Thermal Energy Storage. ERDA-59.

51. Stecher, P. G. 1979. Industrial and Institutional Waste Heat Recovery. Energy Technology Review No. 37, Noyes Data Corporation.

52. University of Maryland. July 1973. Proceedings of the Solar Heating and Cooling for Buildings Workshop. March 21-23, 1973, Part I, Technical Sessions, PB-223 536. Washington D.C.

53. Segaser, C. L. November 1975. Mius Technology Evaluation, Thermal Energy Storage Materials and Devices. ORNL-HUD-MIUS-23, Oak Ridge Nationa1 Laboratory.

58. Baylin, F. July 1979. Low Temperature Thermal Energy Storage: A State of the Art Survey. SERI/RR-54-164.

60. Battelle Memorial Institute. September 30, 1966. Final Technical Report on Thermal Energy Storage. NASA-CR-80058, supporting research to Jet Propulsion Laboratory, California Institute of Technology.

62. Kauffman, K. and Y. C. Pan. June 1973. Congruently Melting Materials for Thermal Energy Storage in Air Conditioning. PB-238-543, University of Pennsylvania.

63. Leiby, C. C., Jr., and T. G. Ryan. July 18, 1973. Thermalphysical Properties of Thermal Energy Storage Materials - Aluminum. Air Force Cambridge Research Laboratories. 
66. Dudley, James C. August 1972. Thermal Energy Storage Unit for Air Conditioning Systems Using Phase Change Material. PB-238-162, National Center for Energy Management and Power.

67. Belton, G., and F. Ajami. May 1973. Thermochemistry of Salt Hydrates/Conservation and Better Utilization of Electric Power By Means of Thermal Energy Storage and Solar Heating. PB-227-966, University of Pennsylvania.

69. Proceedings of Solar Energy Storage Options. March 19-20, 1979. Volume 1, CONF 79032B-P1 and P2. San Antonio, Texas. 
SELECTED STES LIBRARY REFERENCES (UNBOUND MATERIALS)

3u. Armstrong, T. B. November/December 1978. "Wire Mesh Floor Heating System." IEE Transactions on Industry Applications, Volume IA-14, No. 6 .

5u. Bak, D. J., ed. April 23, 1979. "Salt-Filled Tank Supplies Heat for High-Pressure Steam." Design News, pp. 124-125.

6u. "Barrel of Heat Stores Sun's Energy." February 6, 1978. Design News, pp. 30-31.

9u. Beverly, W. D., W. W. Engle and F. 0. Mahony. "Integration of High Temperature Thermal Energy Storage Into a Solar Thermal Brayton Cycle Power Plant." Proceedings of the 12th Intersociety Energy Conversion Engineering Conference, 2:1195-2002.

14u. Bullock, C. E., W. R. Reedy and G. C. Groff. 1979. "Cool Storage as a Means for Residential Air Conditioning Electrical Load Management." American Chemical Society, pp. 528-533.

18u. Chubb, T. A. April 23, 1979. "NRL Builds Energy Storage System." Design News, p. 39.

21u. Davison, R. R., W. B. Harris and J. H. Martin. December 1975. "Storing Sunlight Underground." Chemtech, pp. 736-741.

27u. Ekroth, I. A. 1979. "Thermodynamic Evaluation of Heat Pumps Working with High Temperatures." American Chemical Society, pp. 1713-1719.

31u. Fernandes, R. A., 0. D. Gildersleeve and T. R. Schneider. September 23-27, 1974. "Assessment of Advanced Concepts in Energy Storage and Their Application on Electric Utility Systems." In Proceedings of the 9th World Energy Conference, 7:281-301. Detroit, Michigan.

32u. Fraas, A. P., and G. Samuels. February 1978. "Power Conversion Systems of the 2lst Century." In Proceedings of the American Society of Civil Engineers, 104(P01):83-97.

34u. French, E. P. 1979. "Hybrid Thermal Storage Subroutine for Transient Simulation." American Chemical Society, pp. 516-520.

35u. Frysinger, G. R. 1979. "Storage Assisted Heat Pumps Using Phase Change Materials." American Chemical Society, pp. 1730-1733.

38u. Gordon, L. H. Thremal Storage Technologies for Solar Industrial Process Heat Applications. National Aeronautics and Space Administration, Lewis Research Center.

39u. Gorzelnik, E. F. August 1, 1978. "How to Recycle Low-Grade Process Heat." Electrical World, pp. 60-61. 
44u. Hausz, R., R. K. Anand and N. LaMarche. 1979. "Electric Utility Applications of Thermal Energy Storage and Transport." American Chemical Society, pp. 467-474.

47u. Hockett, R. S. and R. W. Serth. "High Temperature Thermal Energy Storage System, $\mathrm{NA}_{2} \mathrm{SO}_{4}+\mathrm{SO}_{3} \mathrm{NA}_{2} \mathrm{~S}_{2} \mathrm{O}_{7} . "$ In Proceedings of the 12 th Intersociety Energy Conversion Engineering Conference, 2:540-546.

48u. Hoffman, H. W., R. J. Kedl and C. J. Swet. 1977. "ERDA Program on Thermal Energy Storage at Temperatures Below $250^{\circ} \mathrm{C} . "$ A.N.S. Trans, $26: 413-414$.

56u. Margen, P. H. 1972. "Thermal Energy Storage in Rock Chambers - A Complement to Nuclear Power." In Proceedings of the Fourth International Conference on the Peaceful Uses of Atomic Energy, 4:177-194. Geneva.

57u. Marianowski, L. G., and H. C. Maru. "Latent Heat Thermal Energy Storage Systems Above $450^{\circ} \mathrm{C} . "$ In Proceedings of the 12 th Intersociety Energy Conversion Engineering Conference, 2:555-566.

59u. Metz, W. D. June 30, 1978. "Energy Storage and Solar Power: An Exaggerated Problem." Science, 200:1471-1473.

61u. Molz, F. J., A. D. Parr and P. F. Andersen. 1979. "Thermal Energy Storage in Aquifers: Experimental Study." American Chemical Society, pp. 534-537.

62u. Moore, G. L. 1974. "Sizing of Solar Energy Storage Systems Using Local Weather Records." 74-WA/HT-20, Ther American Society of Mechanical Engineers.

63u. Moriarty, M. P. 1979. "A Simplified Algorithm for the Evaluation of Hybrid Thermal Storage with Water Systems." American Chemical Society, pp. 521-527.

65u. Newman, M. E. October/November 1977. "Heat Pump and Water on the Rocks." Building Systems Design, pp. 36-41.

69u. Phillips, W. F. and R. A. Pate. 1974. "A Hot Liquid Energy Storage System Utilizing Natural Circulation." 74-WA/HT-16, The American Society of Mechanical Engineers.

70u. Pierce, B. L., F. R. Spurrier and M. K. Wright. "Thermal Energy Storage." In Proceedings of the 12th Inter society Energy Conversion Engineering Conference, 2:1189-1194.

71u. Powell, W. R. July/August 1978. "The Case for Cases - A Community Annual Energy Storage System." Environmental, 20(6):14-41. 
72u. Quade, R. N. 1974. "The High Temperature Gas-Cooled Reactor as a Source of High Temperature Process Heat." Nuclear Engineering and Design, 26:179-186.

83u. Sevcik, V. J. 1976. "Thermal Energy Storage and Transportation." In Proceedings of the American Section of the International Solar Energy Society and the Solar Energy Society of Canada, Inc., August 15-20, Winnipeg, pp. 177-182.

87u. Sullivan, D. 1979. "Technology Impact Study of a High Efficiency Industrial Heat Pump." American Chemical Society, pp. 1752-1729.

91u. Uehara, H. 1979. "Research and Development on Ocean Thermal Energy Conversion in Japan." American Chemical Society, pp. 2028-2034.

94u. Waters, E. D. and E. W. Saaski. 1979. "A Thermal Energy Storage System for a Stirling Engine Powered Highway Vehicle." American Chemical Society, pp. 475-480.

100u. Qvale, E. B. September 1976. "Seasonal Storage of Thermal Energy in Water in the Underground." In 11th Intersociety Energy Conversion Engineering Conference, $1: 623-6 \overline{35}$.

101u. Desert Reclamation Industries. August 23, 1978. Aquifer Storage at J. F. Kennedy International Airport. DOE Contract No. EC-77-C-01-5083.

102u. Meyer, C. F. February 24, 1978. "Large Scale Thermal Energy Storage for Cogeneration and Solar Systems." 5th Energy Technology Conference and Exposition, GE Tempo P-785. Washington, D.C.

104u. Close, D. J. May 1965. "Rock Pile Thermal Storage for Comfort Air Conditioning." Mechanical and Chemical Engineering Transactions, Institution of Engineers. Australia.

105u. Chapman, H. L. 1970. "A Rock Pile Heating and Cooling System." International Solar Energy Society Conference, Paper No. 6/54. Melbourne, Australia.

106u. Close, D. J., R. V. Durkle and K. A. Robeson. May 1968. "Design and Performance of a Thermal Storage Air Conditioning System." Mechanical and Chemical Engineering Transactions.

107u. Lorsch, H. G. November 1975. "Thermal Energy Storage for Solar Heating." ASHRAE Journal, pp. 47-52.

108u. Stepler, R. May 1978. "Revolving Barrel Banks Solar Heat." Popular Science, p. 91 .

109u. "Joseph Orr's Fabulous 'Mud Heat Storage' Solar Greenhouse." May/June 1978. The Mother Earth News, pp. 94-97. 
110u. "Chemical Mixture Creates 'Midnight Sun'." March 1978. Chemical Week, pp. 34-35.

111u. Smith, G. A., and A. M. Severson. 1975. "Salt Thermal Energy Storage for Solar Systems." International Solar Energy Society, ERDA.

113u. Kosaka, M., and M. Asahina. 1975. "Discussions on Heat Storage Material at Low Temperature Level." International Solar Energy Society, ERDA.

114u. Close, D. J., and T. L. Pryor. 1975. "Energy Storage in Absorbent Beds." International Solar Energy Society, ERDA.

115u. Ervin, G. 1975. "Solar Heat Storage Based on Inorganic Chemical Reactions." International Solar Energy Society, ERDA.

119u. Nielson, C. E. 1975. "Operation of a Small Salt Gradient Solar Pond." International Solar Energy Society, ERDA.

120u. Clark, A. F., W. L. Ahlgren, J. A. Day and W. C. Dickenson. 1975. "Experimental Performance of Shallow Solar Ponds." International Solar Energy Society, ERDA.

121u. Daniels, D. G. 1975. "Fluid Dynamics of Selective Withdrawal in Solar Ponds." International Solar Energy Society, ERDA.

122u. Styris, D. L., R. J. Zaworsk i, 0. K. Harling and J. Leshuk. 1975. "Nonconvecting Solar Pond, Some Applications and Stability Problem Areas." International Solar Energy Society, ERDA.

123u. Saulnier, B., N. Chepurniy, S. B. Savage and T. A. Lawand. 1975. "Field Testing of a Solar Pond." International Solar Energy Soceity, ERDA.

126u. Nicholson, E. W. and R. P. Cahn. September 1976. "Storage in 0il of Off-Peak Thermal Energy From Large Power Stations." 11th Intersociety Energy Conversion Engineering Conference.

130u. Gruen, D. M., R. L. McBeth, M. Mendelsohn, J. M. Nixon, F. Schreiner and I. Sheft. September 1976. "HYCSOS: A Solar Heating, Cooling and Energy Conversion System Based on Metal Hydrides." In 11th Intersociety Energy Conversion Engineering Conference.

131u. Schmidt, E. W., and P. A. Lowe. September 1976. "Thermochemical Energy Storage Systems." In 11th Intersociety Energy Conversion Engineering Conference.

132u. Libowitz, G. G., and Z. Blank. September 1976. "An Evaluation of the Use of Metal Hydrides for Solar Thermal Energy Storage." In 11th Intersociety Energy Conversion Engineering Conference. 
133u. Duval1, G. D. September 1976. "Operational Evaluation of a Closed Brayton Cycle Laboratory Engine." In 11th Intersociety Energy Conversion Engineering Conference.

134u. Fayrweather, D. J., R. A. Rackley and F. A. Robbins. September 1976. "Advanced Marine Closed Brayton Engines." In 11th Intersociety Energy Conversion Engineering Conference.

135u. Kuo, S. C. September 1976. "A Conceptual Design Study of Closed Brayton Cycle Gas Turbines for Fusion Power Generation." In 11th Intersociety Energy Conversion Engineering Conference.

137u. Kenney, W. D. September 1976. "Brayton Isotope Power System Ground Demonstration." In 11 th Intersociety Energy Conversion Engineer ing Conference.

138u. Aller, P., W. Saylor, G. Schmidt and D. Wein. September 1976. "Multipurpose Insulation System for a Radioisotope Fueled Mini-Brayton Heat Source Assembly." In 11th Intersociety Energy Conversion Engineering Conference.

142u. Schaetzle, W. J., J. E. LeCroy, M. S. Seppanen and C. E. Brett. Waste Heat Utilization with Annual Aquifer Storage. DOE Contract No. 31-109-38-4550.

143u. Schaetzle, W. J., C. E. Brett and J. Ansari. Thermal Energy Storage in Aquifers for a Solar Power Plant." University of ATabama.

144u. Schaetzle, W. J., L. R. Fang, C. E. Brett and D. M. Grubbs. December 2-7, 1979. "A Solar Energy System with Annual Aquifer Storage." Presented at the ASME Winter Annual Meeting, University of Alabama.

145u. Schaetzle, W. J., C. E. Brett and D. M. Grubbs. 1979. "Energy Storage in Groundwater Aquifers." Presented at the International Solar Energy Society Silver Jubilee Congress, May 28-June 1, 1979, Atlanta, Georgia.

146u. Schaetzle, W. J., C. E. Brett and D. M. Grubbs. "Commun ity Integrated Cooling and Heating System." Presented at the International Conference on Energy Use Management. October 22-26, Los Angeles, California.

147u. Schaetzle, W. J., C. E. Brett and D. M. Grubbs. "Annual Thermal Energy Storage in Groundwater Aquifers." Solar Energy Storage Options, Trinity University.

149u. Schaetzle, W. J., C. E. Brett and D. M. Grubbs. 1980. "A Heat Pump Community - Integrated Energy System Using Annual Aquifer Energy Storage." Presented at the ASHRAE Winter Meeting, February 3-7, 1980, Los Angeles, California. 
150u. Schaetzle, W. J., C. E. Brett and D. M. Grubbs. Direct Cooling Utilizing Aquifer Thermal Energy Storage. University of Alabama. DOE Contract No. 31-109-4550.

152u. Cropsey, M. G. 1964. "Soil as a Heat Storage Source for an Air to Air Heat Pump." Iransactions of the American Society of Agricultural Engineers. 


\section{SELECTED STES LIBRARY REFERENCES (MICROFICHE)}

1m. Hoffman, H. W. and R. J. Ked1. 1976. Thermal Energy Storage for Building Heating and Cooling Applications, Quarterly Progress Report, Apri1 - June 1976. ORNL/TM-5700, Oak Ridge National Laboratory.

18m. Brumleve, T. D. 1974. Sensible Heat Storage in Liquids, SLL-73-0263. Sandia Laboratories. Albuquerque, New Mexico.

19m. Silverman, M. D., and J. R. Engle. 1977. Survey of Technology for Storage of Thermal Energy in Heat Transfer Salt. ORNL/TM-5682, Oak Ridge National Laboratory, Tennessee.

20m. Borucka, A. 1975. Survey and Selection of Inorganic Salts for Application to Thermal Energy Storage. ERDA-29, Borucka Research Co. Livingston, New Jersey.

21m. Bramlette, T. T., R. M. Green, J. J. Barte11, D. K. Ottesen, C. T. Shafter and T. D. Brumleve. 1976. Survey of High Temperature Thermal Energy Storage. SAND-75-8063, Sandia Laboratories. Albuquerque, New Mexico.

22m. Kovach, E. G. 1976. Thermal Energy Storage. The Report of NAT0 Science Committee Conference Held at Turnberry, Scotland, March 1-5, 1976, NP-21237, NATO. Brussels, Belgium.

23m. French, R. L., and R. E. Bartera. 1978. Solar Energy for Process Heat: Design/Cost Studies of Four Industrial Retrofit Applications. JPL-PUBL-78-25, Jet Proputsion Lab. Pasadena, California. 


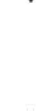


APPENDIX

TES CONCEPT DESCRIPTIONS 


\section{APPENDIX}

\section{TES CONCEPT DESCRIPTIONS}

A potpourri of TES concept schematics was found in the literature. Some of the concepts are listed in this Appendix as follows:

\begin{tabular}{|c|c|}
\hline $\begin{array}{r}\text { Concept } \\
\text { Sensible TES } \\
\end{array}$ & Figures \\
\hline Ponds & $A .1$ and $A .2$ \\
\hline Lakes & $A .3$ and $A .4$ \\
\hline Tanks & A. 5 to $A .9$ \\
\hline Caverns & A.10 to $A .13$ \\
\hline Earth & A.14 to $A .16$ \\
\hline Rocks & A.17 to $A .23$ \\
\hline Sand & A.24 and $A .25$ \\
\hline Ceramic & A.26 to $A .29$ \\
\hline Metal & A. 30 \\
\hline Hybrids & A.31 to $\mathrm{A} .35$ \\
\hline Latent TES & A. 36 to $A .46$ \\
\hline Thermochemical TES & A. 47 to $A .51$ \\
\hline Hybrid TES & A.52 and $A .53$ \\
\hline
\end{tabular}

Where applicable, the sources from which the schematics were drawn are acknowledged by reference number (from the bibliography of this report) and by author(s). 


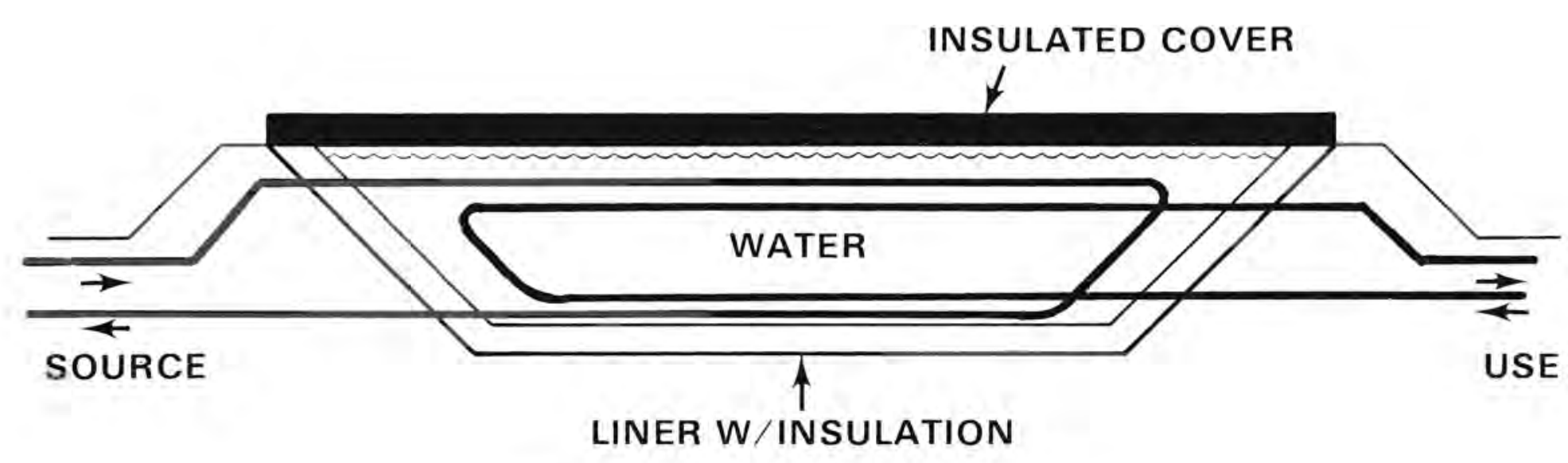

FIGURE A.1. Engineered Pond Storage 


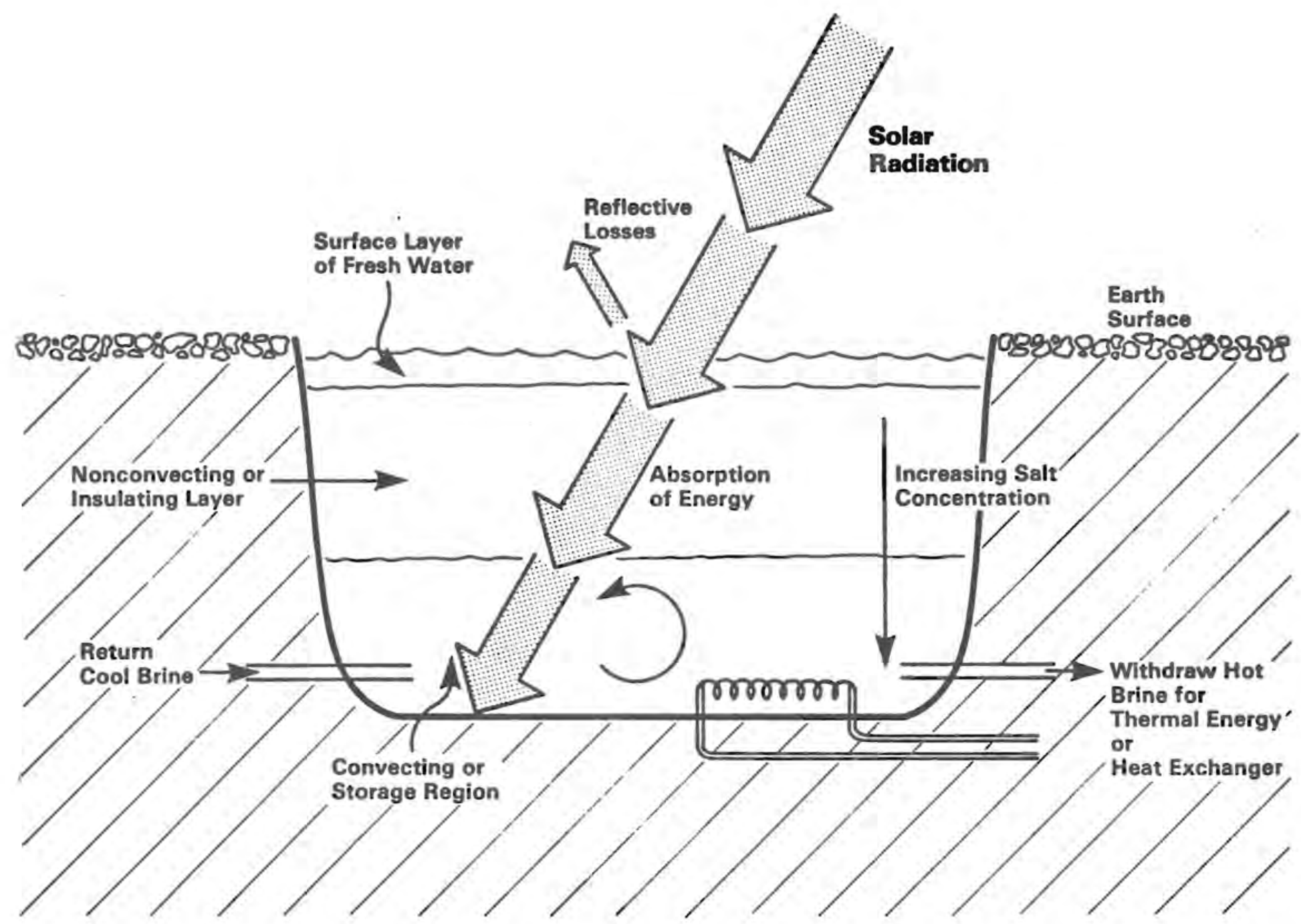

FIGURE A.2. Schematic Representation of Salt Gradient Solar Pond (58; Bayl in 1979, p. 7) 


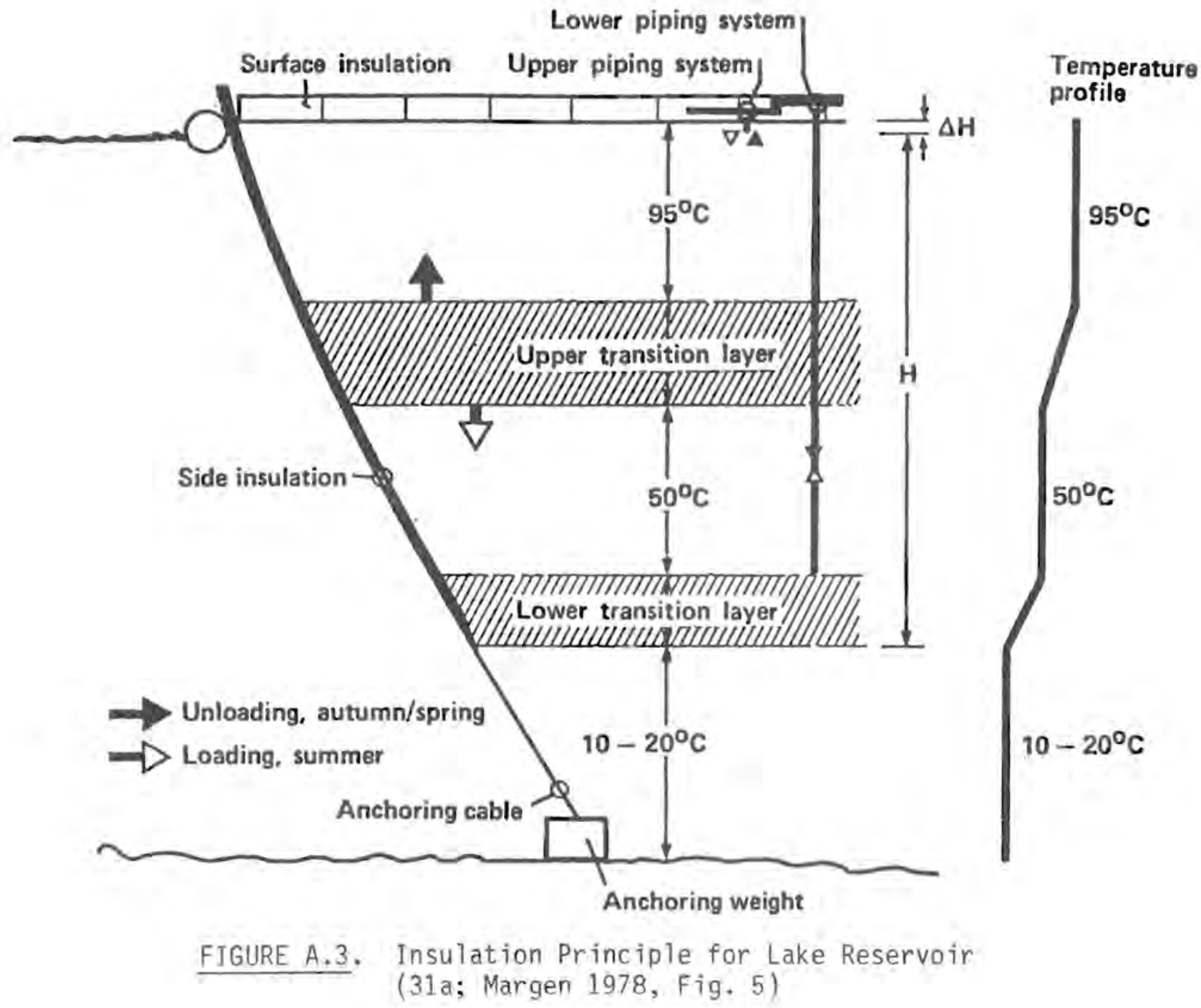


Transparent protective layer (or several layers) to prevent radiation and convection

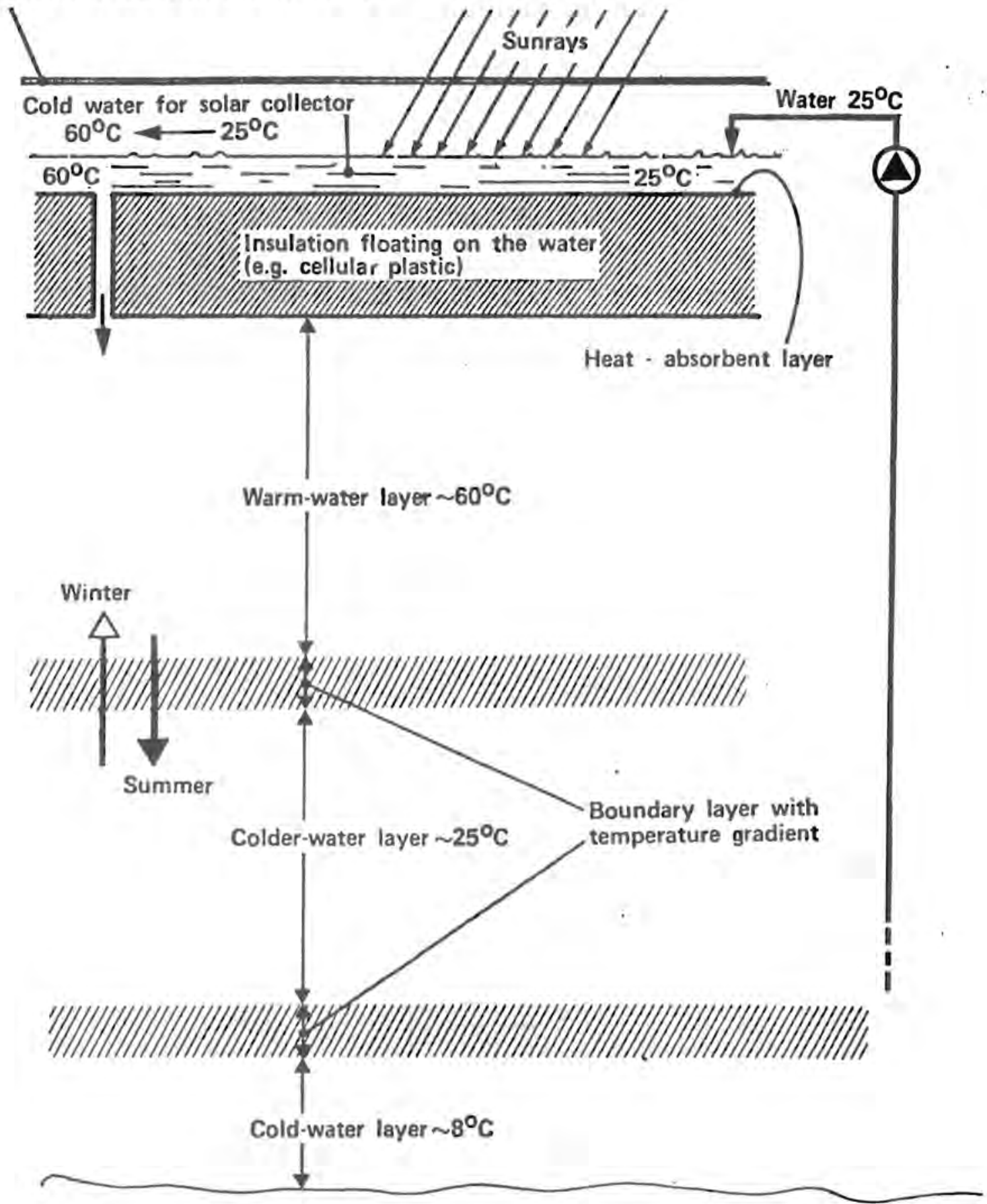

FIGURE A.4. Diagram of Combined Solar Collector and Lake Reservoir (31a; Margen 1978, Fig. 8) 


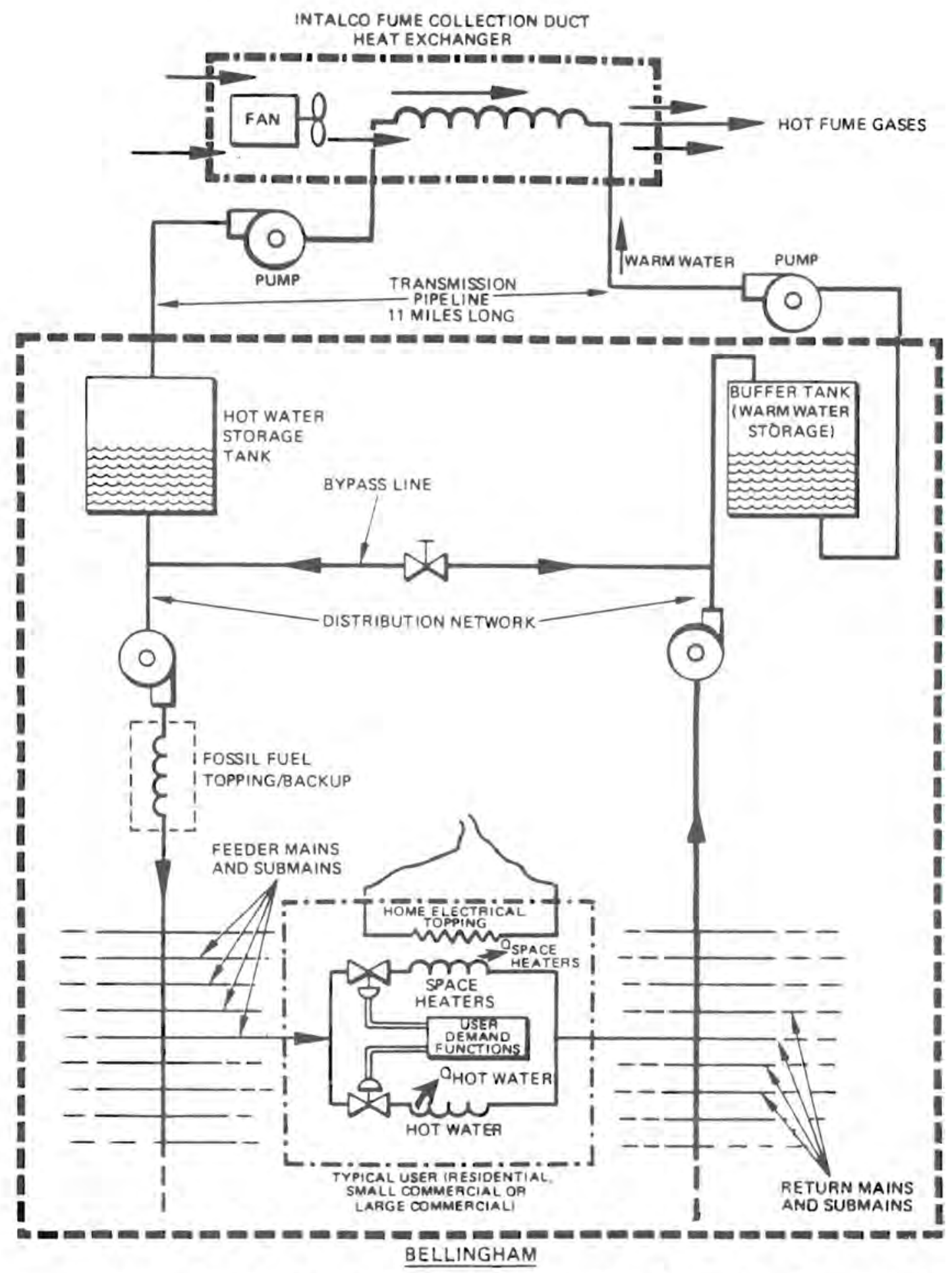

FIGURE A.5. District Heating System Flow Schematic Electrical Home Topping (43; Katter and Hoskins 1978, p. 86) 


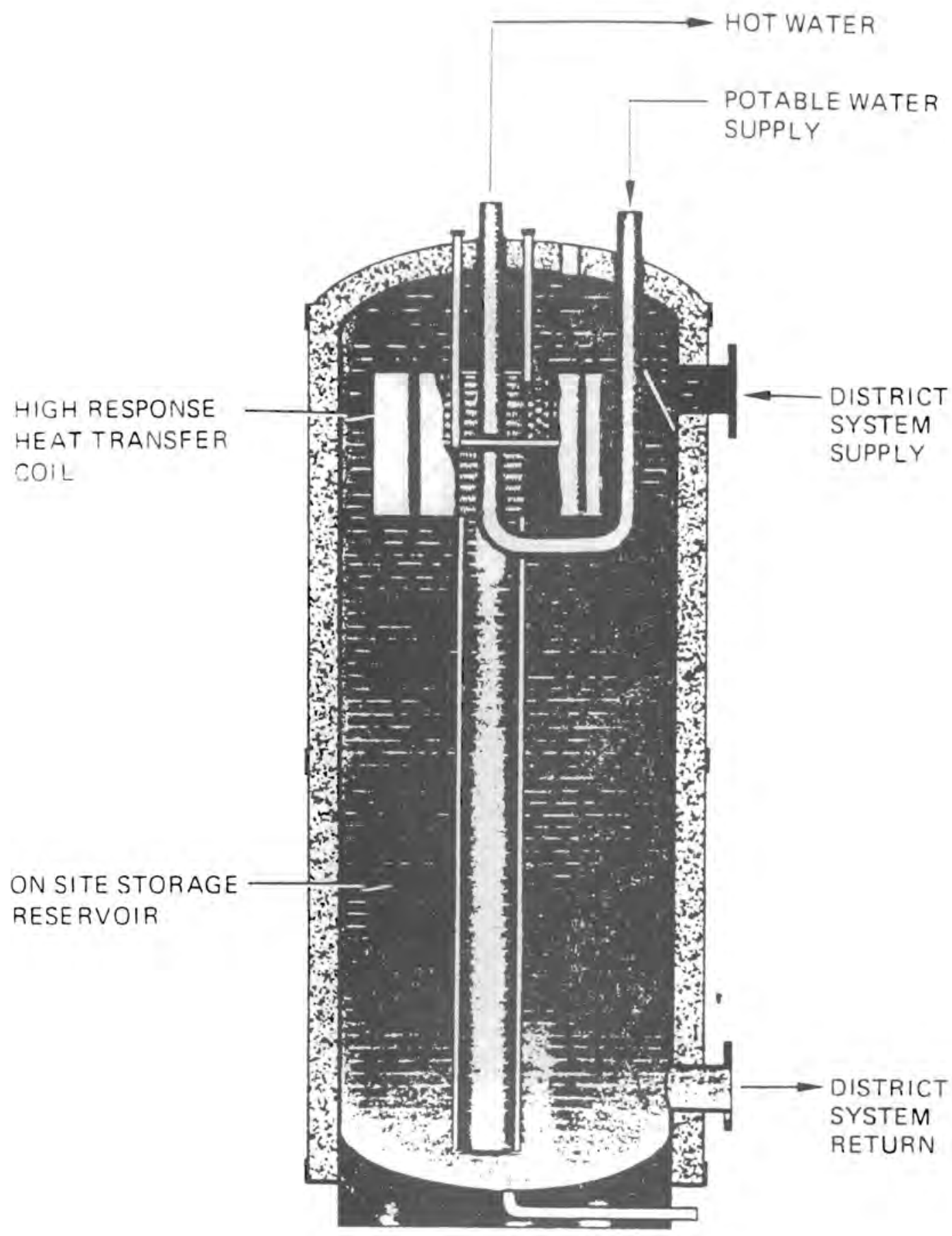

FIGURE A.f. Domestic Hot Water Heater

To Receive Energy from District Heating System (43: Katter and Hoskins 1978) 


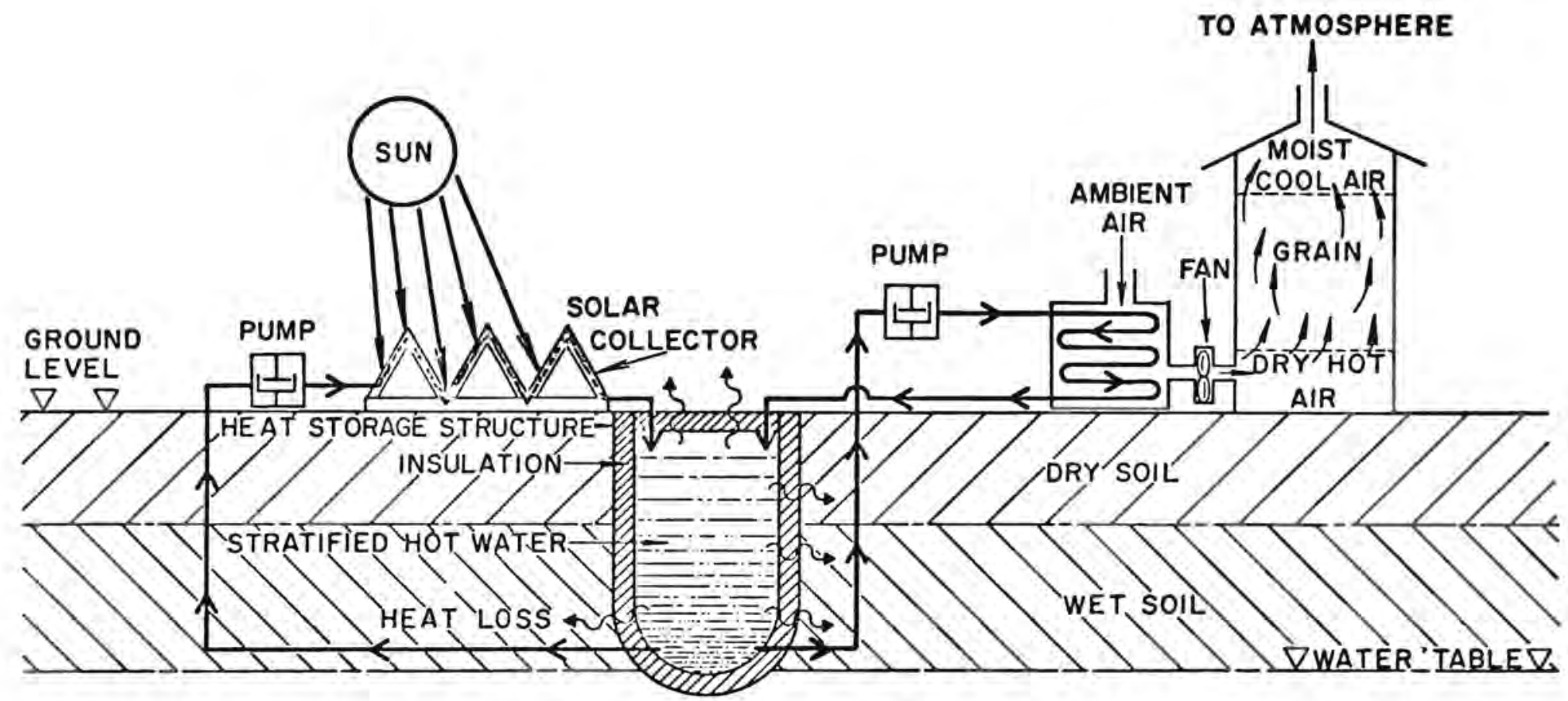

FIGURE A.7. Schematic of a Grain Drying System Using Energy Stored in Water by a Solar Collector (56a; Misra and Keener 1979, p. 304) 


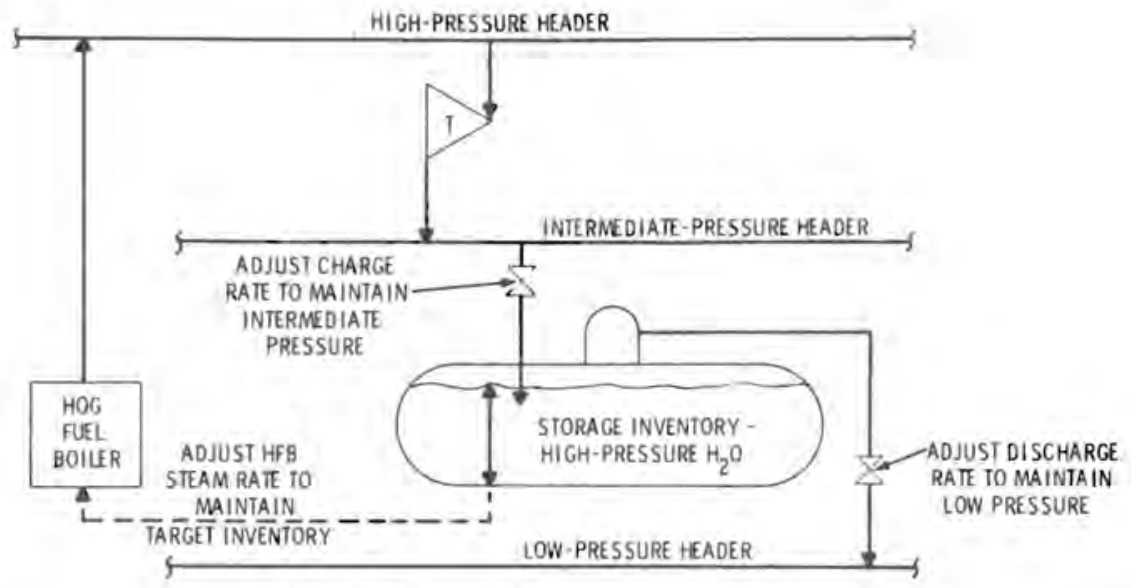

FIGURE A.8. Variable Pressure Accumulator Provides Thermal Energy Storage Capability (31a; Margen 1978, p. 5)

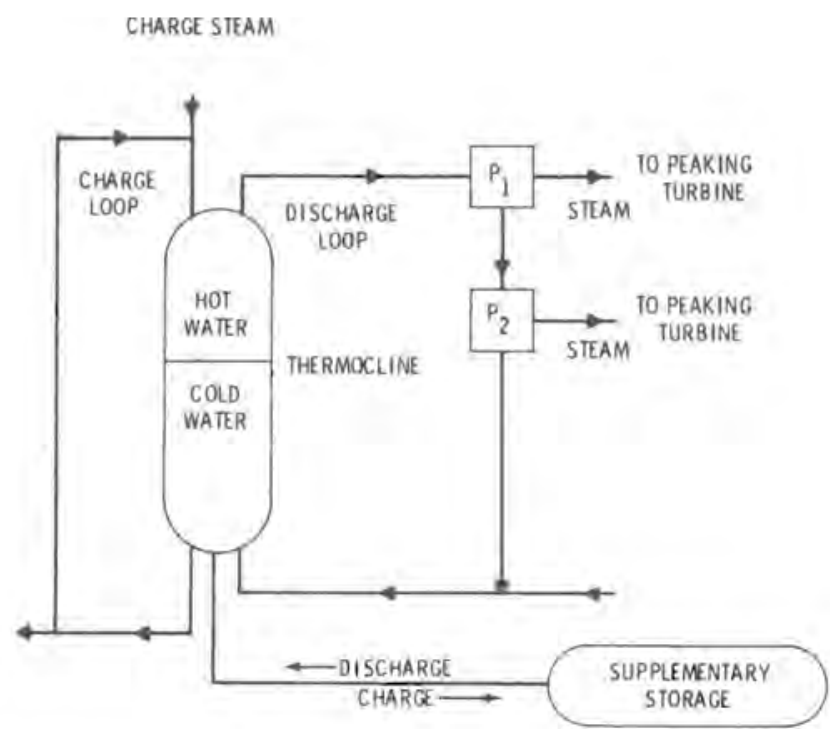

FIGURE A.9. Displacement A-cumulator with Flash Evaporators (39; Hausz, Berkowitz and Hare 1978, p. 2-14) 


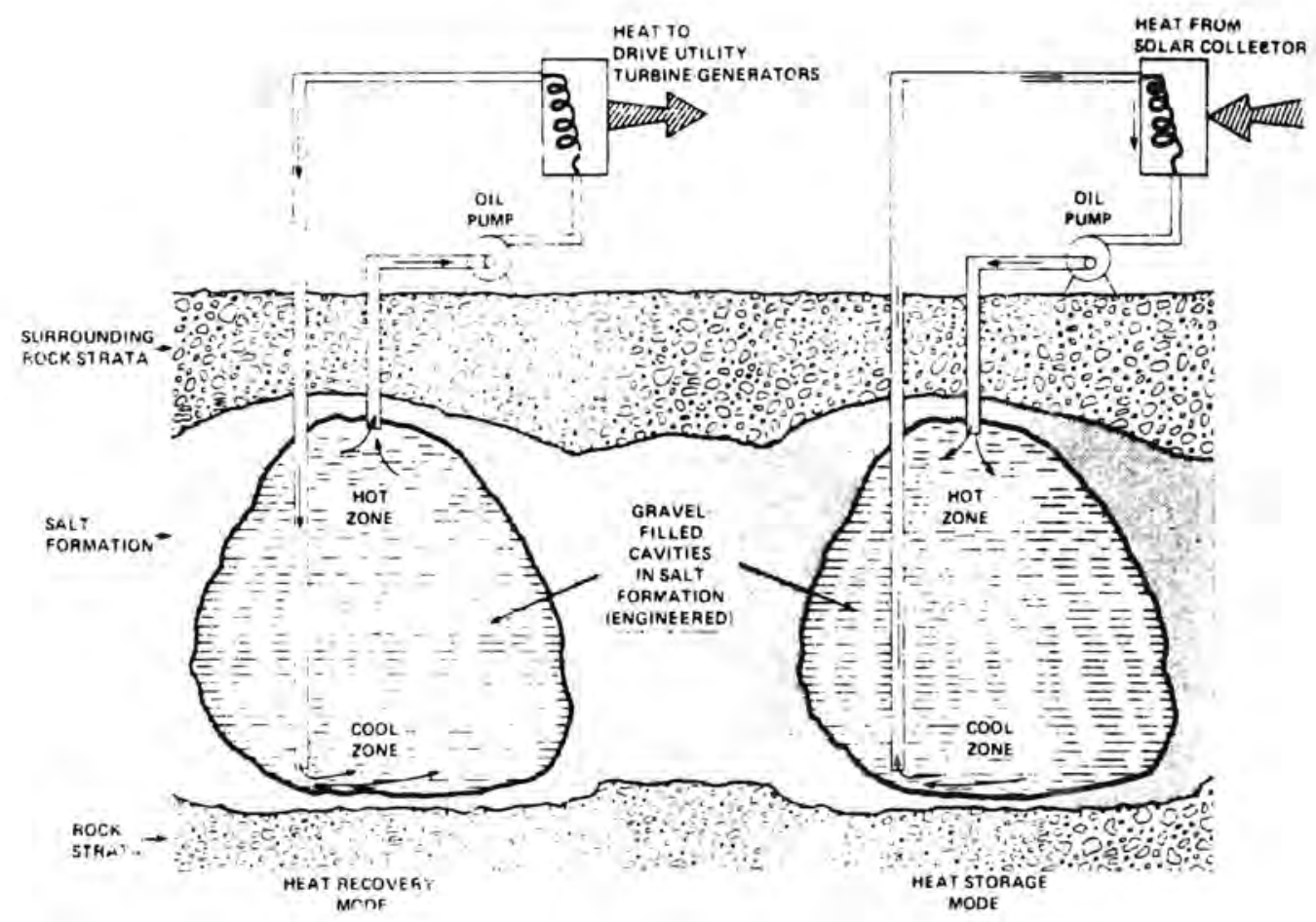

FIGURE A.10. Hot-0i1 Thermocline System for Thermal Storage in Solar-Thermal Power Generaton (1; TRW 1979 p. 10)

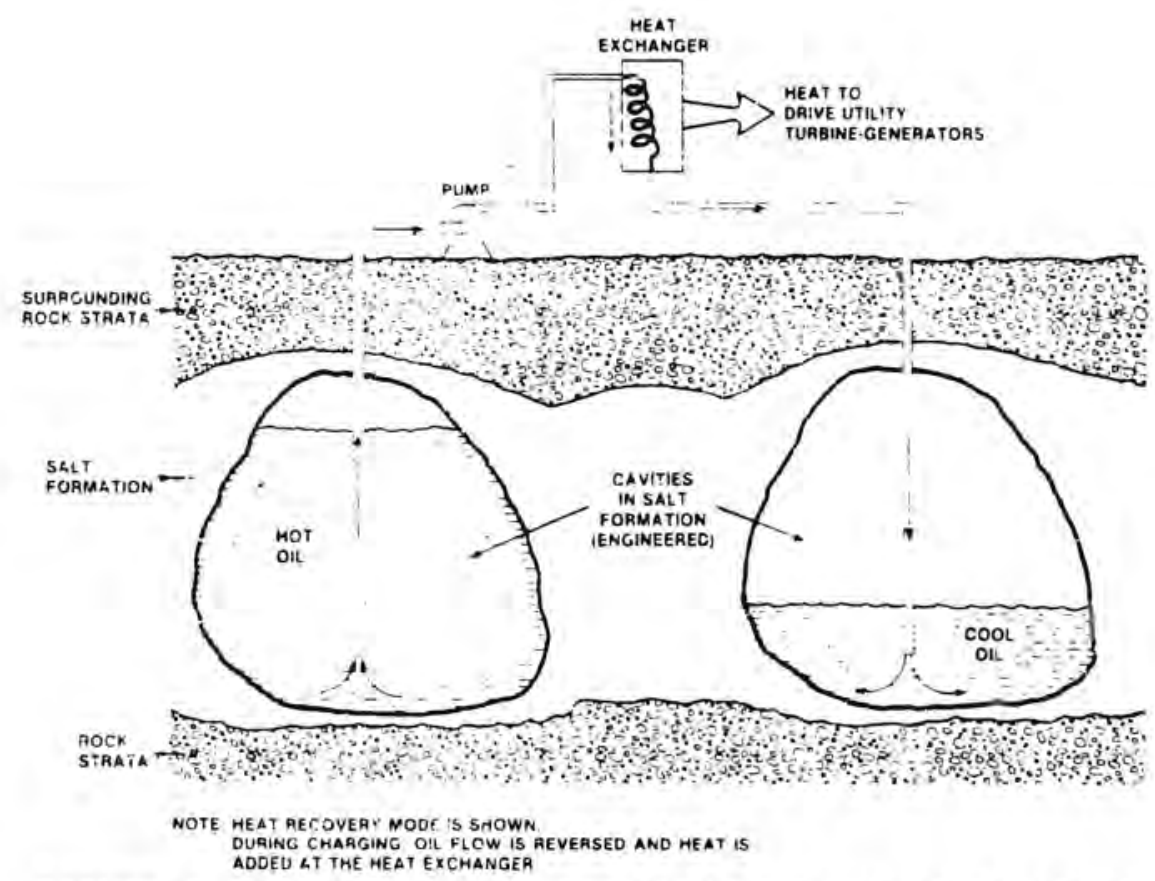

FIGURE A.11. Doublet Cavern System for Thermal Storage in Solar-Thermal Power Generation (1; TRW 1979 , p. 10) 


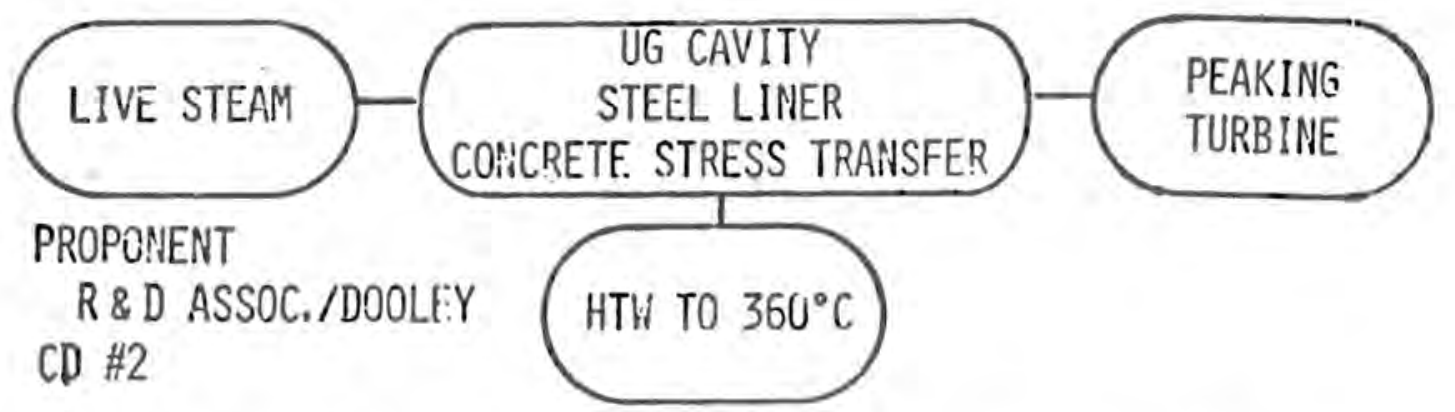

- ChaRGE: LIVE STEAM THROTTLED TO REFILL VARIABLE-PRESSURE ACCUMULATOR

- discharge: VARIABLE PRESSURE Flashed SteAM gOES tO PEAKING TURBINE EFFICIENCY $=90-95$ PERCENT

- SPHERICAL CAVITY IN COMPETENT ROCK CONCRETE FOR STRESS TRANSFER AND INSULATION COST OF CONTAINMENT $150-300 \$ / \mathrm{M}^{3}$

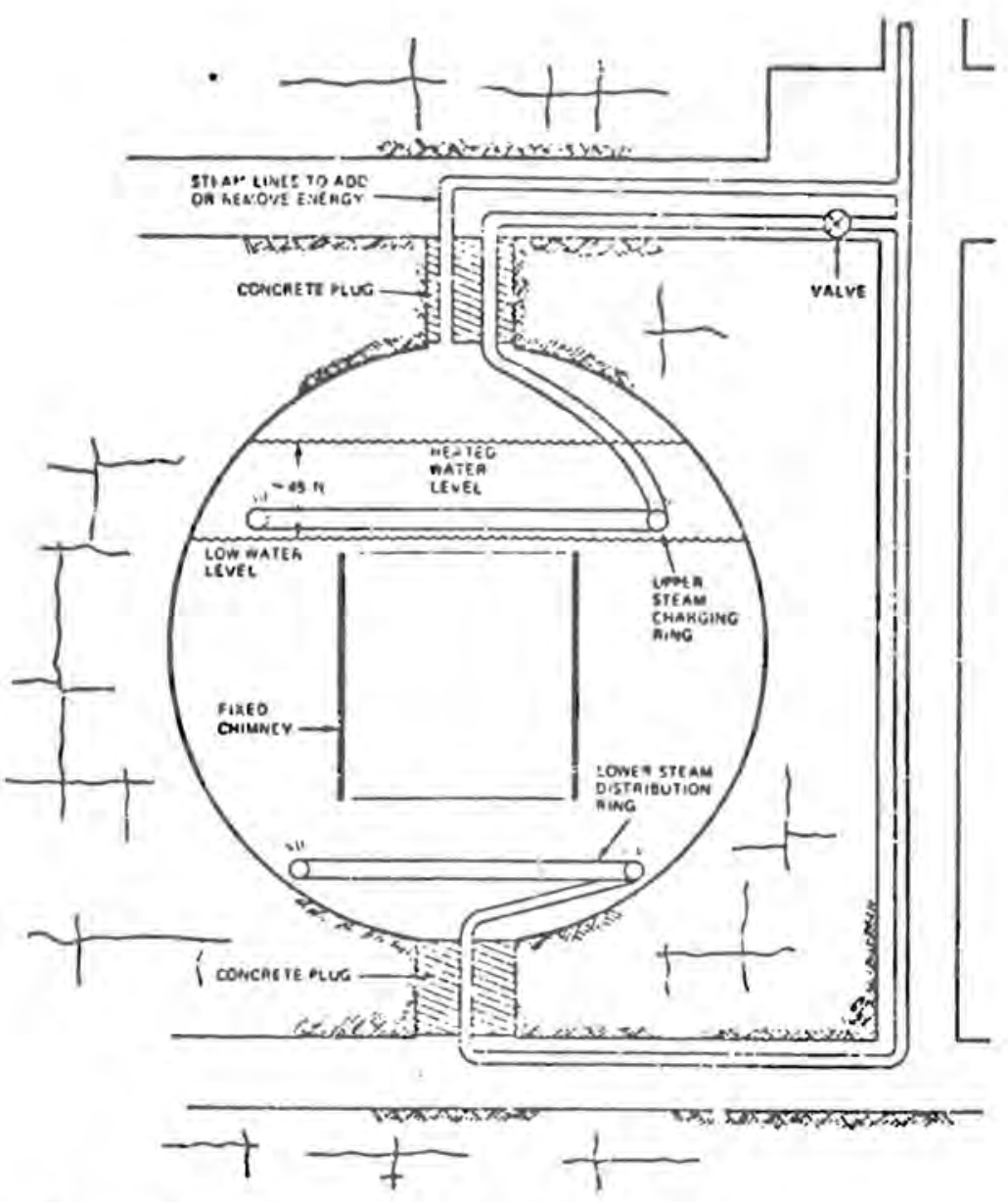

FIGURE A.12. Lined Cavern with High-Temperature $\mathrm{H}_{2} \mathrm{O}$ (39; Hausz, Berkowitz and Hare 1978, p. 3-20) 


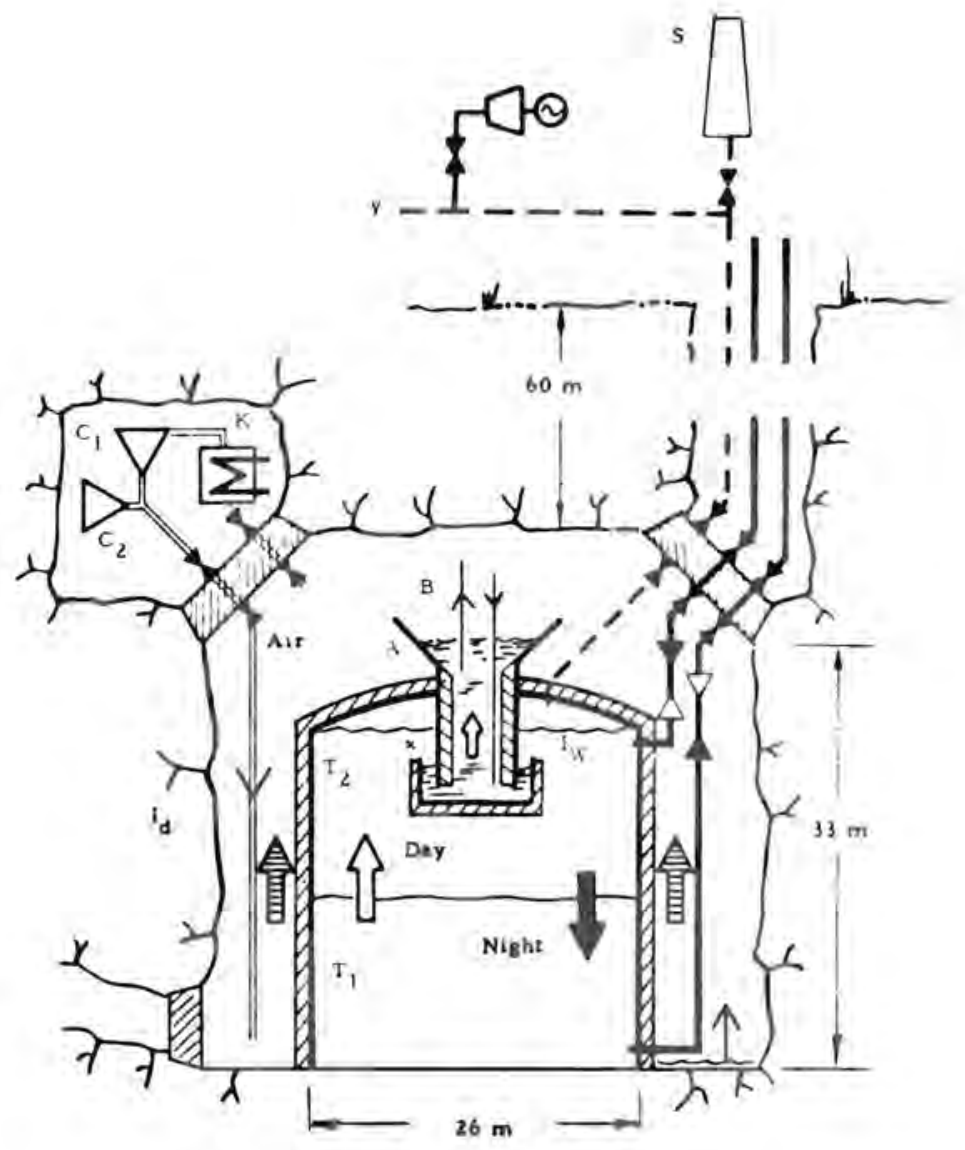

FIG.4. Accumulator with dry insulation and intemal steam expansion volume.

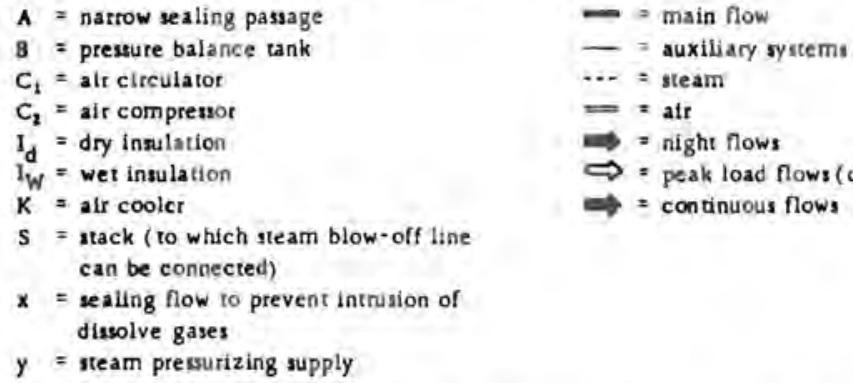

FIGURE A.13. Accumulator With Dry Insulation and Internal Steam Expansion Volume (30a; Margen, p. 184) 


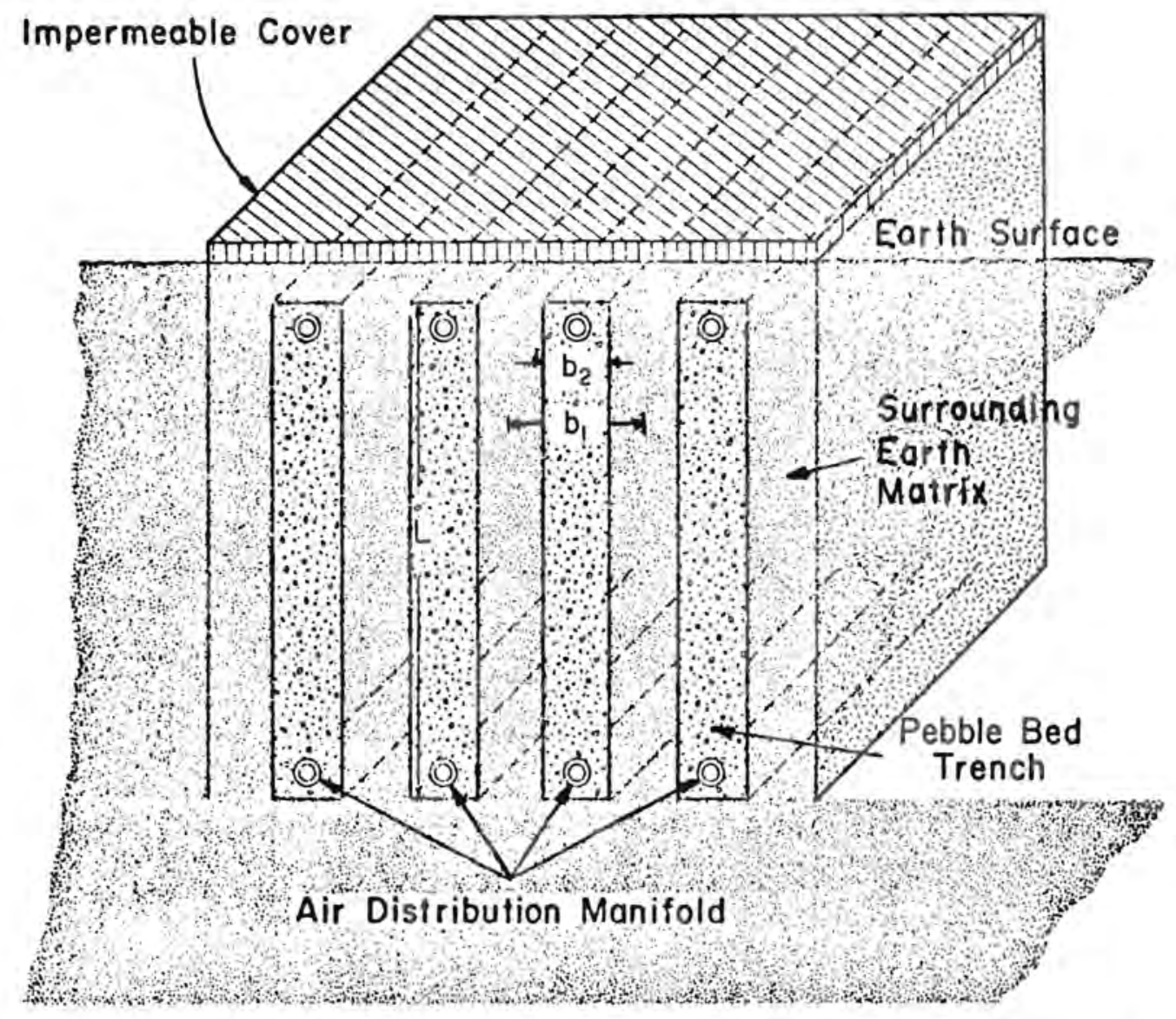

FIGURE A.14. Generic Configuration of Pebble Bed Heat Accumulator (40a; Riaz, Blackshear and Pfannkuch, p. 125) 
SOIL SURFACE

$\downarrow$

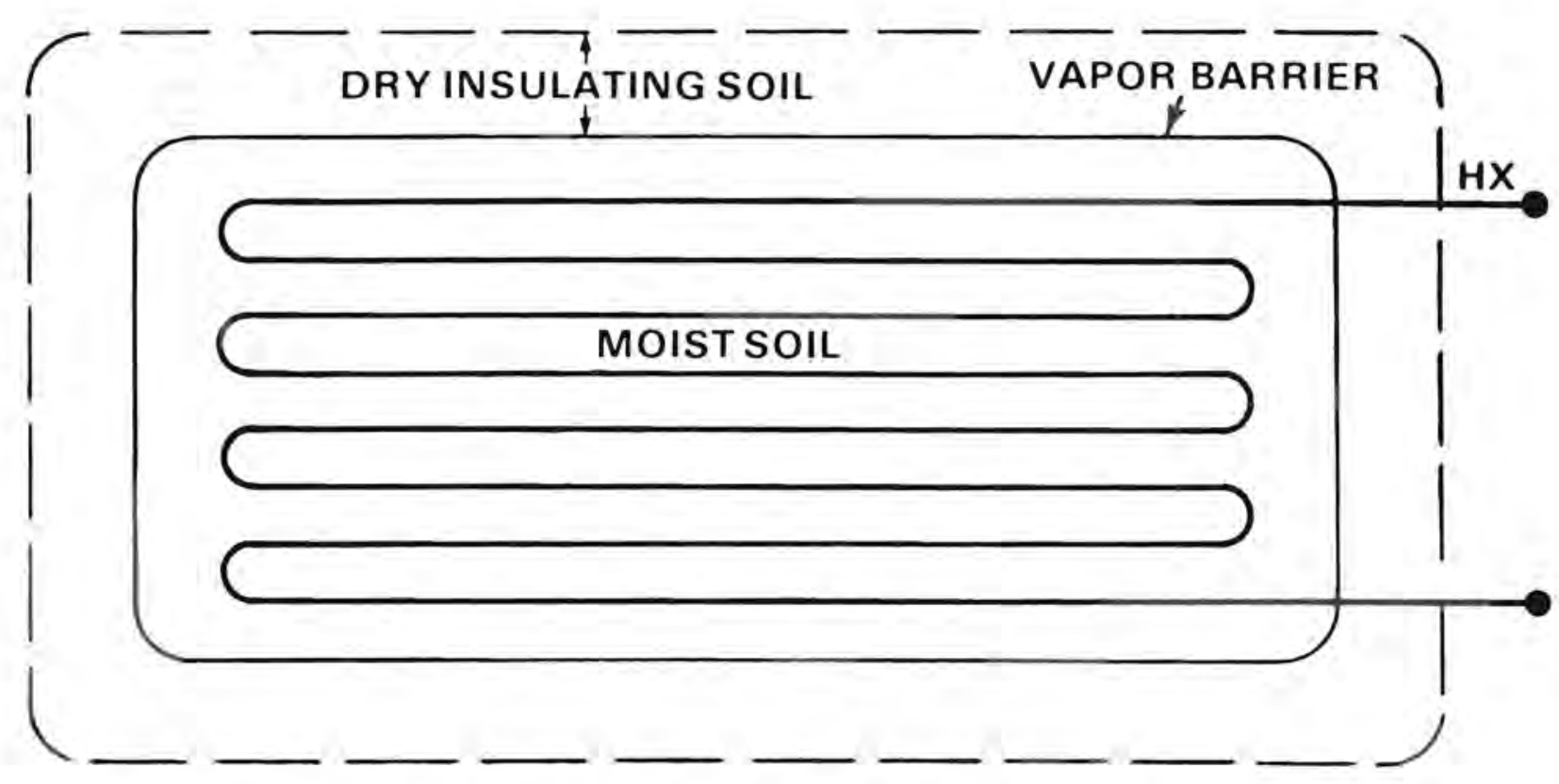

FIGURE A.15. Basic Concept for Low Cost Underground Storage of Heat (56a: Kemper, Walker and Sabey 1979, p. 156) 


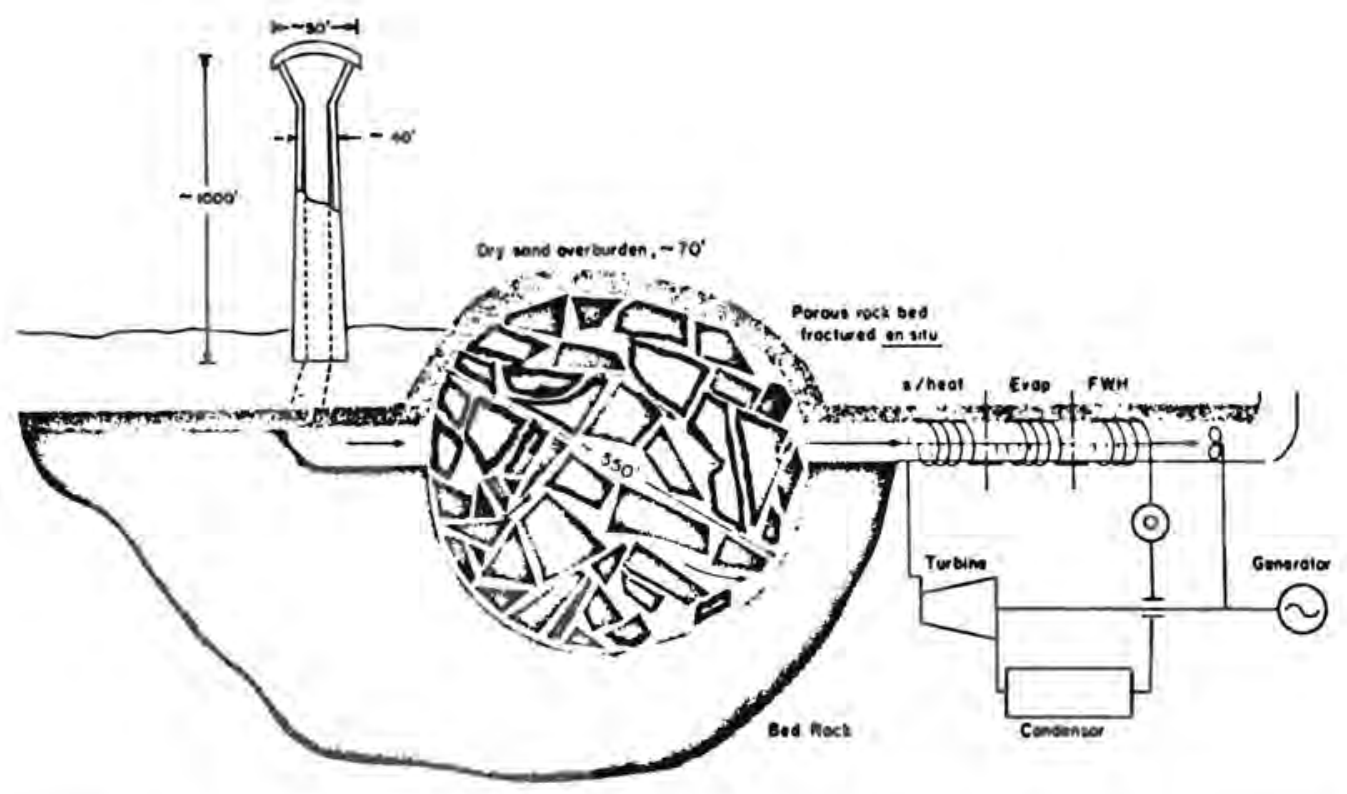

FIGURE A.16. A Solar-Excited Earth Heat Accumulator for Electric Power Generation (40a; Riaz, Blackshear and Pfannkuch, p. 124) 


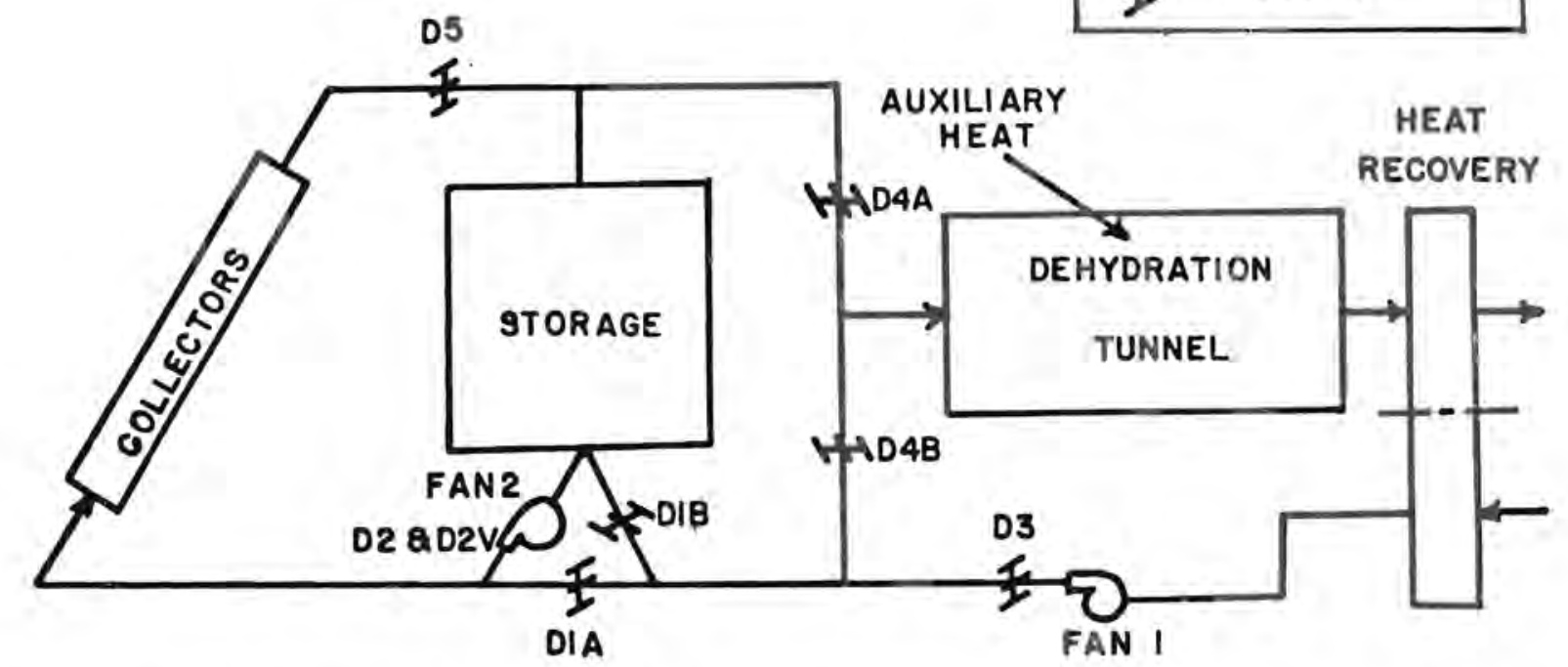

FIGURE A.17. Dehydration System Schematic (56a; Stine and Carnegie 1979 , p. 322)

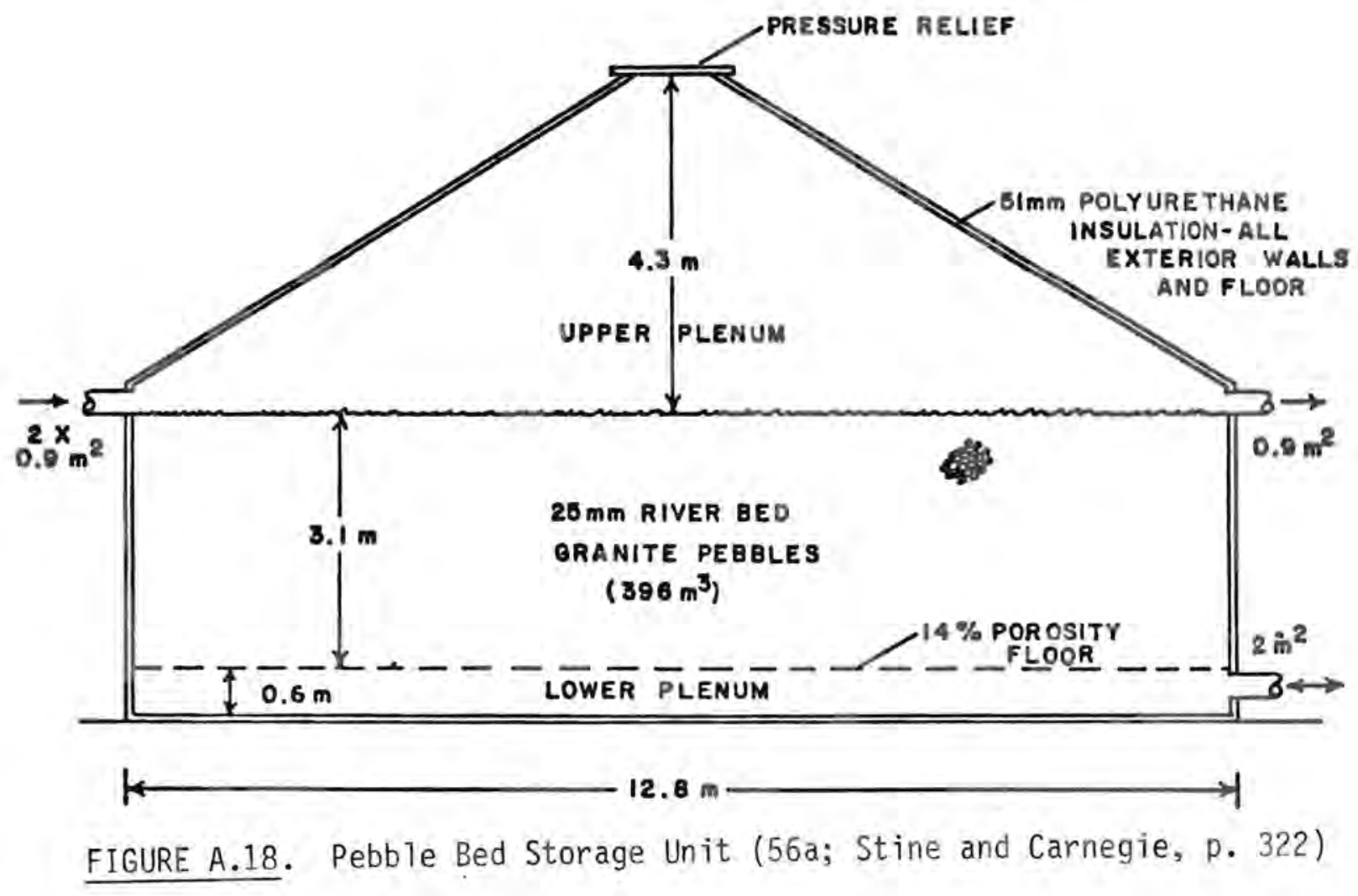



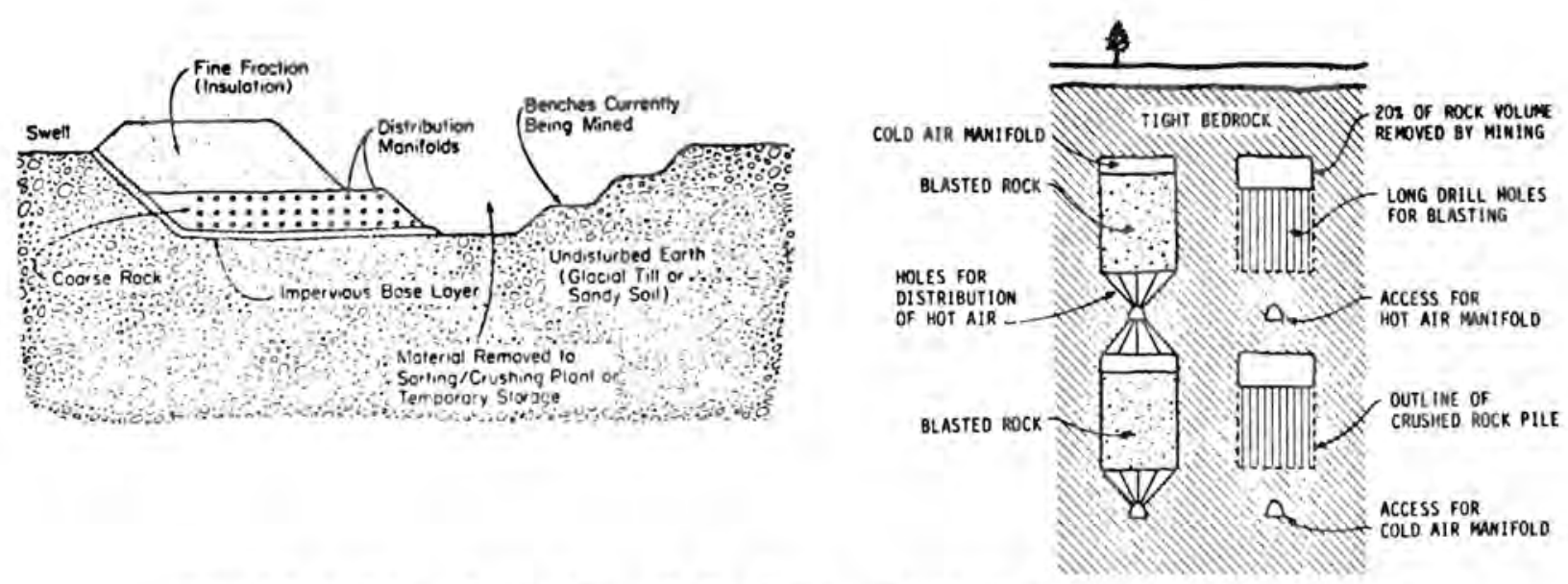

FIGURE A.19. Examples of Surface and Underground Rockbed TES (3; Riaz 1977, p. 265)
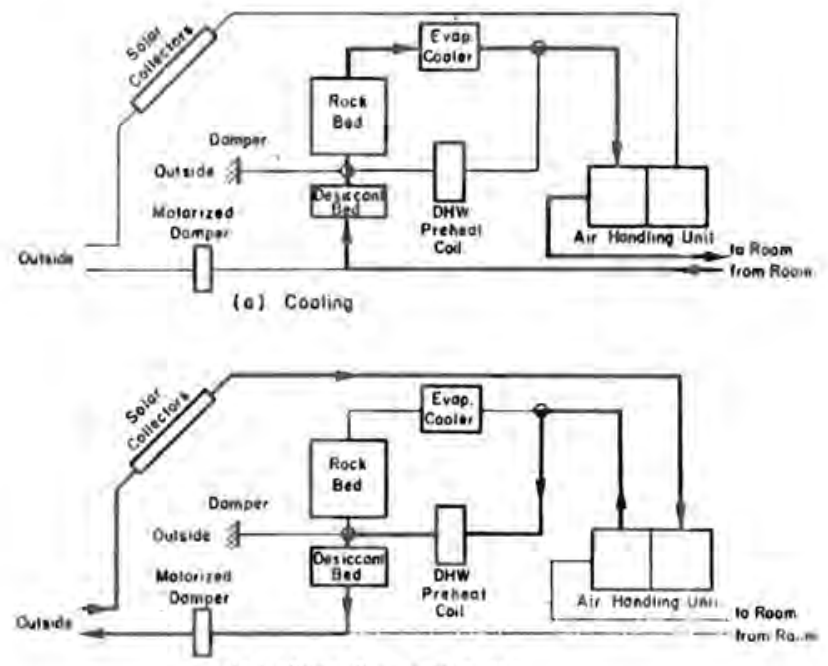

(b) Solor Regenaration of Dosicconi Beda

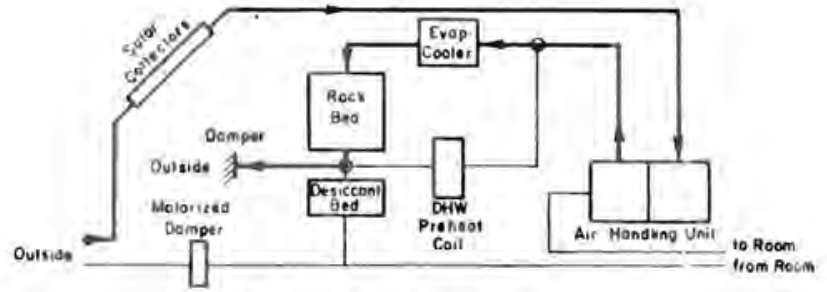

(c) Rock Bed Regenaration

FIGURE A.20. D. RBM Modes of Operation (32a; Meredith and Wilbur 1979, p. 274) 


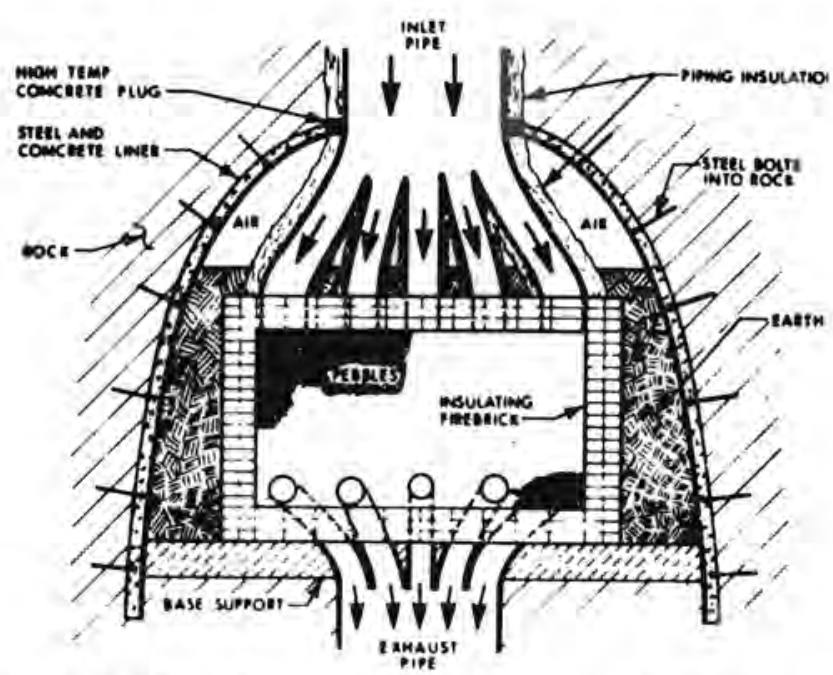

FIGURE A.21. Conceptual Design of Packed Bed (2; Hamilton 1978, p. 271)

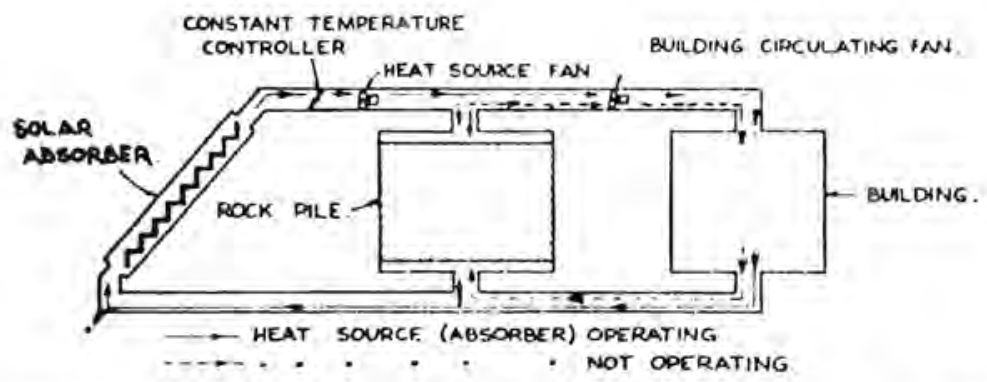

FIGURE A.22, Diagram Shoring the Operation of an Intermittent Heat Source with a Rock Pile Thermal Storage (104u; Close 1964, p. 12) 


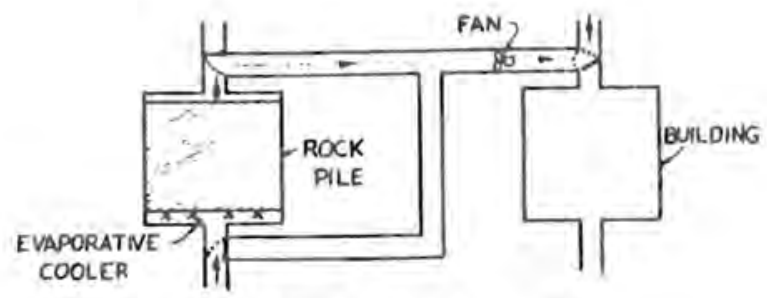

(a) NIGHT CHARGING OF PILE

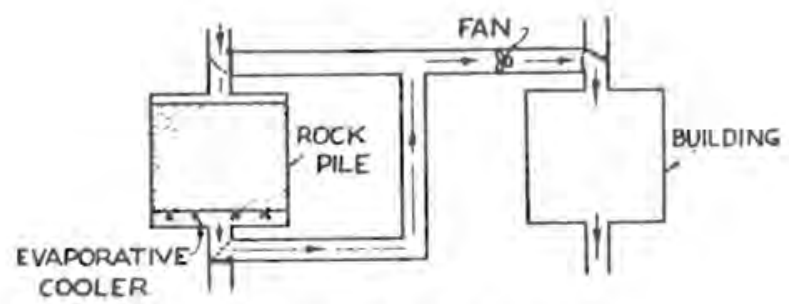

(b) DAY COOLING OF BUILDING

FIGURE A.23. Diagram Showing the Operation of a Rock Pile Thermal Storage as a

Source of Cooling Air Conditioning

(104u; Close 1974, p. 12)

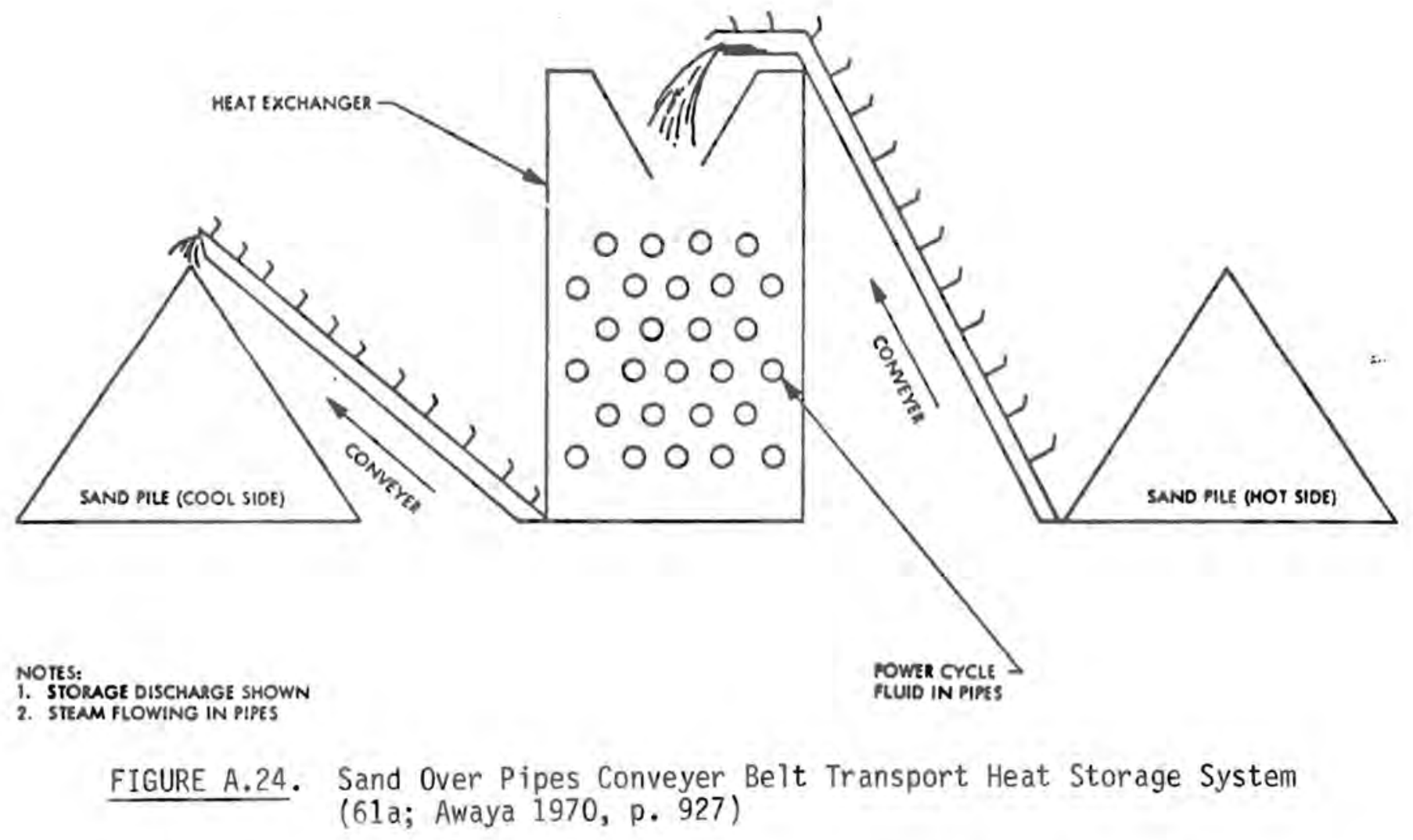



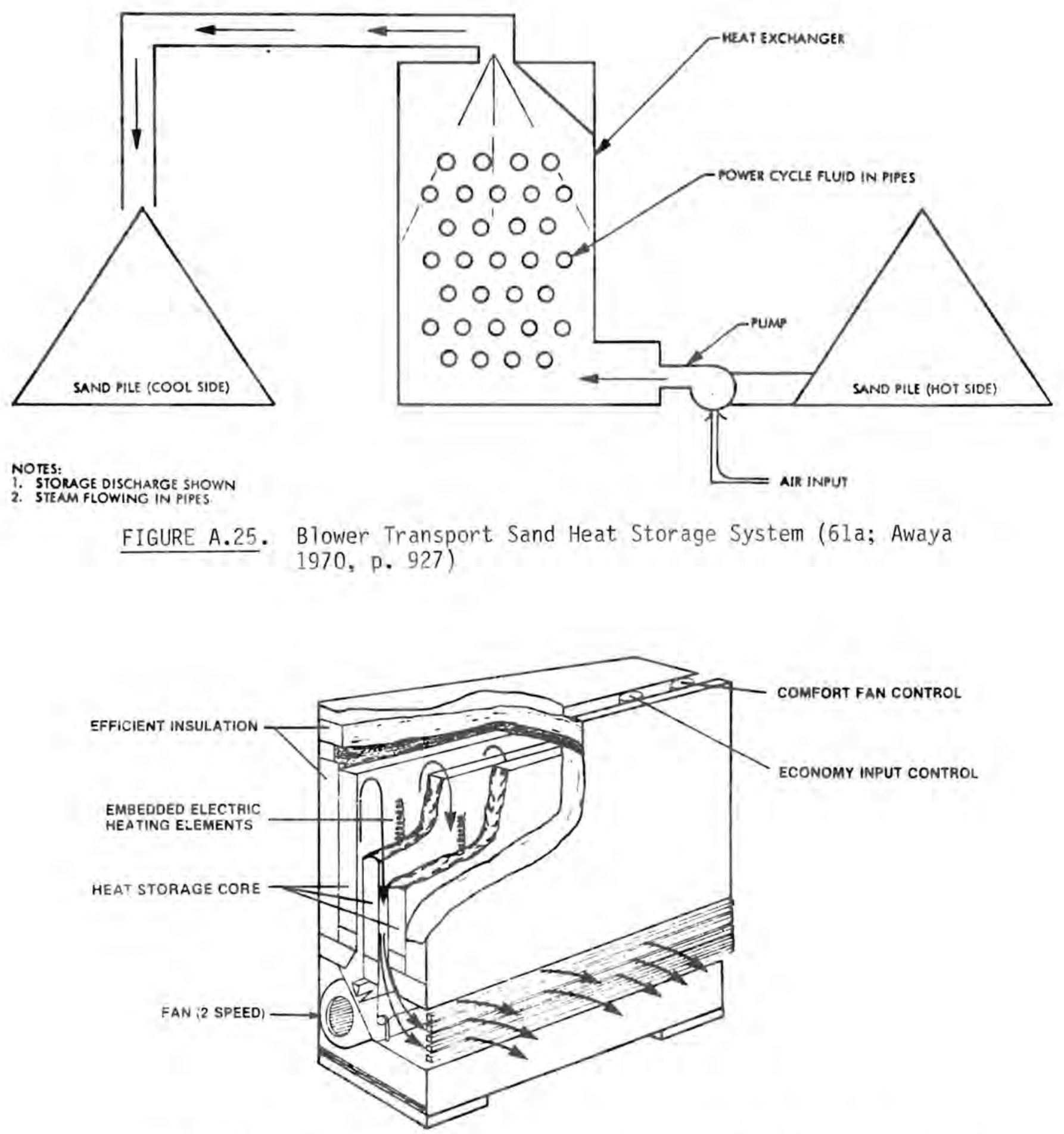

FIGURE A.26. Commercially Available, Eruopean Design for an Electric Space Heater with Thermal Storage (1; TRW 1979, p. 6) 


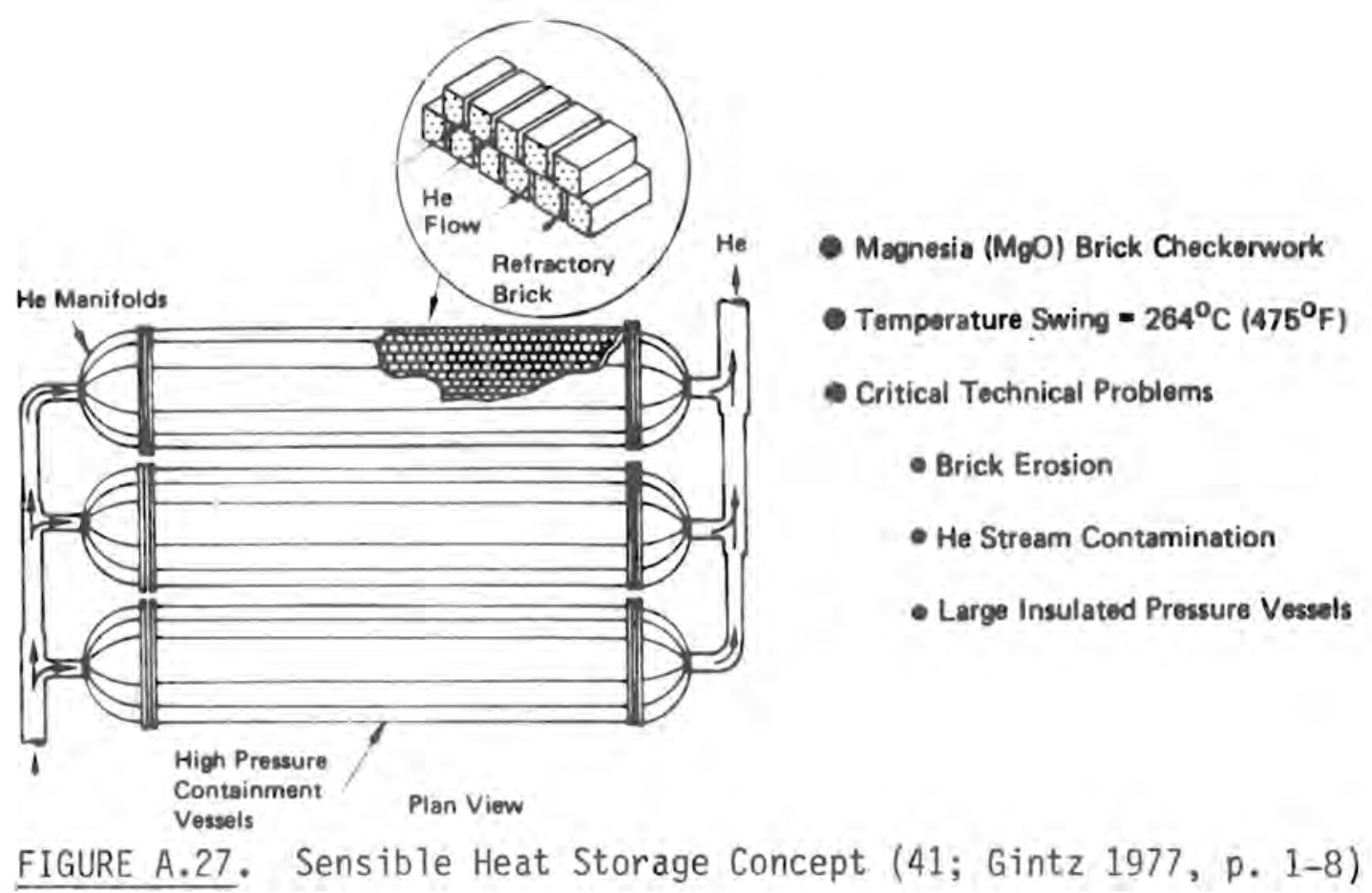




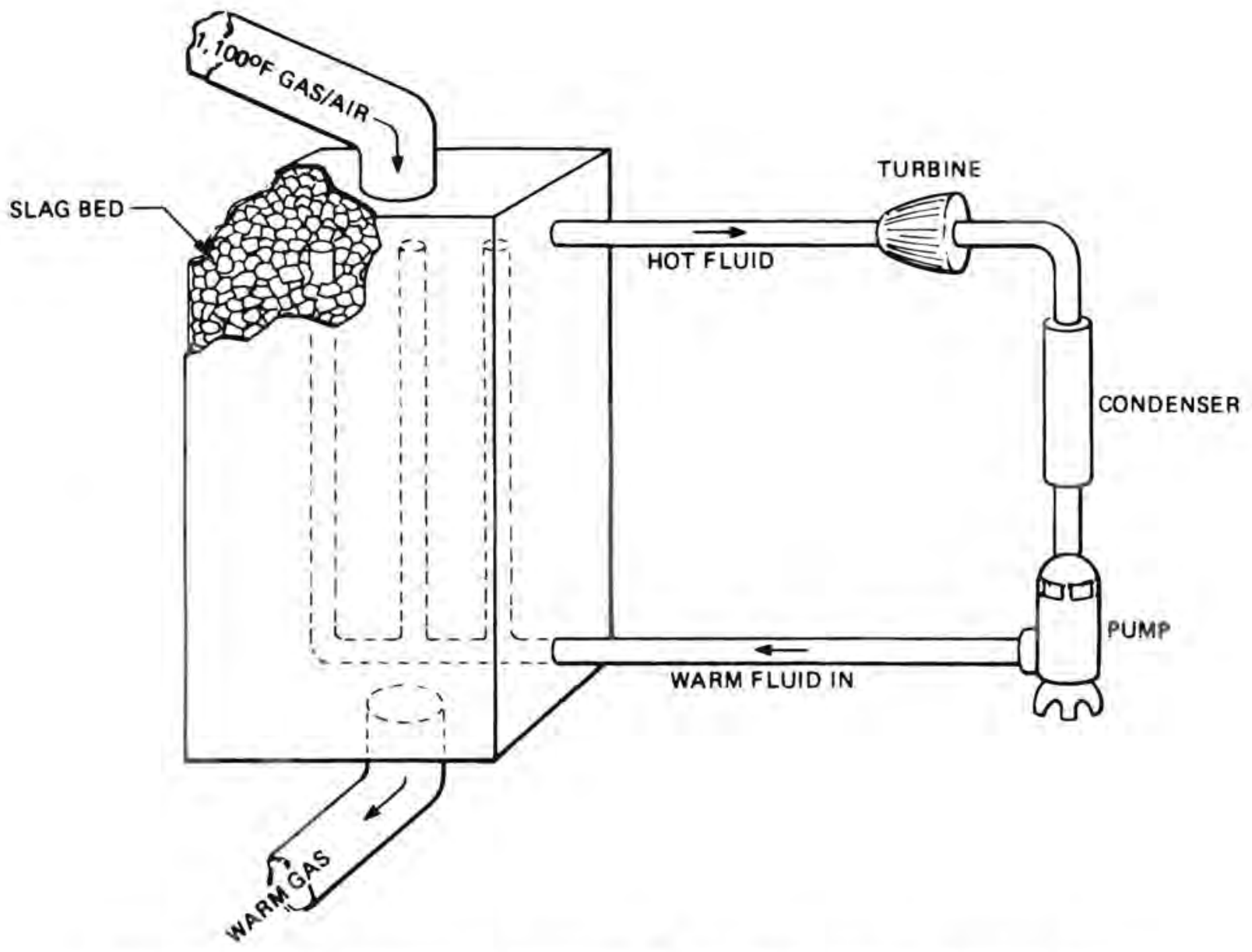

FIGURE A.28. Schematic Diagram of Thermal Energy Storage System (3; Katter 1977, p. 241) 


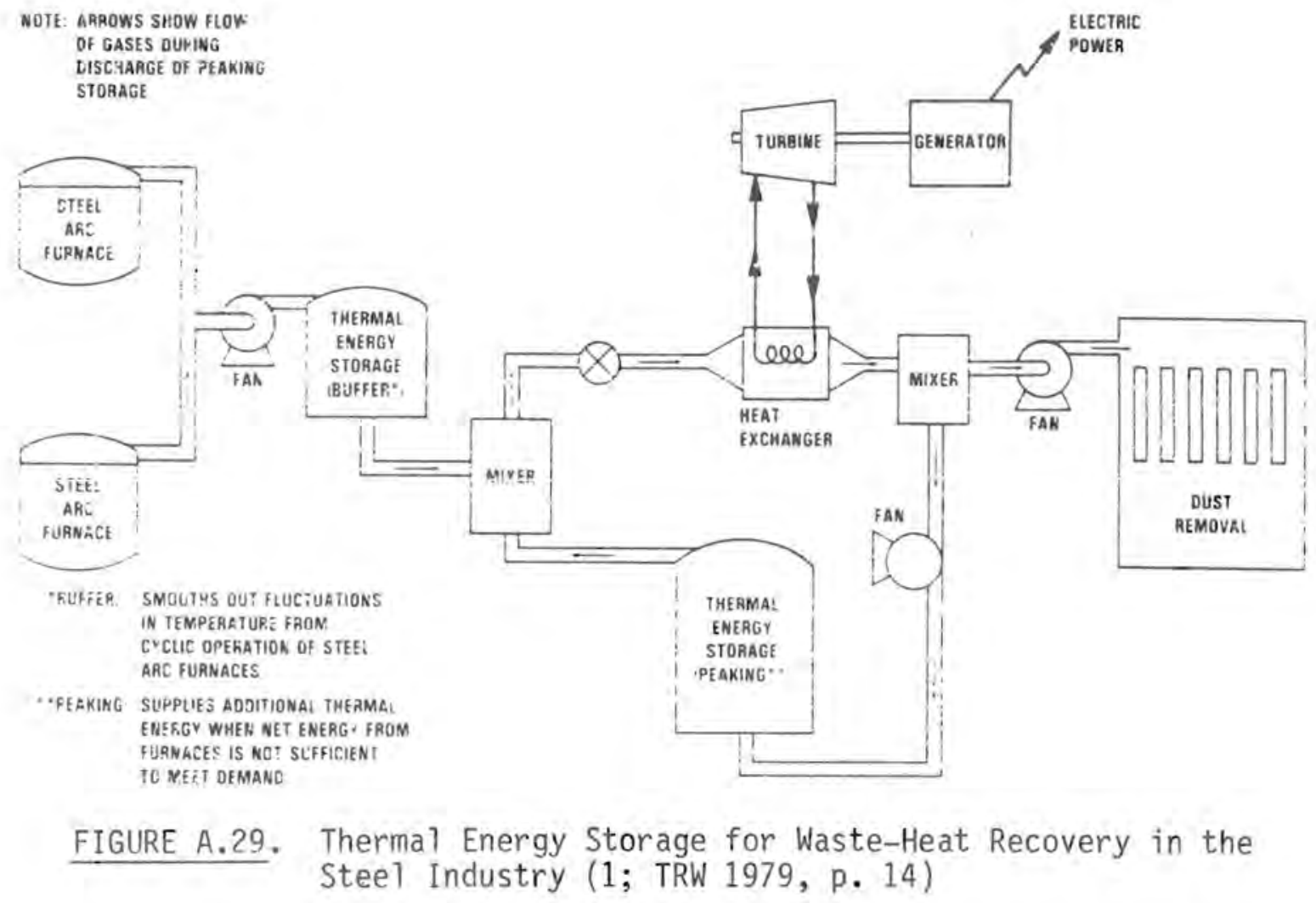




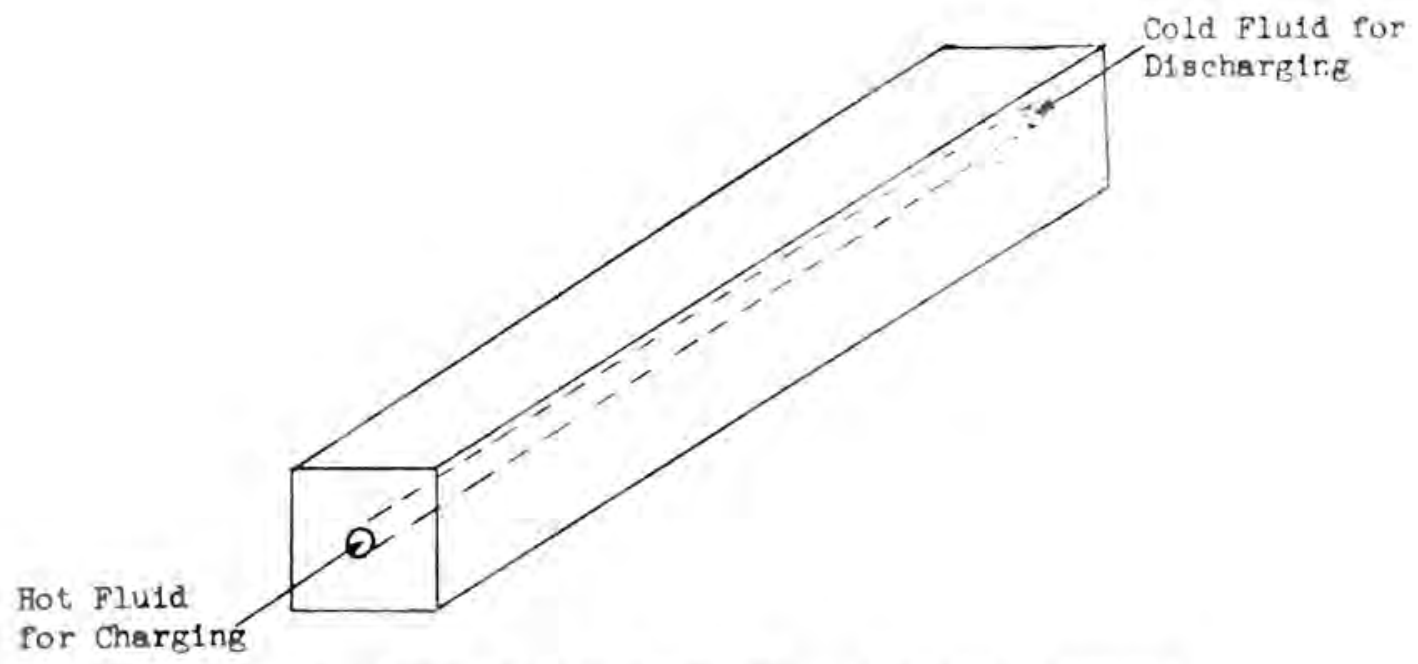

A) Hollow Steel Ingot TSU, Original Concept

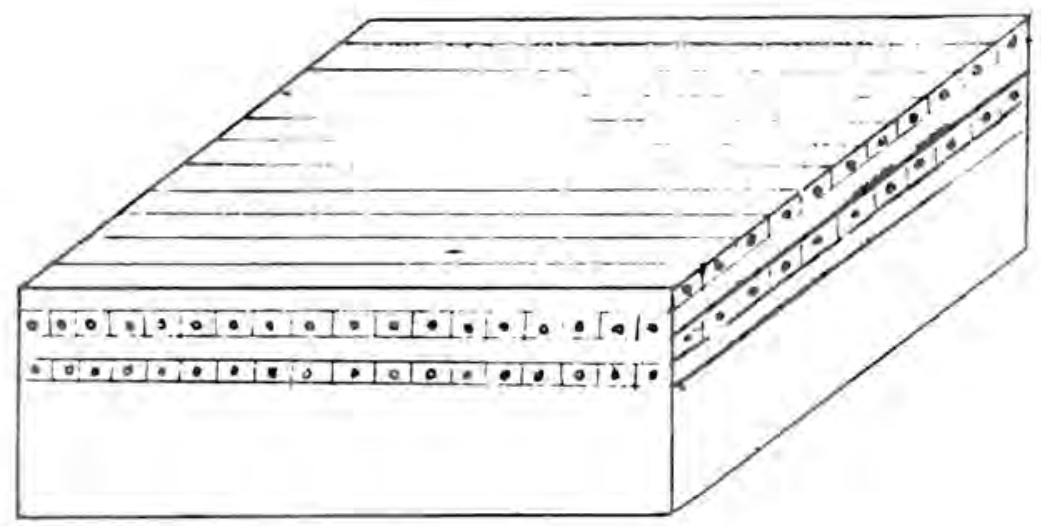

NOTES:

* Header system not shown

* Blanket insulation exterior, not shown

* Ingots cross-stacke for stability

b) Many Ingots Stacked to Form a TSU

FIGURE A.30. Hollow Steel Ingot Thermal Storage Units (3; Turner 1977 , p. 223) 


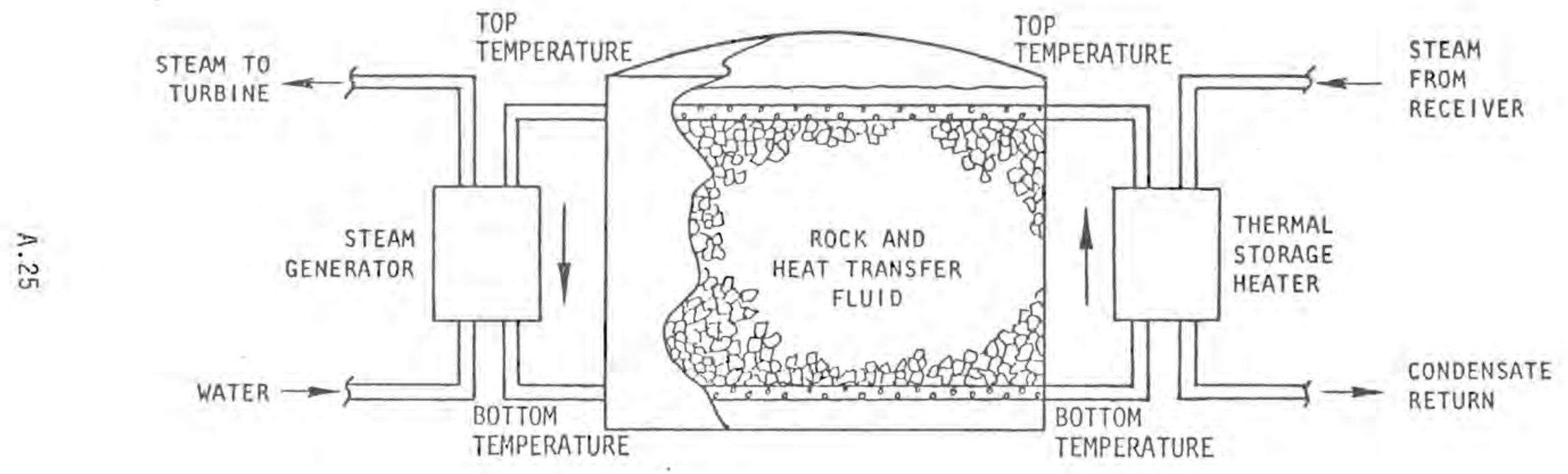

FIGURE A.31, Dual-Medium Thermal Storage Concept (39; Hausz, Berkowits and Hare $1978, \mathrm{p}, 3-32)$ 


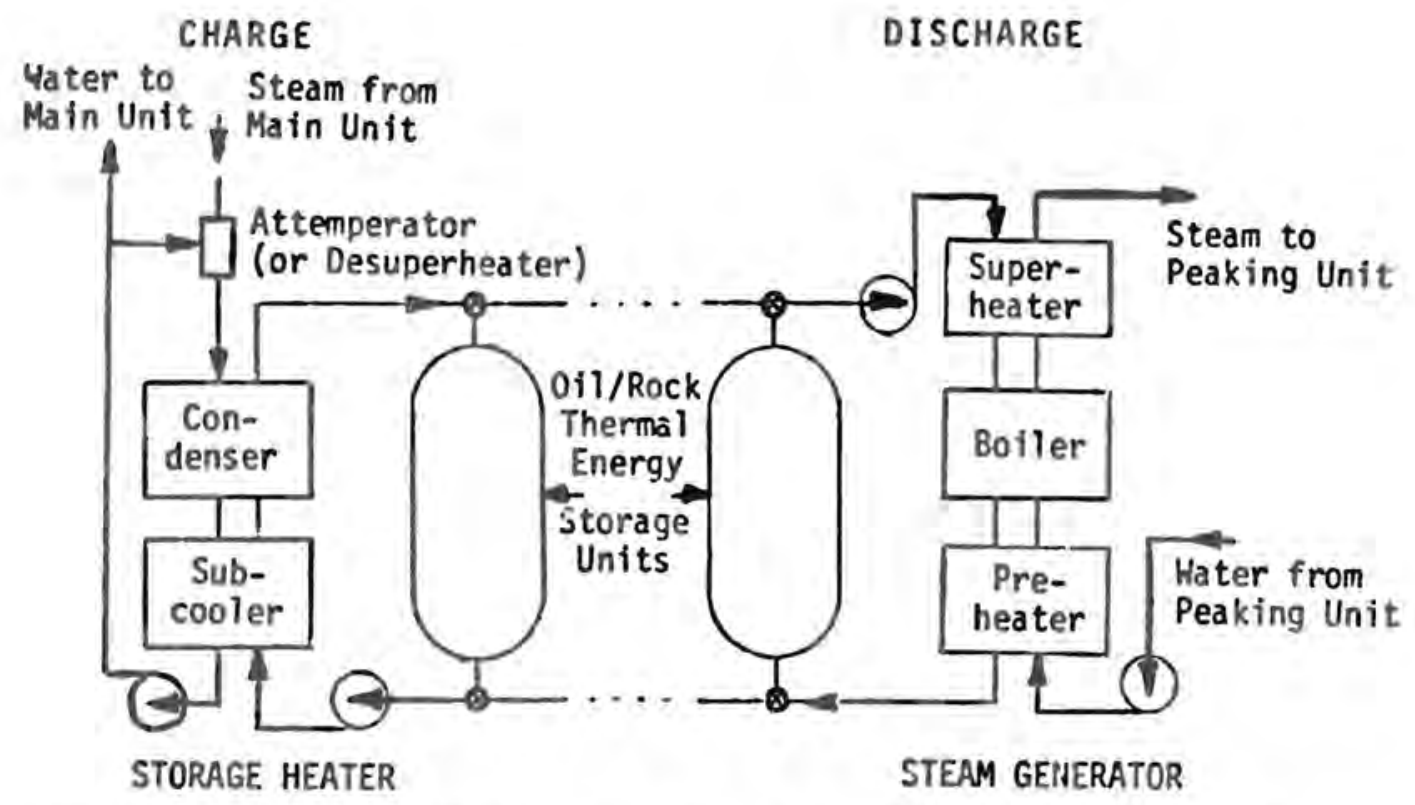

FIGURE A.32. Heat Exchangers for a Sensible Heat Storage System (39; Hausz, Berkowitz and Hare 1978, p. 2-15)

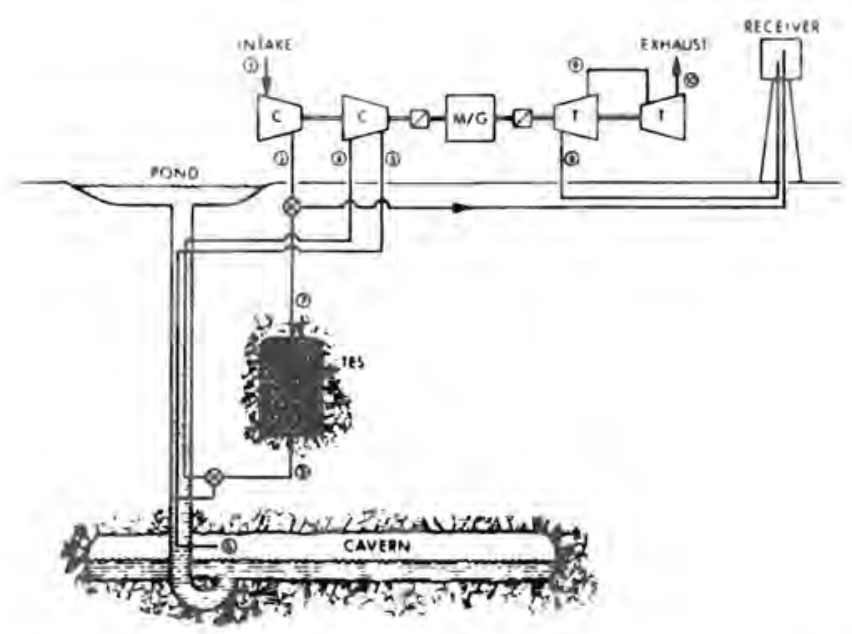

FIGURE A.33. Combine Solar-Thermal and Compressed Air Storage System (2; Hamilton 1978, p. 269) 


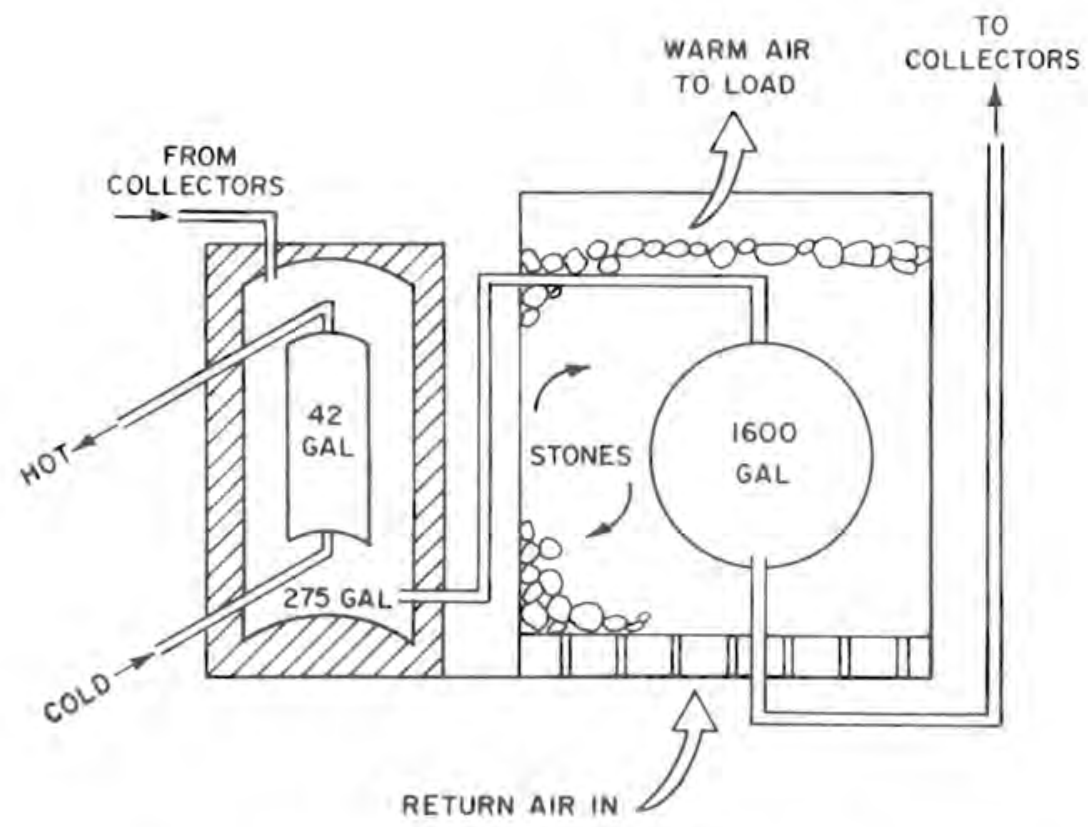

FIGURE A.34. Hybrid Air and Water Storage

(6; Dean 1978, p. 30)

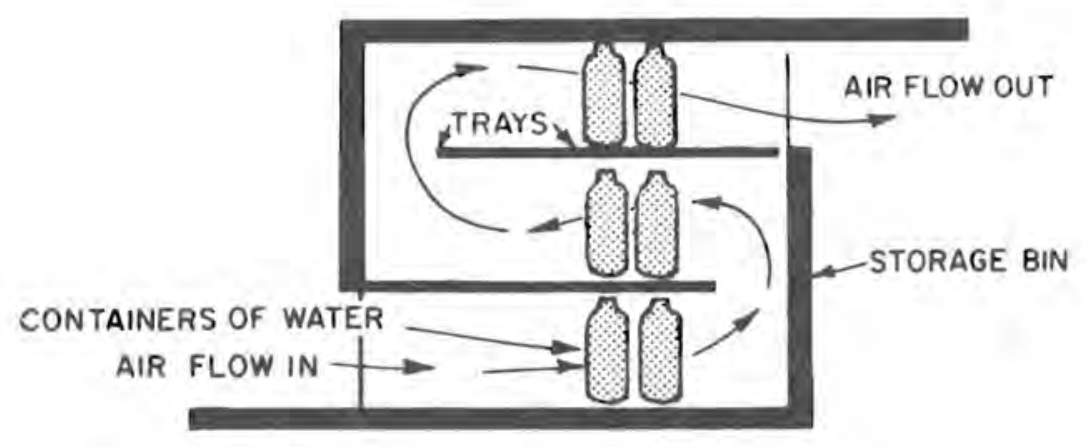

FIGURE A.35. Water-Filled Containers on Racks Used with Air Systems (6; Dean 1978, p. 31) 


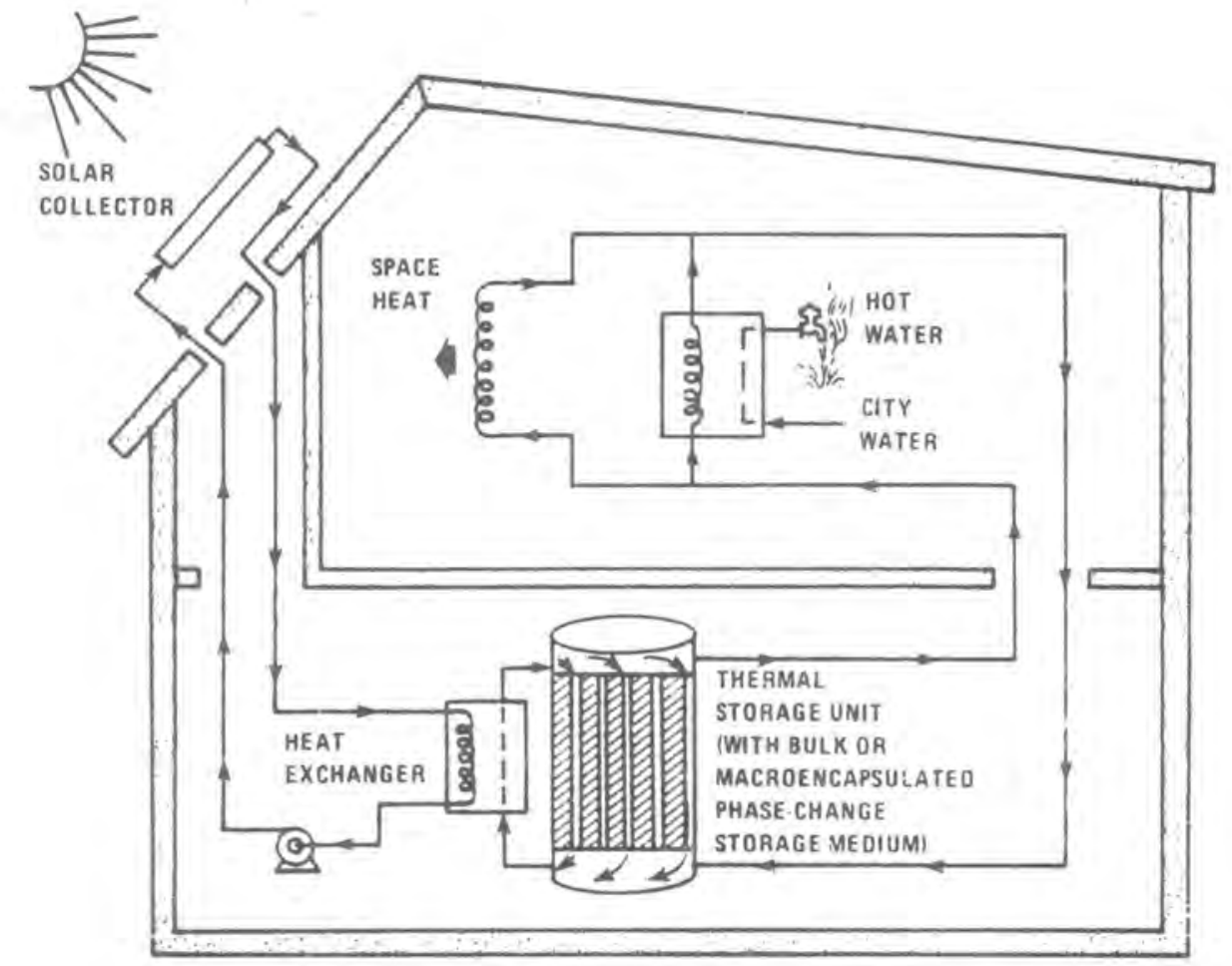

FIGURE A.36. Latent-Heat Thermal Storage in an Active Solar-Thermal Heating System (1; TRW 1979 , p. 9) 


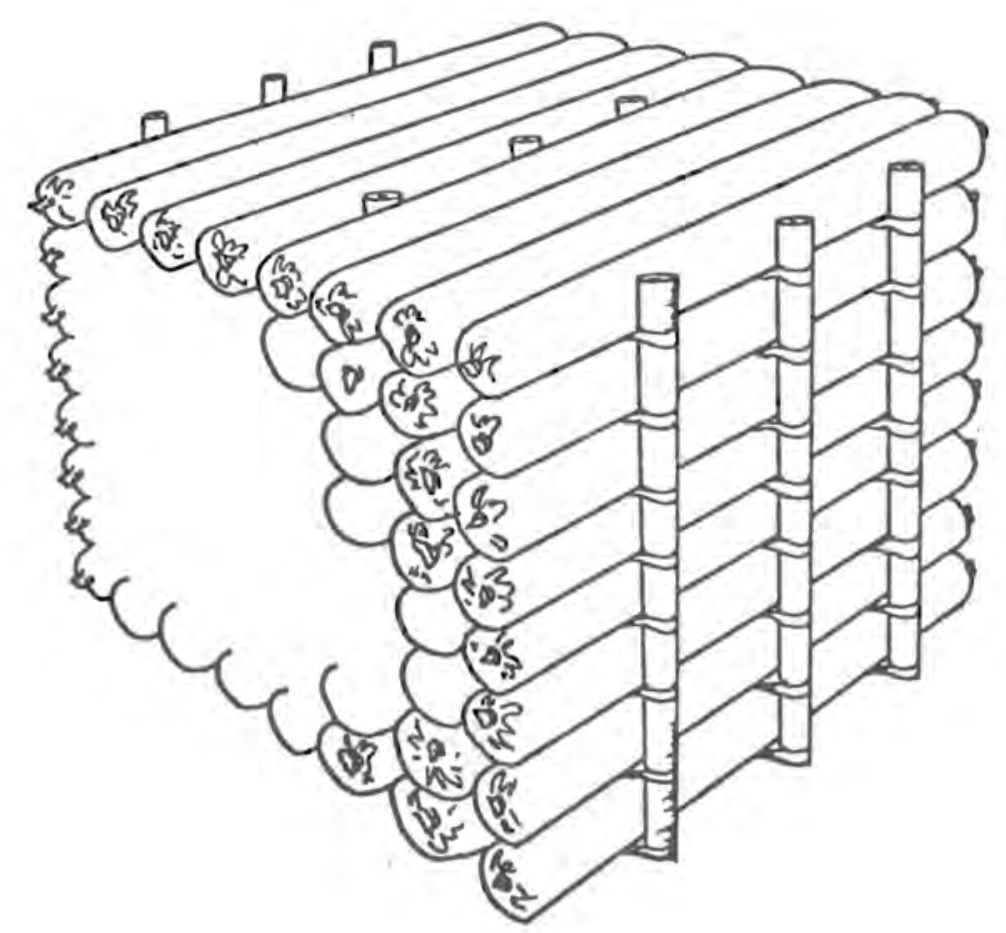

FIGURE A.37. Thermal Energy Storage Module - Chubs (56a; Frysinger 1979 , p. 223) 

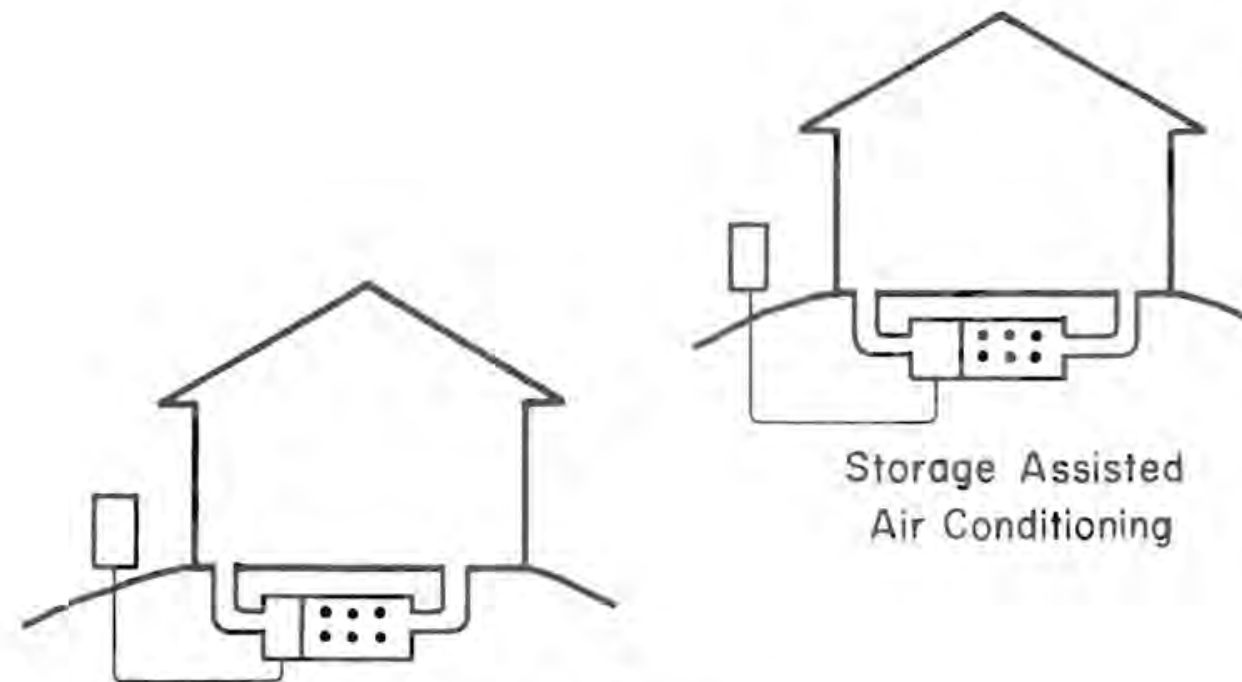

Storage Assisted Air Conditioning

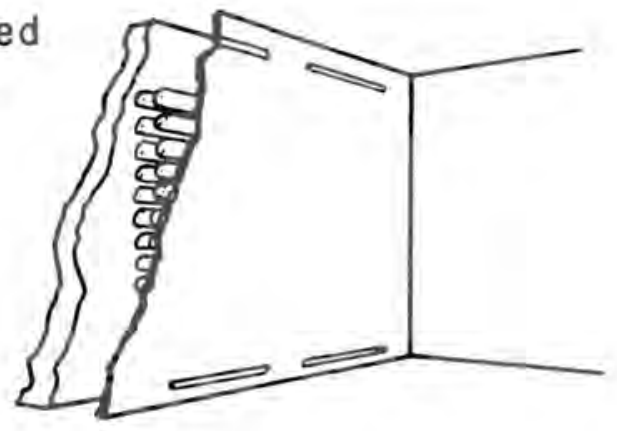

Latent Thermal Mass
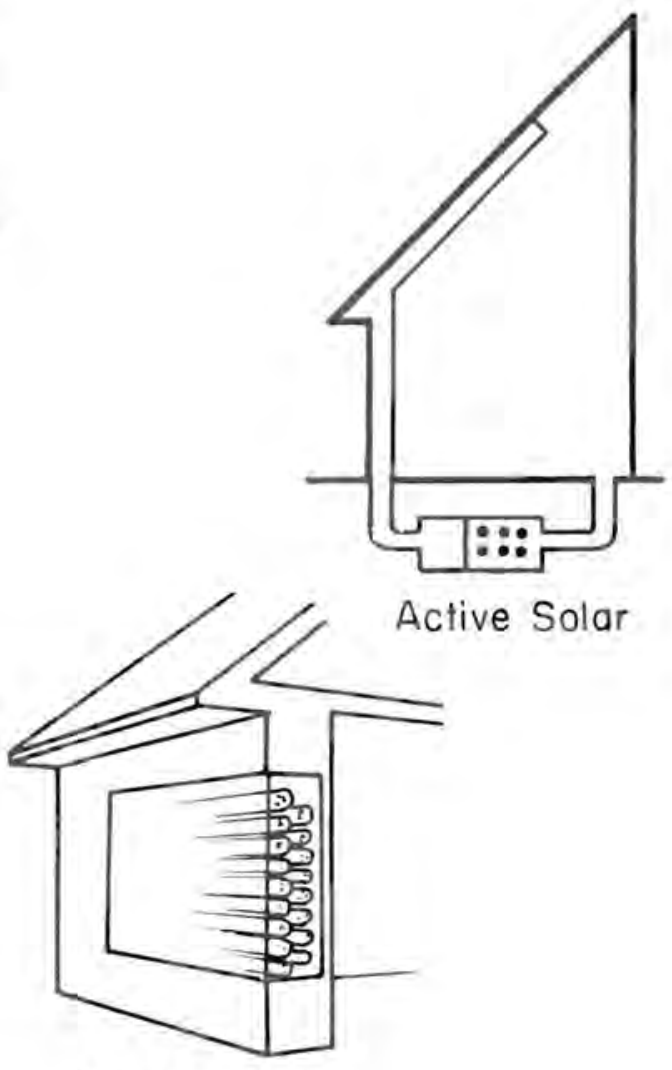

Passive Solar

FIGURE A.38. Chub Applications (2; Frysinger 1978, p. 57) 


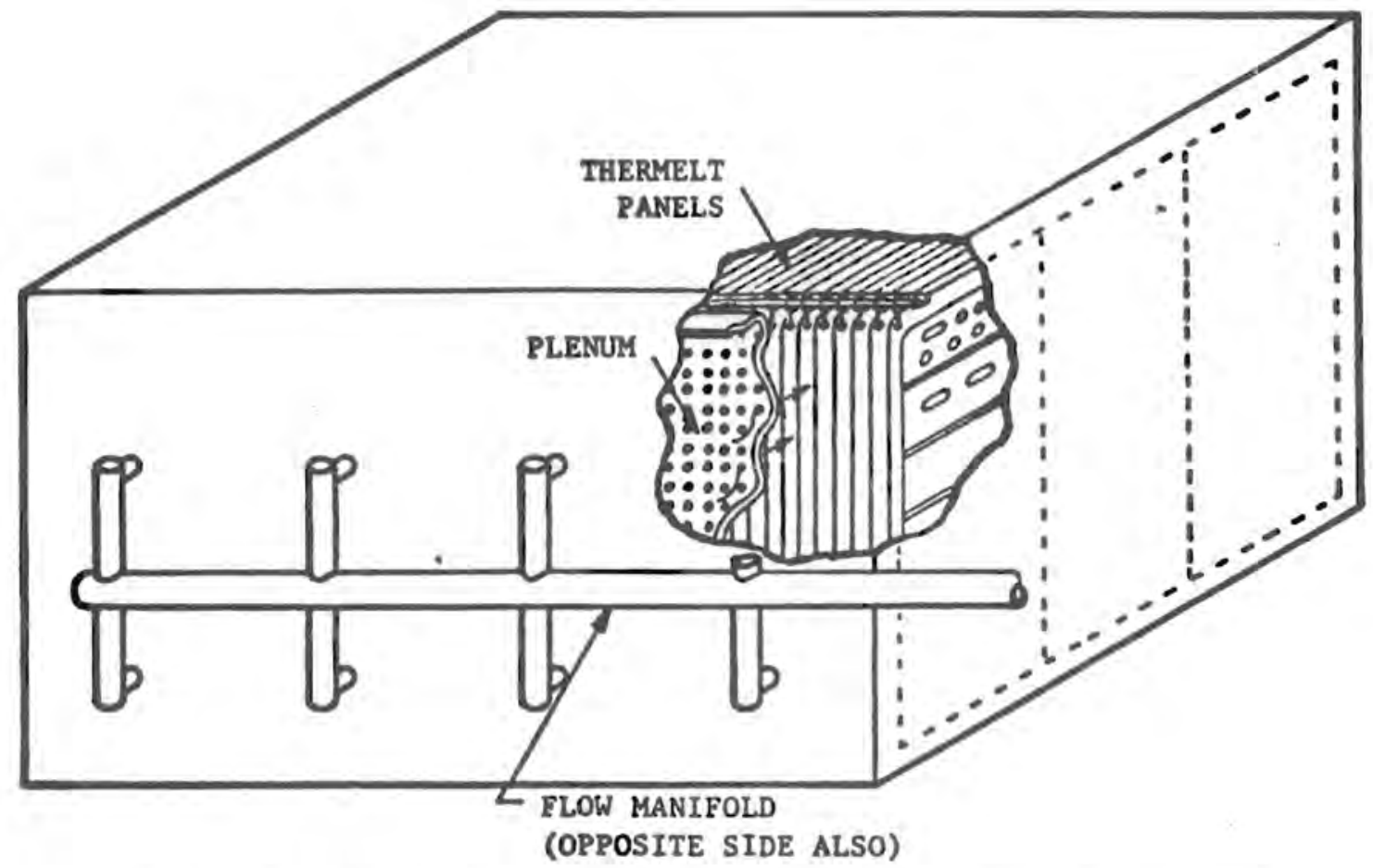

FIGURE A.39. Tank-Type Capacitor (56a; Murray 1979, p. 315) 


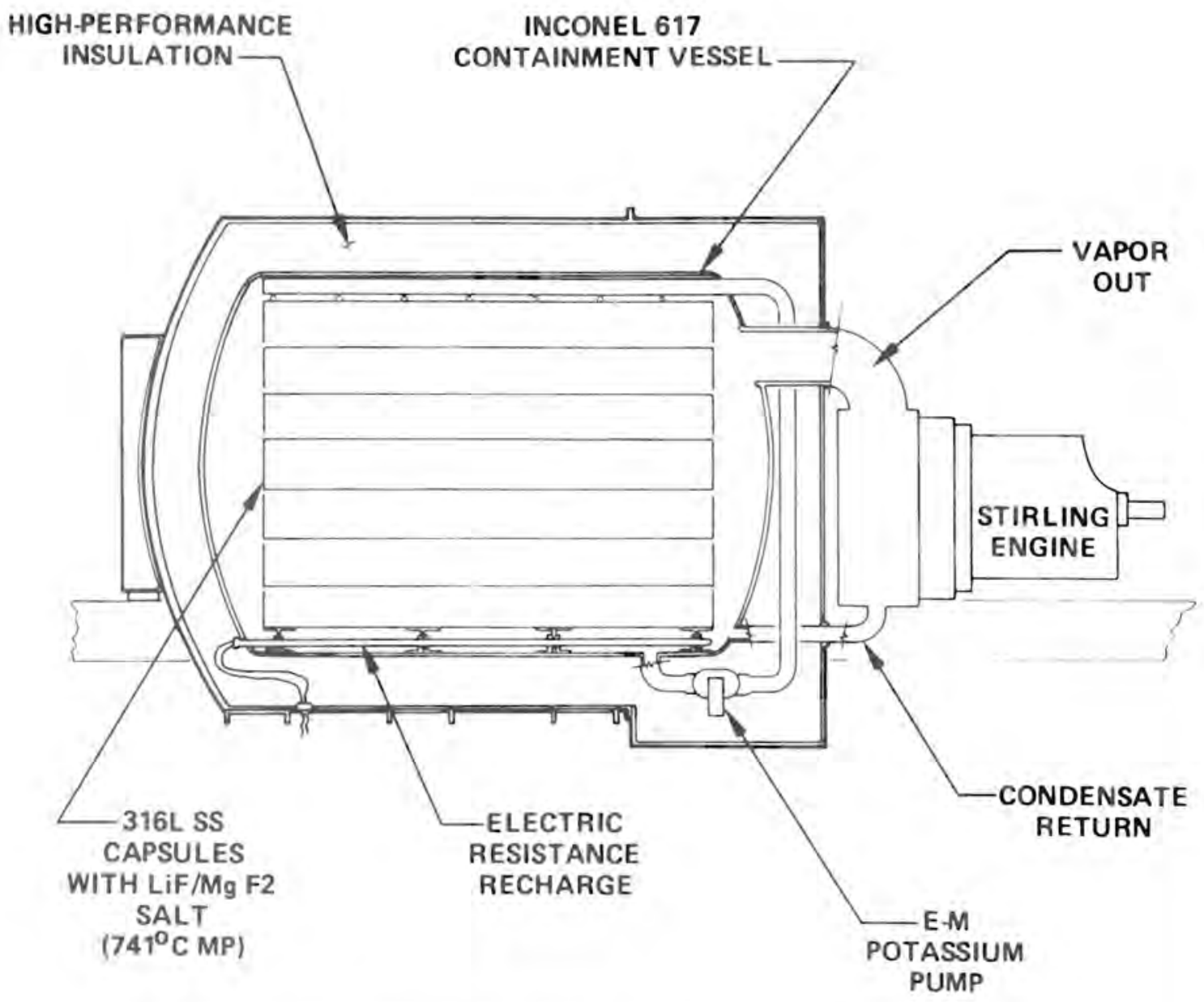

FIGURE A.40. Salt TES WI Sterling Engine (2; Farahat 1978, p. 249) 


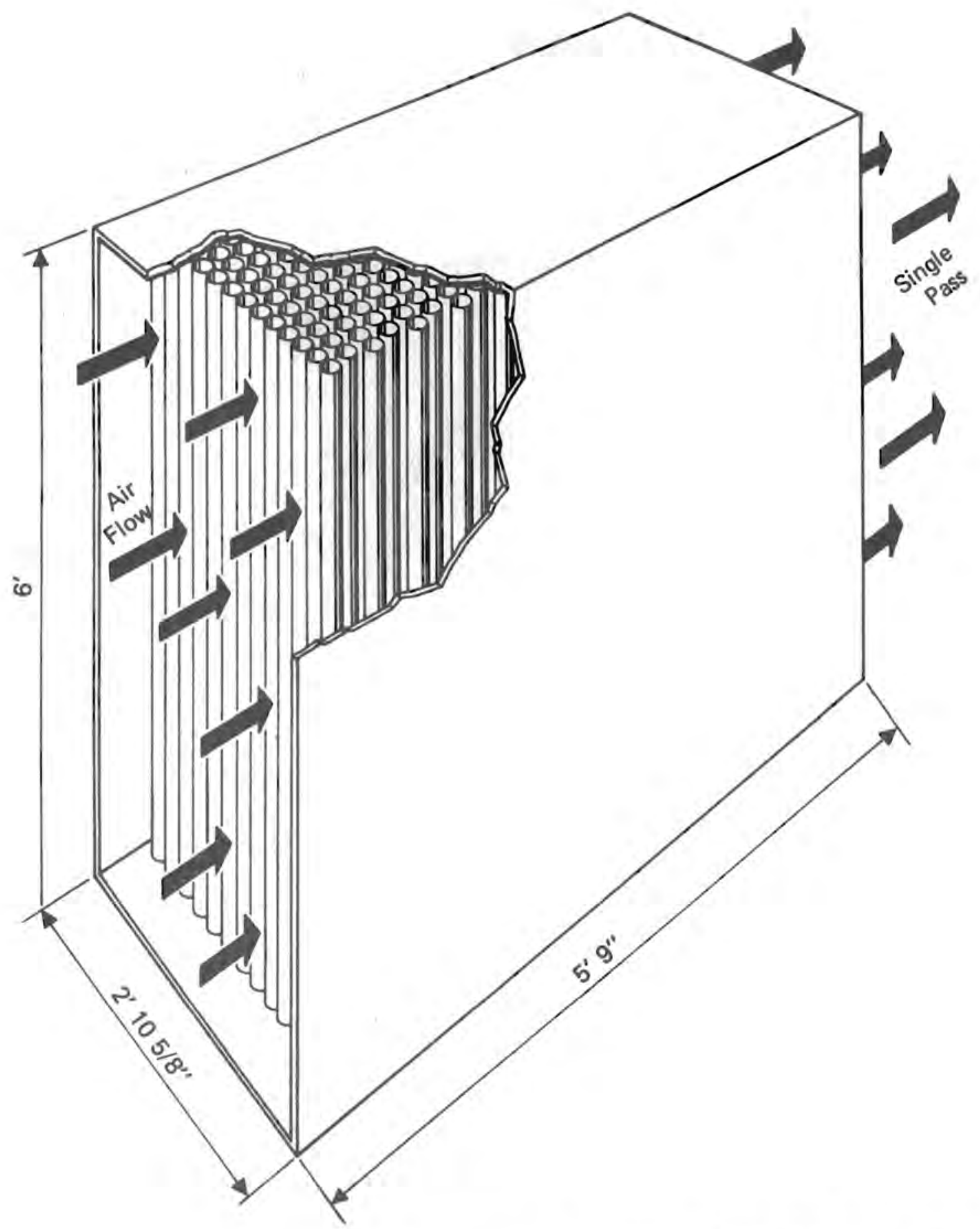

FIGURE A.41. Ful1-Scale Storage Unit Calcium Chloride Hexahydrate
Encapculated in HDPE Cylinders (2; Lane 1978, p. 125) 


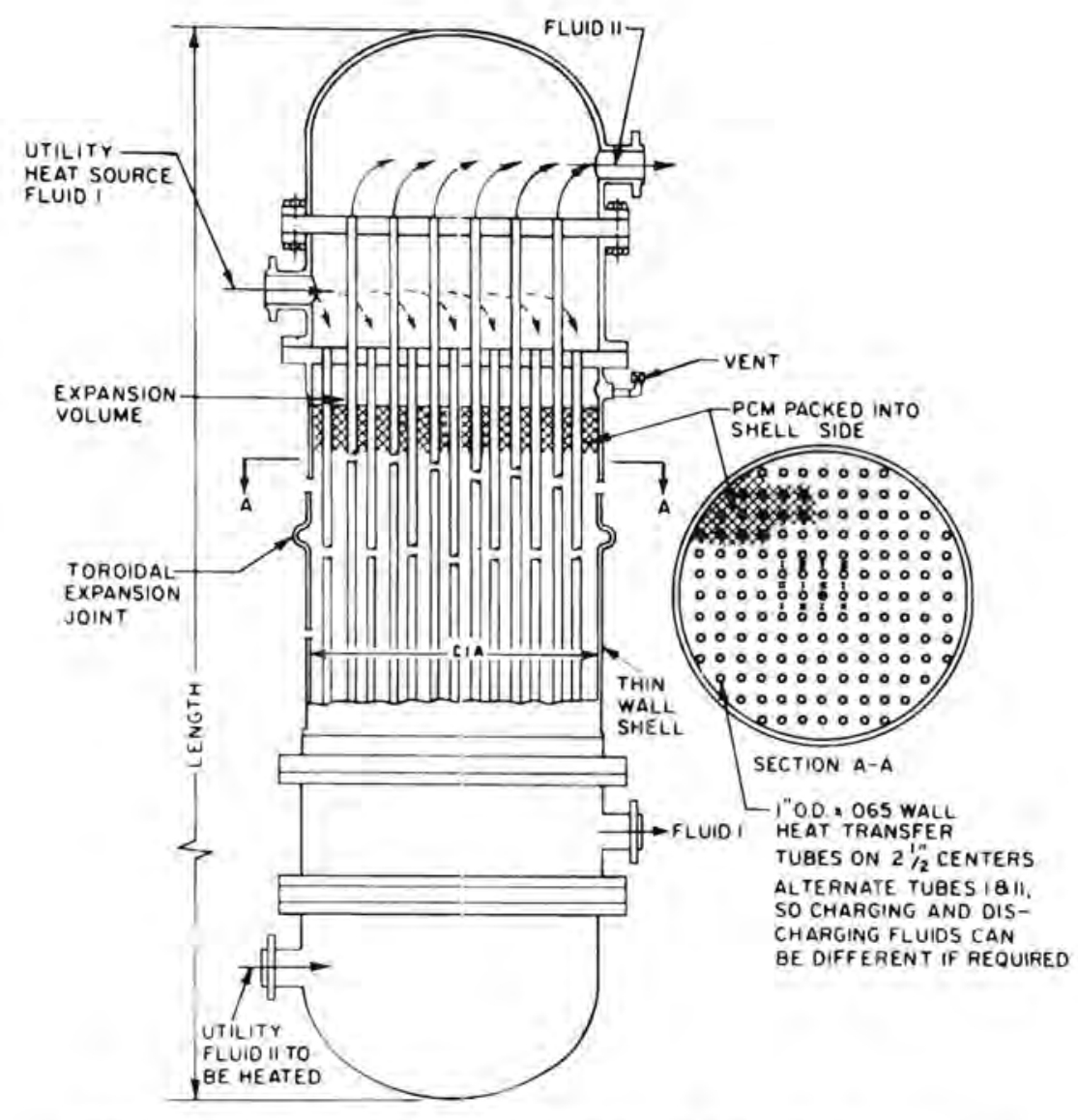

FIGURE A.42. Liquid/PCM/Liquid Heat Exchanger (7; Turner 1978, p. 85) 


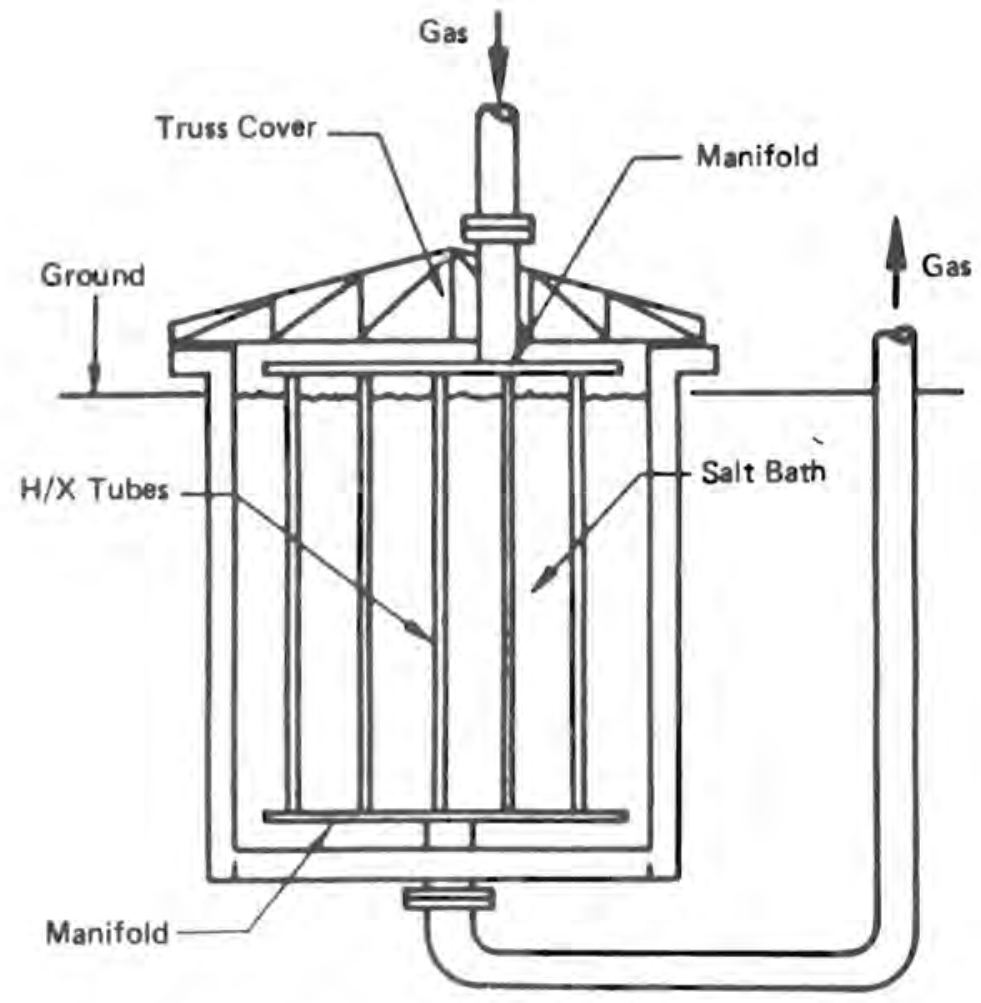

- Fusible fluoride salt bath

- Temperature swing $222^{\circ} \mathrm{C}$

- Critical technical problems material compatibility

FIGURE A.43. Phase Change Storage Concept (41; Gintz 1977, p. 1-11) 


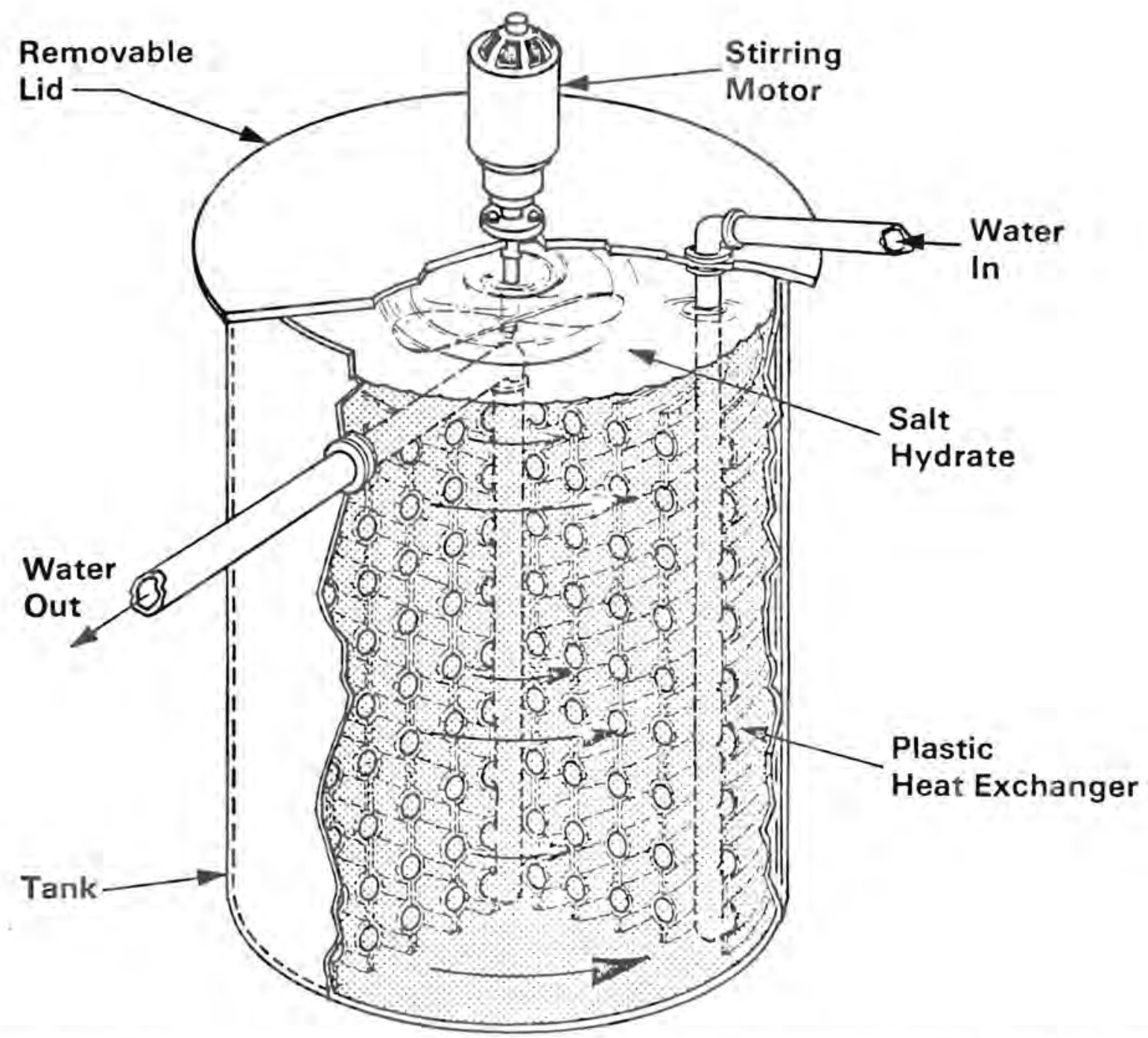

FIGURE A.44. Calmac Corporation-PCM Storage Device (58; Baylin 1979, p. 78) 


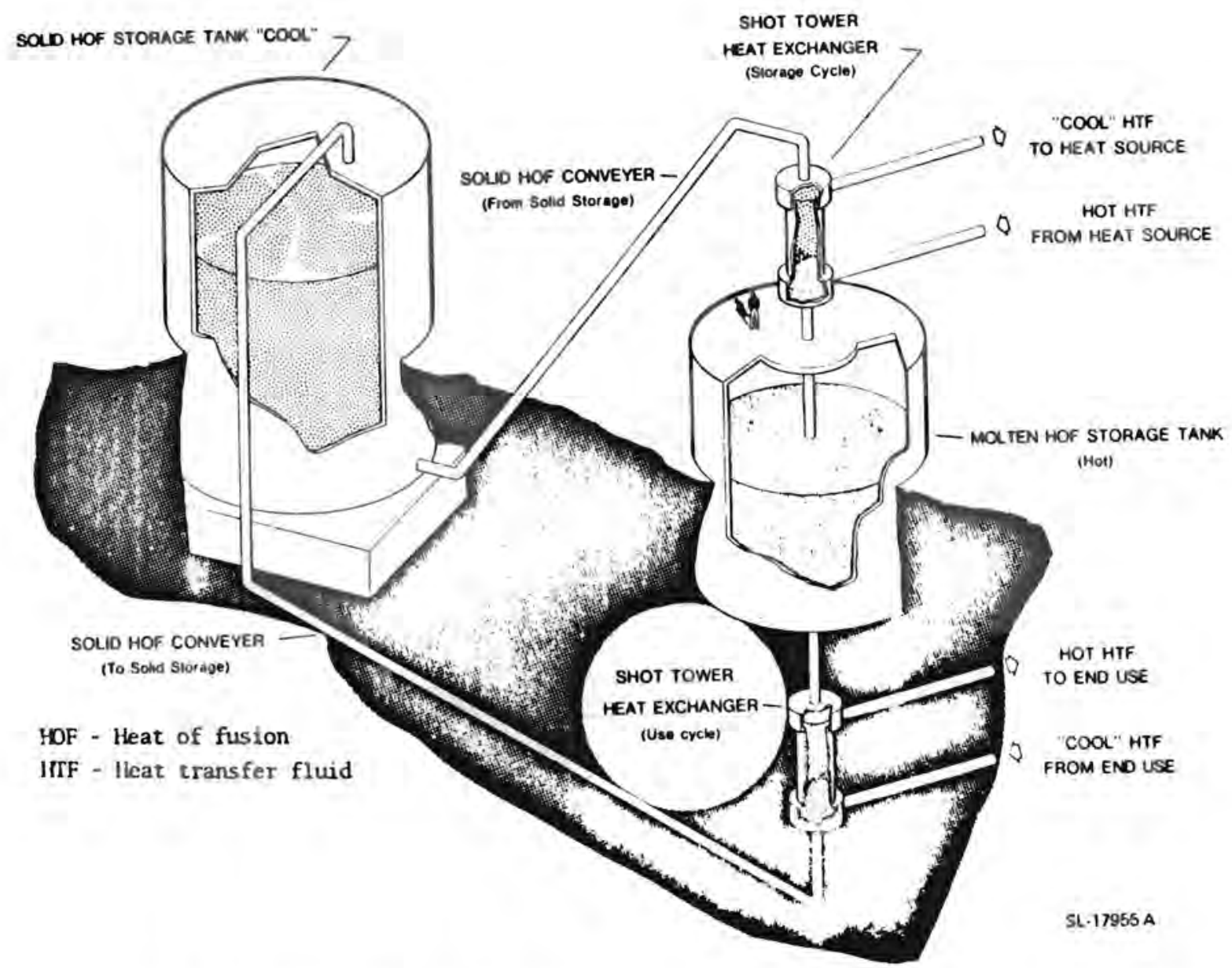

FIGURE A.45. Shot Tower Process (34a; Nichols and Green, p. 3956)

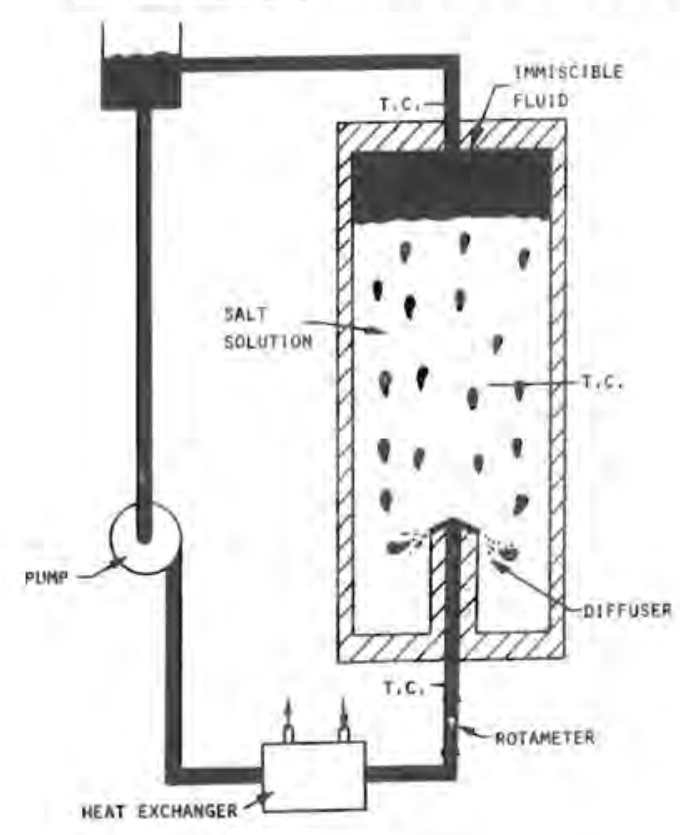

FIGURE A.46. Immiscible Fluid-Heat of Fusion Storage. System (3; Edie 1977, p. 34) 


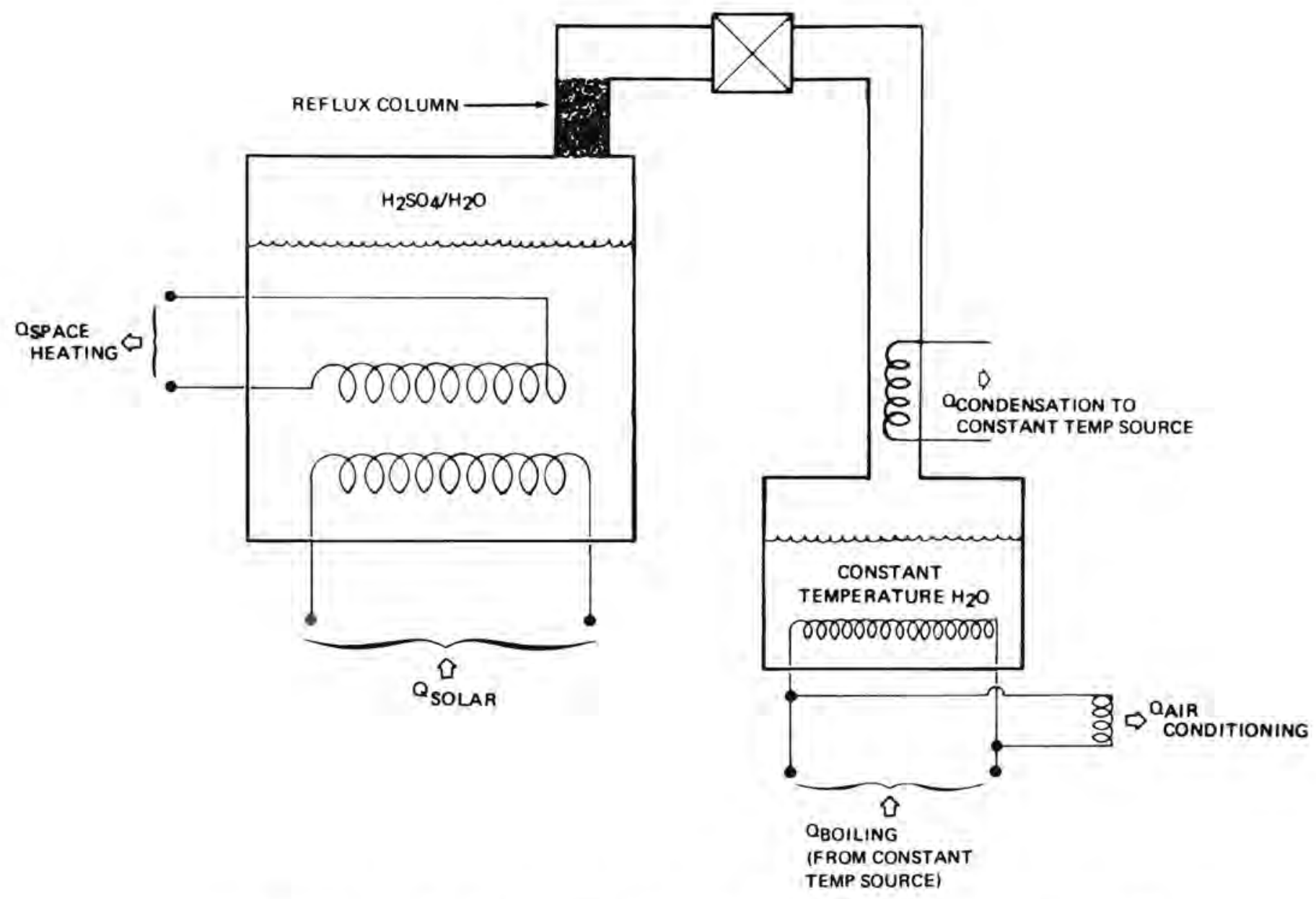

FIGURE A.47. $\mathrm{H}_{2} \mathrm{SO}_{4} / \mathrm{H}_{2} \mathrm{O}$ Chemical Heat Pump (3; Clark 1977, p 350) 


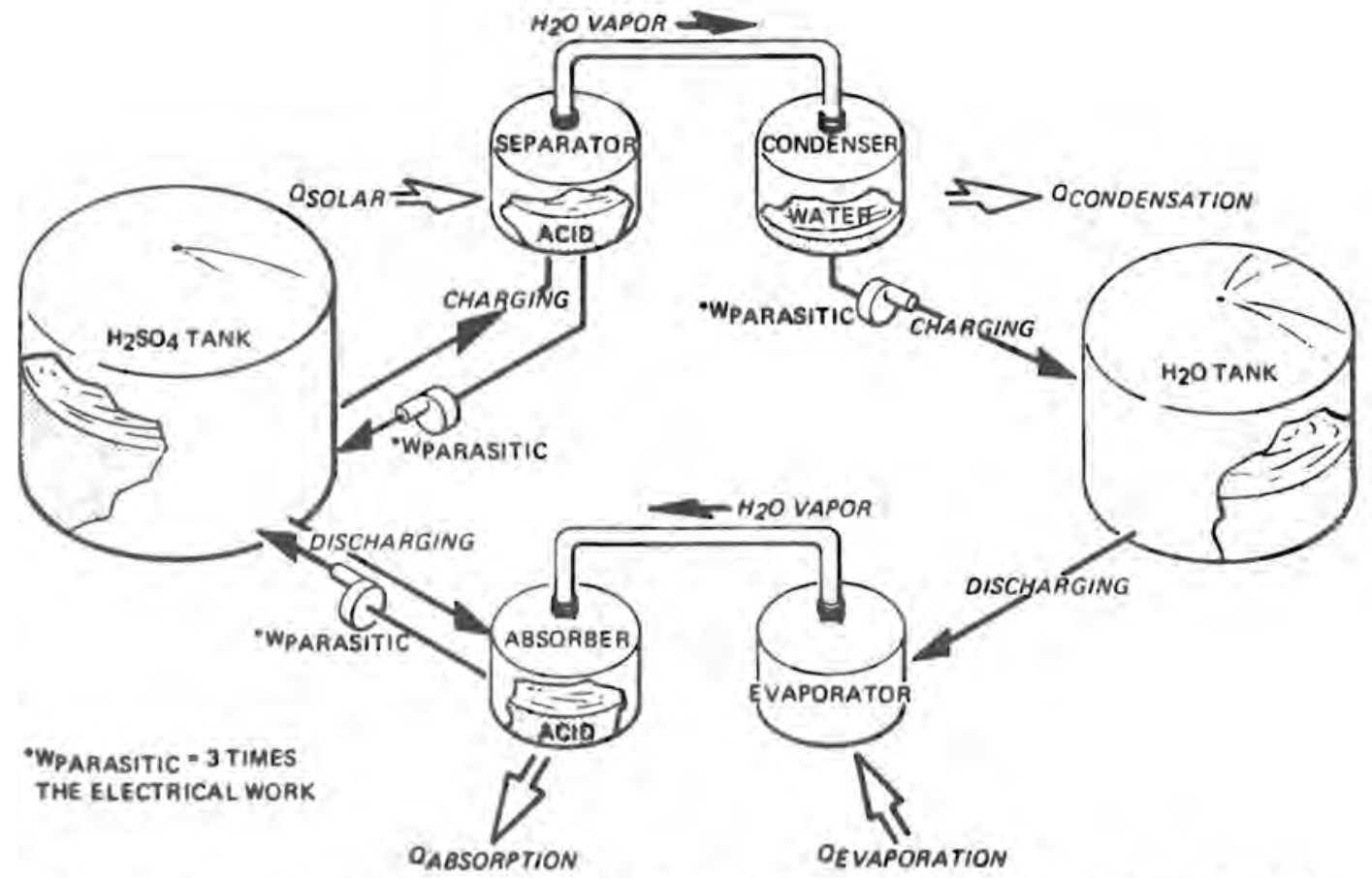

FIGURE A.48. Solar/CHP/TES System Schematic (56a; Clark and Hiller 1979, p. 443) 


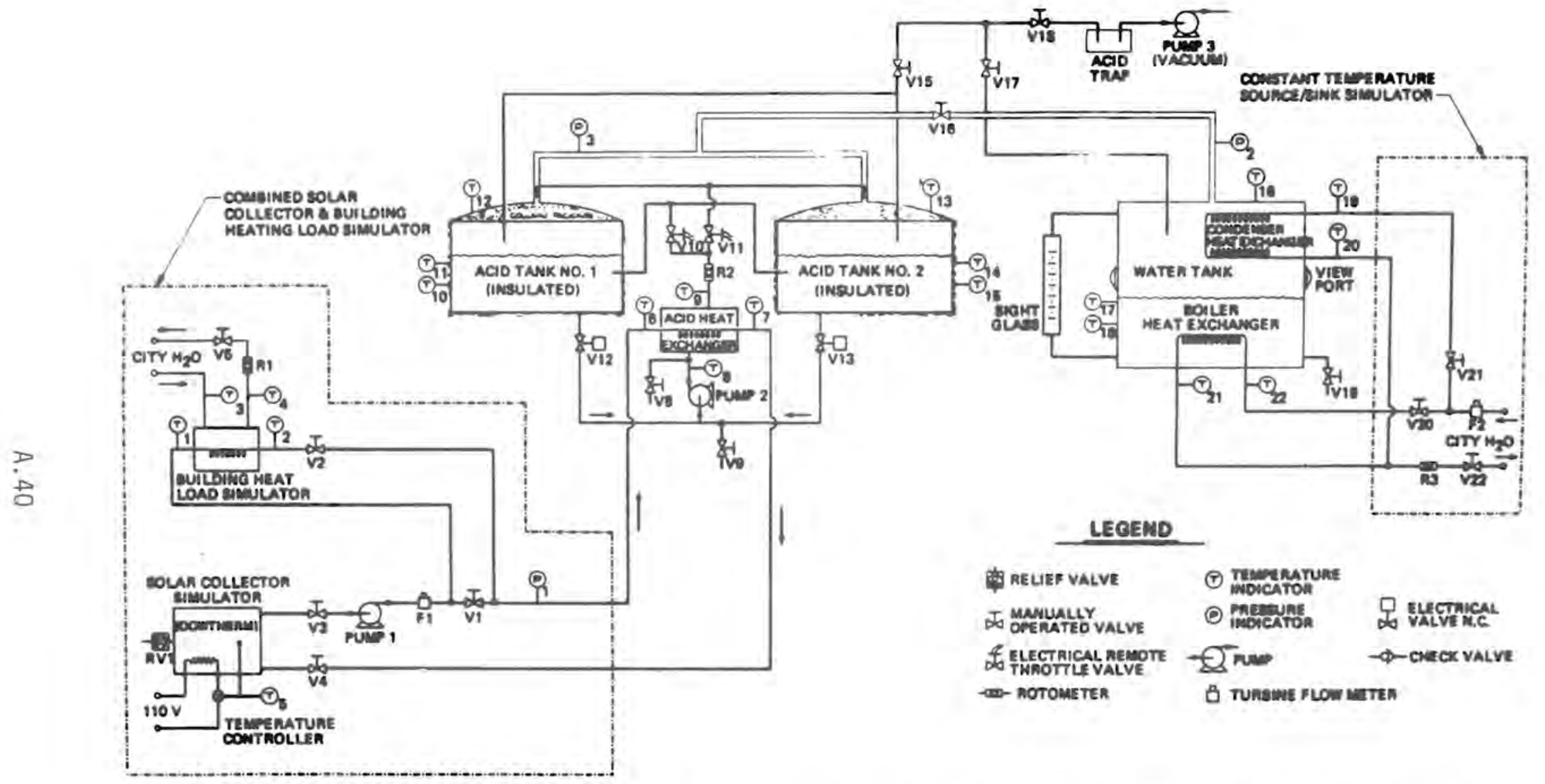

FIgURE A.49. Subscale $\mathrm{H}_{2} \mathrm{SO}_{4} / \mathrm{H}_{2} \mathrm{O}$ Chemical Heat Pump Schematic (2; Clark 1978, p. 422) 


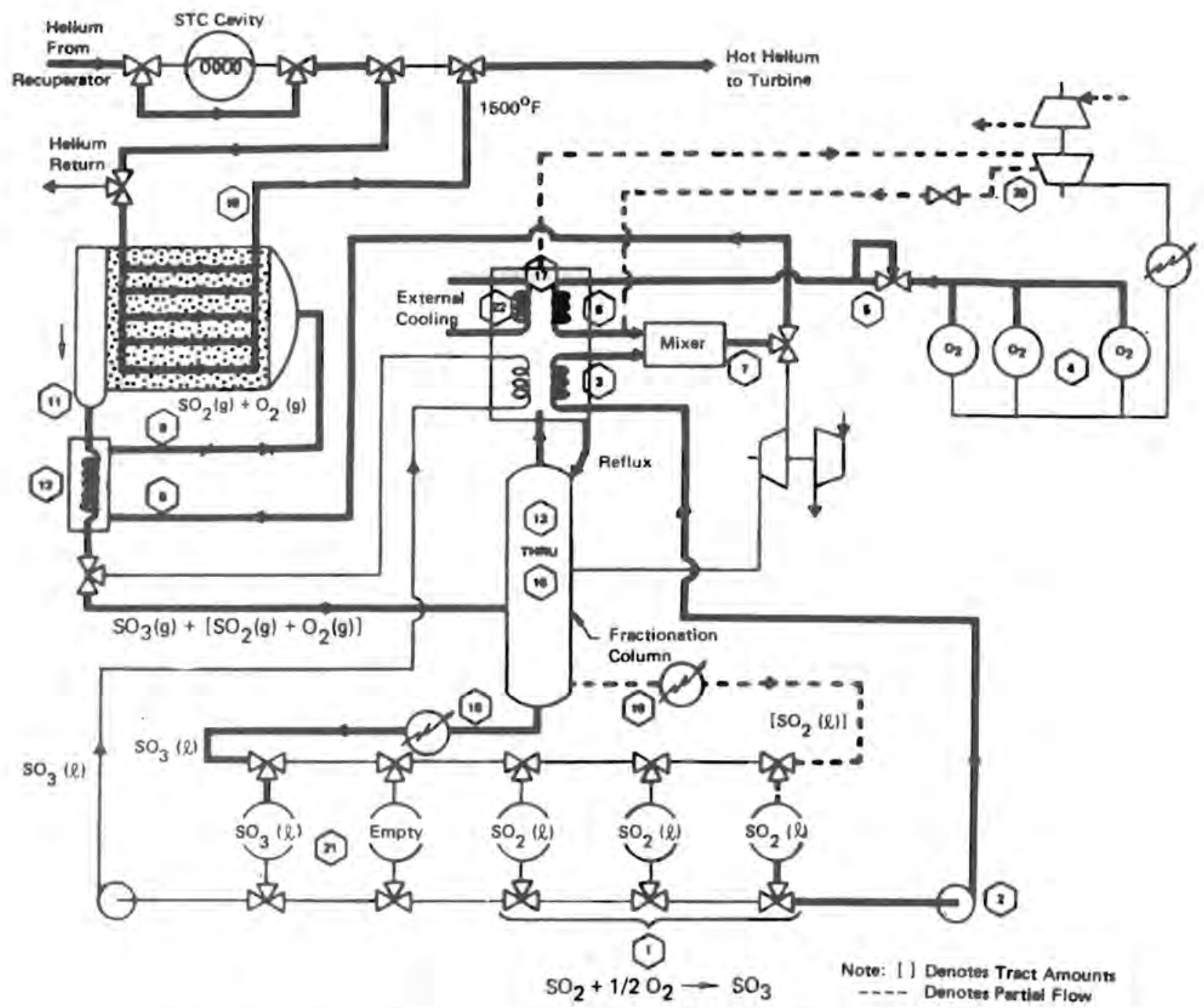

FIGURE A.50. Chemical Energy Storage System-Heat Generation Cycle (41; Gintz 1977, p. 4-6) 


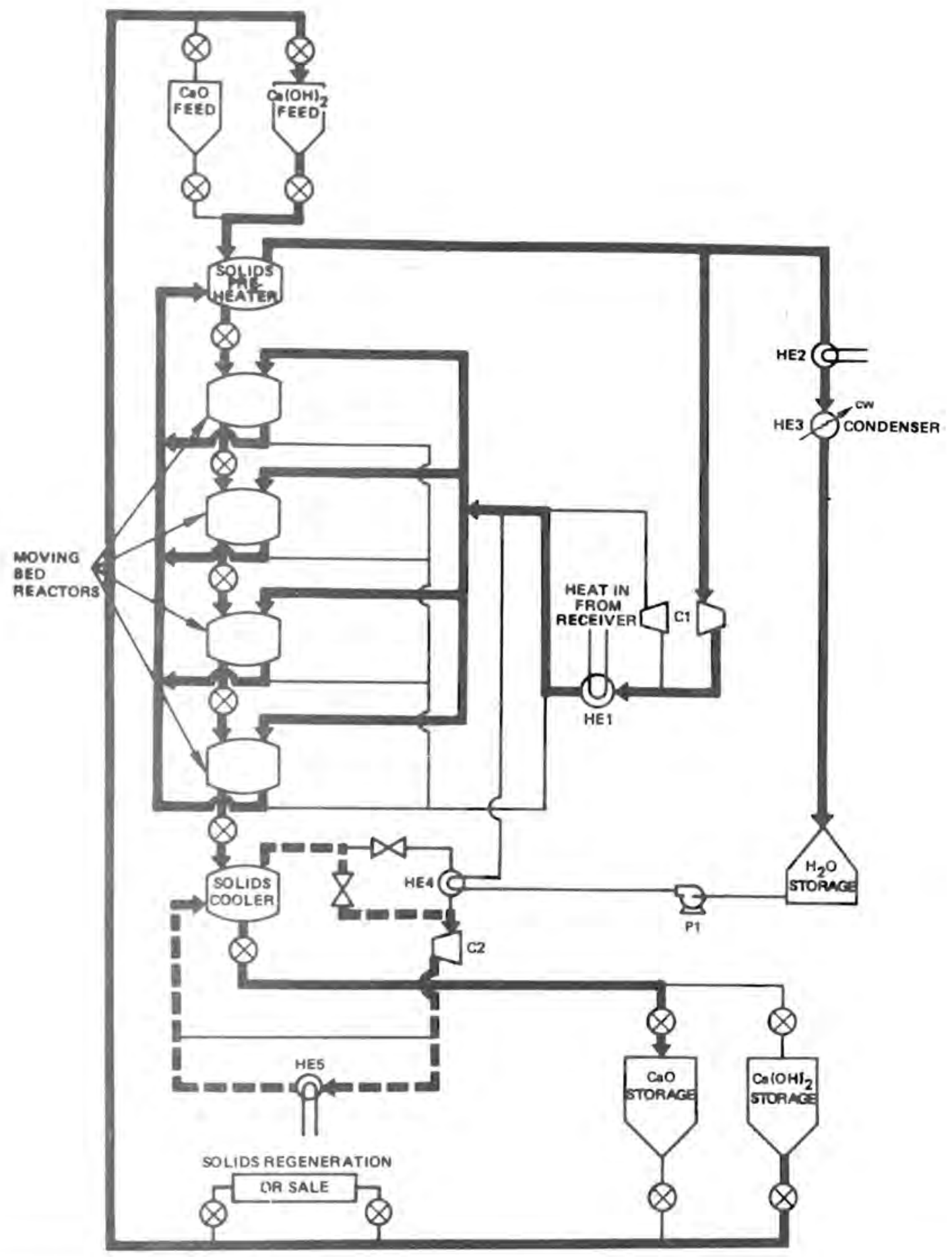

FIGURE A.51. $\mathrm{CaO} / \mathrm{Ca}(\mathrm{OH})_{2}$ Energy Storage System Preliminary Process Flowsheet Endothermic Mode $\left(\mathrm{Ca}(\mathrm{OH})_{2} \mathrm{CaO}+\mathrm{H}_{2} \mathrm{O}\right)$
(2; Smith 1978, p. 362) 


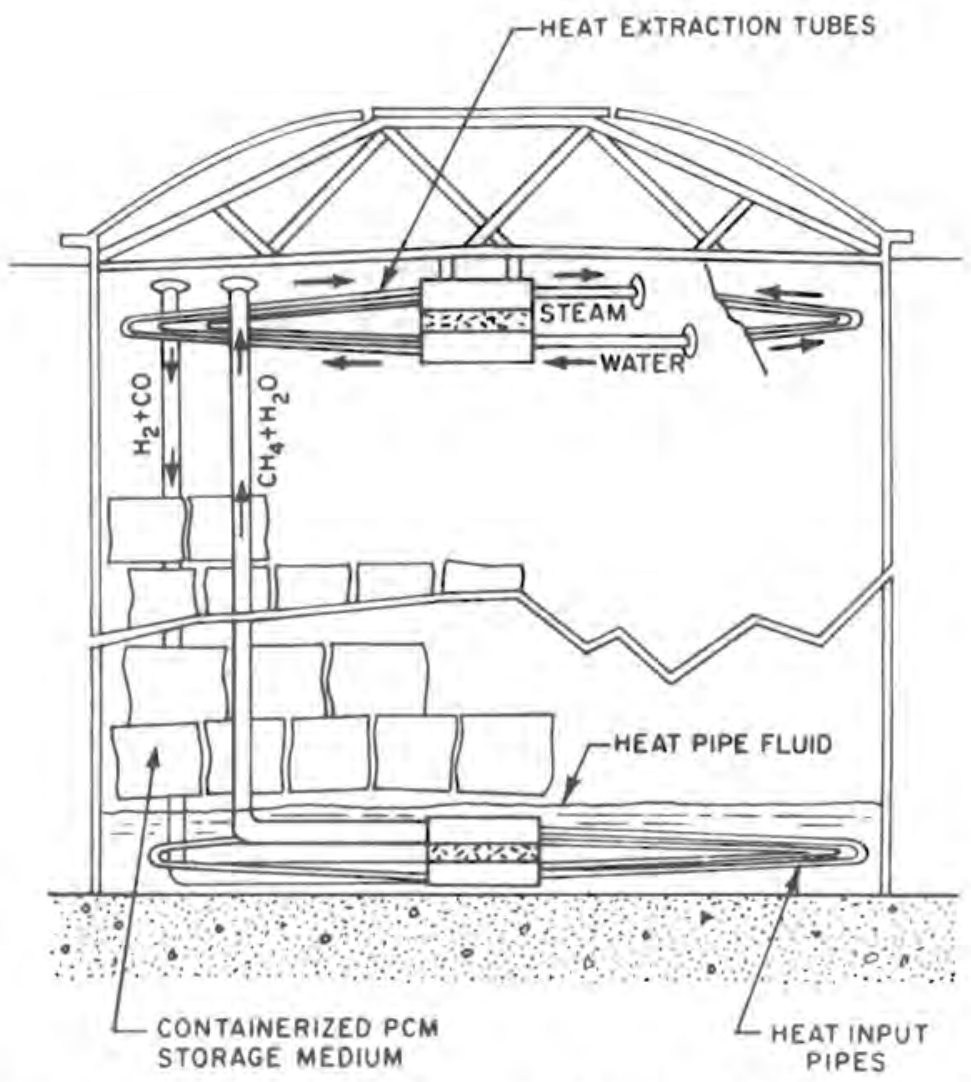

FIGURE A.52. The NRL Thermal Storage Concept (7; Turner 1978, p. 91) 


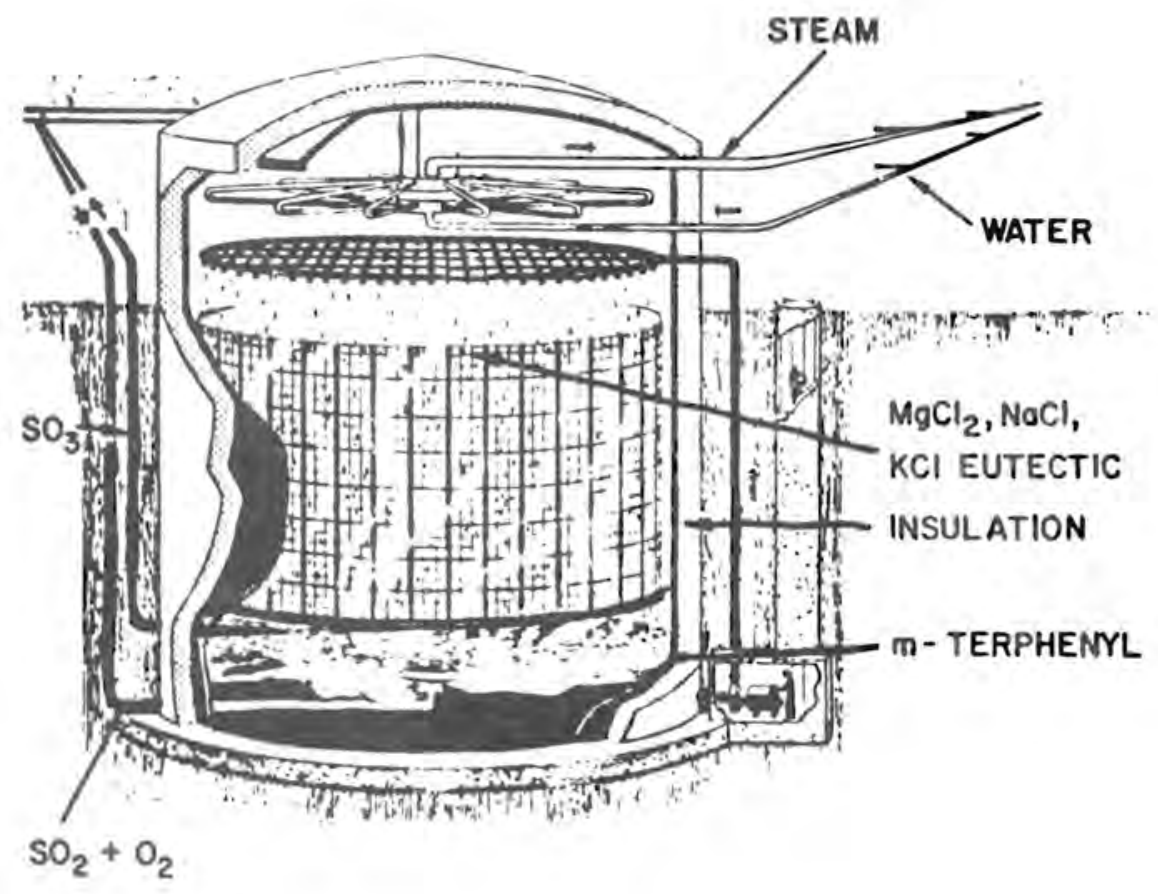

FIGURE A.53. Energy Storage-Boiler Tank (56a; Gordon 1979, p. 63) 
PNL -3625

UC-94e

\section{DISTRIBUTION}

No. of

Copies

OFFSITE

A. A. Churm

DOE Patent Division

9800 S. Cass Avenue

Argonne, IL 60439

J. Gahimer

DOE Office of Advanced Conservation Technologies

600 E Street NW

Room 416, MS404

Washington, DC 20585

R. Jones

DOE Office of Advanced Conservation Technologies

$600 \mathrm{E}$ Street NW

Room 416, MS404

Washington, DC 20585

G. Karadi

DOE Office of Advanced Conservation Technologies

600 E Street NW

Room 416, MS404

Washington, DC 20585

G. F. Pezdirtz

DOE Office of Advanced Conservation Technologies

600 E Street NW

Room 416, MS404

Washington, DC 20585
No. of

Copies

S. Strauch

DOE Office of Advanced Conservation Technologies

600 E Street NW

Room 416, MS404

Washington, DC 20585

J. H. Swisher

DOE Office of Advanced Conservation Technologies

$600 \mathrm{E}$ Street NW

Room 416, MS404

Washington, DC 20585

D. M. Eissenberg

Oak Ridge National Laboratory

P. O. Box $Y$

Oak Ridge, TN 37830

J. F. Martin

Oak Ridge National Laboratory P. 0. Box $Y$

Oak Ridge, TN 37830

Frank Baylin

Solar Energy Research Institute

1536 Cole Blvd

Golden, CO 80401

Charles Wyman

Solar Energy Research Institute

1536 Cole Blvd

Golden, CO 80401

Craig Cooley

Terra Tek

University Research Park

400 Wakara Way

Salt Lake City, UT 84108 
No. of

Copies

James W. Crosby III

Geology Department

Washington State University

Pullman, WA 99164

Mat Walton

Minnesota Geological Survey

319 15th Avenue S.E.

Minneapolis, MN 55455

Louis Stern

Dames \& Moore

6 Commerce Drive

Cranford, NJ 07016

Melvin Singer

New York State Energy Research

\& Development Agency

Rockefeller Plaza

Albany, NY 12223

James C. 0'Gara

Program Director, ATES

University of Minnesota

Physical Plant Operations

200 Shops Bldg.

319 15th Avenue S.E.

Minneapolis, MN 55455

J. M. Cherne

TRW

One Space Park

Redondo Beach, CA 90278

R. A. Duscha

NASA Lewis Research Center

21000 Brookpark Blvd

Cleveland, $\mathrm{OH} 44135$

E. R. Furman

NASA Lewis Research Center

21000 Brookpark Blvd

Cleveland, $\mathrm{OH} 44135$
No. of

Copies

\author{
Victor E. Hampel \\ Integrated Information Systems \\ Computation Dept., L-275 \\ University of California \\ Lawrence Livermore Laboratory \\ P.0. Box 808 \\ Livermore, CA 94550 \\ Walter Hausz \\ GE-TEMPO \\ Center for Advanced Studies \\ 816 State Street \\ P.0. Drawer QQ \\ Santa Barbara, CA 93102 \\ Charles $F$. Meyer \\ GE-TEMPO \\ Center for Advanced Studies \\ 816 State Street \\ P.0. Drawer QQ \\ Santa Barbara, CA 93102 \\ Douglas D. Huxtable, Director \\ Energy R\&D \\ Rocket Research Company \\ York Center \\ Redmond, WA 98052 \\ L. B. Katter \\ Rocket Research Company \\ York Center \\ Redmond, WA 98052 \\ Charles H. Lee \\ Midwest Research Institute \\ 425 Volker Blvd \\ Kansas City, MO 64110 \\ Stanley N. Davis \\ Department of Hydrology and \\ Water Research \\ University of Arizona \\ Tucson, AZ 85705
}


No. of

Copies

David L. Schreiber, Ph.D., P.E. Consulting Hydraulic Engineer

P.0. Box 1087

(c/o The Colony)

Coeur d'Alene, ID 83814

Donald Langmuir

Department of Chemistry and Geochem istry

Colorado School of Mines

Golden, CO 80401

Robert D. MacNish,

District Chief

Arizona District

U.S. Geological Survey

Federal Building

Tucson, AR 85718

Fred J. Molz

School of Engineering

Auburn University

Auburn, AL 36830

National Aeronautics and Space Administration Asst Adm for Energy Programs Washington, DC 20546

National Science Foundation Division of Advanced Energy Research and Technology Room 1140 $1800 \mathrm{G}$ Street NW Washington, DC 20550

A. William Nice NASA Lewis Research Center 21000 Brookpark Blvd

Cleveland, $\mathrm{OH} \quad 44135$

Jerry J. Phillips

Projects Manager

Tennessee Valley Authority 350 Commerce Union Bank Bldg Chattanooga, TN 37401
No. of

Copies

L. Radosevich

Sandia Laboratories, Livermore

P.0. Box 969

Livermore, CA 94550

Donald L. Reddell

Agricultural Engineering Dept.

Texas A\&M University

College Station, TX 77843

213 Technical Information Center

Sandia Laboratories

Technical Library Div. 3151

Albuquerque, NM 87185

John F. Spencer

Department of Ecology

State of Washington

01 ympia, WA 98504

Chin $\mathrm{Fu}$ Tsang

Bldg 90, Room 102-H

University of California

Lawrence Berkeley Laboratory

1 Cyclotron Road

Berkeley, CA 94720

Union Carbide Corporation

Nuclear Division

Attn. Library

Y-12 Plant

P.0. Box $Y$

Oak Ridge, TN 37830

U.S. Army Corps of Engineers

Attn: Library

P.0. Box 59

Louisville, KY 40202

U.S. Department of Energy

Attn: Chief, APMBR

Division of Energy Storage Systems

Washington, DC 20545 
No. of

Copies

U.S. Department of Energy

Attn: Director, Policy and Planning

Office of Conservation and

Solar Applications

Washington, DC 20545

U.S. Department of Interior

Attn: Natural Resources Library

Serials Branch (G/E)

Washington, DC 20240

William Waldrop

Assistant Branch Chief

Water Systems Development Branch

Division of Water Management

Tennessee Valley Authority

P.0. Drawer $E$

Norris, TN 37828

W. G. Wilson

Sandia Laboratories, Livermore

P. 0. Box 969

Livermore, CA 94550

\section{ONSITE}

2 DOE Richland Operations office

D. K. Jones

H. E. Ransom
No. of

Copies

51 Pacific Northwest Laboratory

D. E. Blahnik (9)

C. H. Bloomster

S. M. Brown

D. B. Cear lock

R. N. Coy

T. J. Doherty

J. R. Eliason

J. D. Etchemendy

K. Fox

W. A. Frier

D. L. Gale

A. F. Gasperino

P. L. Hendrickson

L. K. Inaba

R. K. Johnson

C. T. Kincaid

W. W. Laity

L. R. Lambert

W. V. Loscutoff

R. P. Marshall

J. E. Minor

D. A. Myers

M. E. 01son

L. S. Prater

J. R. Raymond

R. W. Reilly

W. D. Richmond

J. A. Stottlemyre

A. M. Sutey

R. Walter

G. E. Wukelic

STES Library (5)

Publishing Coordination (2)

Technical Information SH (5) 